Integrando projeções multidimensionais à análise visual de redes sociais

\author{
Gabriel de Faria Andery
}





\title{
Integrando projeções multidimensionais à análise visual de redes sociais
}

\author{
Gabriel de Faria Andery
}

Orientadora: $\operatorname{Prof}^{a}$. Dr ${ }^{a}$. Rosane Minghim

Dissertação apresentada ao Instituto de Ciências Matemáticas e de Computação - ICMC-USP - como parte dos requisitos para obtenção do título de Mestre em Ciências de Computação e Matemática Computacional.

USP - São Carlos

Agosto/2010 

Aos meus pais e à minha irmã. 



\section{Agradecimentos}

Agradeço à minha orientadora, Rosane, por ter me apoiado durante todo o desenvolvimento do trabalho e pela confiança depositada em mim.

Ao professor Alneu, por toda a ajuda com o projeto, fazendo sugestões para melhorálo sempre.

Aos professores Maria Cristina e Fernando, pelo incentivo e suporte.

Ao Instituto Brasileiro de Opinião e Estatística - Media (IBOPE Media), pelos dados do Orkut por eles coletados, que foram de grande ajuda para o desenvolvimento do trabalho.

Ao Conselho Nacional de Desenvolvimento Científico e Tecnológico (CNPq) pelo recurso financeiro que viabilizou a realização deste projeto. 

Any intelligent fool can make things bigger, more complex, and more violent. It takes a touch of genius - and a lot of courage - to move in the opposite direction.

-Albert Einstein 



\section{Resumo}

Há várias décadas, pesquisadores em ciências sociais buscam formas gráficas para expressar as relações humanas na sociedade. O advento do computador e, mais recentemente, da internet, possibilitou o surgimento de um campo que tem despertado a atenção de estudiosos das áreas de visualização de informação e de ciências sociais, o da visualização de redes sociais. Esse campo tem o potencial de revelar e explorar padrões que podem beneficiar um número muito grande de aplicações e indivíduos em áreas tais como comércio, segurança em geral, redes de conhecimento e pesquisa de mercado. Grande parte dos algoritmos de visualização de redes sociais são baseados em grafos, destacando relacionamentos entre indivíduos e grupos de indivíduos, mas dando pouca atenção aos seus demais atributos. Assim, este trabalho apresenta um conjunto de soluções para representar e explorar visualmente redes sociais levando em consideração tais atributos. A primeira solução faz uso de redes heterogêneas, onde tanto indivíduos quanto comunidades são representados no grafo; a segunda solução utiliza técnicas de visualização baseadas em projeção multidimensional, que promovem o posicionamento dos dados no plano de acordo com algum critério de similaridade baseado em atributo; e a última solução coordena múltiplas visões para focar rapidamente em regiões de interesse. Os resultados indicam que as soluções proveem um poder de representação e identificação de conceitos não facilmente detectados por formas convencionais de visualização e exploração de grafos, com indícios fornecidos através dos estudos de caso e da realização de avaliações com usuários. Este trabalho fornece um estudo das áreas de visualização em grafos para a análise de redes sociais bem como uma implementação das soluções de integração da visualização em redes com as projeções multidimensionais. 



\section{Abstract}

For decades, social sciences researchers have searched for graphical forms to express human social relationships. The development of computer science and more recently of the Internet has given rise to a new field of research for visualization and social sciences professionals, that of social network visualization. This field can potentially offer new opportunities in reveal new patterns that can benefit a large number of applications and individuals in fields such as commerce, security, knowledge networks and marketing. A large part of social network visualization algorithms and systems relies on graph representations, highlighting relationships amongst individuals and groups of individuals, but mostly neglecting the other available attributes of individuals. Thus, this work presents a set of tools to represent and explore social networks visually, taking into consideration the attributes of the nodes. The first technique employs heterogeneous networks, where both individuals and communities are represented in the graph; the second solution uses visualization techniques based on multidimensional projection, which promote the placement of data in the plane according to some similarity criterion based on attribute; still another proposed technique coordinates multiple views in order to speed up focus in regions of interest in the data sets. The results indicate that the solutions promote high degree of representation power and that concept identification not easily obtained via other methods is possible; the evidence comes from case studies as well as a user evaluation. This work includes a study in the area of graph visualization for social network analysis as well as a system implementing the proposed solutions, that integrate network visualization and multidimensional projections to extract patterns from social networks. 

Esta dissertação adota as regras do novo acordo ortográfico da língua portuguesa de 2009. Algumas palavras utilizadas neste trabalho não foram traduzidas da língua inglesa para a portuguesa por serem amplamente conhecidas e difundidas na comunidade acadêmica. 



\section{Sumário}

1. Introdução 1

2. Visualização de informação em grafos 5

2.1. Formas de representação de grafos . . . . . . . . . . . . . . . . . . . . . 7

2.2. Representação de conhecimento em grafos . . . . . . . . . . . . . . 8

2.3. Visualização de grafos . . . . . . . . . . . . . . . . . . . . . . 9

2.4. Interação em visualização de grafos . . . . . . . . . . . . . . . . . . . . 18

2.5. Introdução a redes complexas . . . . . . . . . . . . . . . . . . . . . . 21

3. Análise visual de redes sociais 25

3.1. Visualização de redes sociais . . . . . . . . . . . . . . . . . . . . . 27

3.2. Métricas para análise de redes sociais . . . . . . . . . . . . . . . 30

3.3. Ferramentas para exploração de redes sociais . . . . . . . . . . . . . . . 31

4. Exploração visual multidimensional de redes sociais 41

4.1. Projeções multidimensionais e o PEx . . . . . . . . . . . . . . . . . . . 42

4.2. Abordagens propostas e o PEx-Graph . . . . . . . . . . . . . . 45

4.2.1. Redes heterogêneas . . . . . . . . . . . . . . . . . 45

4.2.2. Projeções multidimensionais . . . . . . . . . . . . . . . . . . . 47

4.2.3. Coordenação por identidade e coordenação relacional . . . . . . 48

4.2.4. PEx-Graph . . . . . . . . . . . . . . . . 50

5. Resultados

5.1. Estudos de caso . . . . . . . . . . . . . . . . . . . . 57

5.1.1. Netlog . . . . . . . . . . . . . . . . . 57

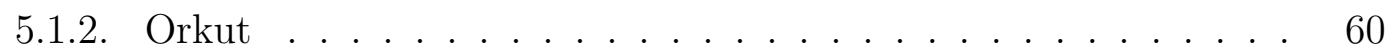


5.1.3. Revisão sistemática . . . . . . . . . . . . . . . . . . . . . 64

5.2. Avaliação com usuário . . . . . . . . . . . . . . . . . . 67

$\begin{array}{ll}\text { 6. Conclusões } & 71\end{array}$

6.1. Contribuições . . . . . . . . . . . . . . . . . . . . . . . 71

6.2. Trabalhos futuros . . . . . . . . . . . . . . . 72

$\begin{array}{ll}\text { Referências } & 73\end{array}$

A. Formulários da avaliação com usuário $\quad 83$ 


\section{Lista de Figuras}

1. Exemplo de representação visual de um grafo. Os círculos numerados representam os vértices, e as linhas conectando-os representam as arestas. 8

2. Diferentes formas de representação de um grafo: (a) matriz de adjacência, (b) lista de adjacência, (c) lista de incidência, (d) matriz Laplaciana. 9

3. Diagrama Entidade-Relacionamento de um banco de dados de publicações científicas. . . . . . . . . . . . . . . . . . . . 9 9

4. Rede de co-autoria: (a) apenas autores, (b) autores e artigos. . . . . . . 10

5. Árvore gerada a partir do algoritmo de Reingold-Tilford [Reingold and Tilford, 1981; Walker, 1990]. . . . . . . . . . . . . 11

6. Exemplo de árvore radial $[$ Eades, 1984] . . . . . . . . . . . . . . . . . 11

7. Exemplo de visualização de grafo baseado no posicionamento hiperbólico [Zhou, 2004]. . . . . . . . . . . . . . . . . . . . . 12

8. Exemplo de posicionamento baseado em força proposto por Eades [Ea-

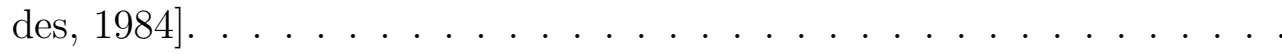

9. Exemplo de posicionamento ortogonal baseado no algoritmo de Tamassia

e Tollis $[$ Tamassia and Tollis, 1989] . . . . . . . . . . . . .

10. Aplicativo para visualização do valor das ações das principais empresas americanas utilizando a técnica Treemap [SmartMoney, 2008]. . . . . .

11. Matriz de adjacência de um grafo de co-autoria em artigos científicos

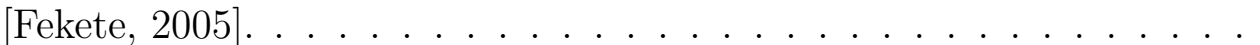

12. Elastic Hierarchies: exemplo de técnica híbrida na qual é possível representar grafos utilizando tanto nós e arestas quanto Treemaps [Zhao et al., 2005]. 
13. ASK-GraphView: ferramenta que utiliza agrupamentos para visualizar grafos que contêm uma grande quantidade de vértices e arestas [Abello et al., 2006] . . . . . . . . . . . . . . . . . . . .

14. PivotGraph: ferramenta para gerar representações visuais de grafos baseadas nos dados contidos nos vértices e nas arestas [Wattenberg, 2006].

15. Técnica de interação na qual ímãs posicionados pelo usuário atraem ou repelem os vértices de acordo com critérios definidos [Spritzer and Freitas, 2008]. . . . . . . . . . . . . . . .

16. GUESS: ferramenta para análise exploratória de dados em grafos que engloba algoritmos de posicionamento de diferentes abordagens e faz uso de técnicas de interação $[$ Adar, 2006] . . . . . . . . . . . . .

17. Exemplo de representação de rede social desenhada a mão [Moreno, 1932]. 26

18. Sociograma criado utilizando a abordagem baseada em alvo [Northway, $1952]$.

19. Exemplo de sociograma visualizado utilizando a abordagem circular [Mitchell, 1994].

20. Exemplo de sociograma baseado em grupos, em que os vértices conectados entre si aparecem próximos uns dos outros [Freeman, 1999]. . . . .

21. Sociograma de um indivíduo no Myspace, construído utilizando uma variação do algoritmo de posicionamento radial [Roos, 2007]. . . . . . .

22. Janela da aplicação Vizster exibindo a rede egocêntrica de um usuário do site de relacionamento Friendster, na qual as arestas indicam amizade. O painel da direita exibe o perfil de um usuário selecionado na rede [Heer and Boyd, 2005]. . . . . . . . . . . . . . . .

23. Exemplo de rede criada com a ferramenta MatrixExplorer. À esquerda é apresentada uma representação da rede como uma matriz de adjacência, e à direita uma representação como um conjunto de nós e arestas [Henry and Fekete, 2006]. . . . . . . . . . . . . . . . 
24. Exemplo de rede criada com a ferramenta NodeTrix, sendo que cada matriz representa uma comunidade, as conexões entre indivíduos de uma mesma comunidade são representadas na matriz de adjacência, e as conexões entre indivíduos de comunidades diferentes são representadas como arestas do grafo. A cor representa algum atributo da aresta [Henry et al., 2007]. . . . . . . . . . . . . . . . . .

25. Janela da ferramenta DualNet, na qual o nó do sociograma da esquerda agrupa um conjunto de indivíduos selecionados no sociograma da direita [Namata et al., 2007]. . . . . . . . . . . . . . . . . .

26. Exemplo de sociograma de redes terroristas criado com o OntoVis, no qual nós em laranja representam terroristas, nós em azul organizações terroristas e nós em verde casos legais relacionados com atentados terroristas $[$ Shen et al., 2006] . . . . . . . . . . . . . . .

27. Exemplo de visualização da evolução de redes sociais ao longo do tempo [Falkowski et al., 2006] . . . . . . . . . . . . . . . .

28. Exemplo de visualização com a ferramenta C-Group, que apresenta dois vértices e três regiões de grupos. À esquerda, os grupos do vértice "Benjamin B. Bederson"; à direita, os grupos do vértice "Allison Druin"; e no centro, os grupos comuns a ambos [Kang et al., 2007]. . . . . . . . . .

29. Rede de e-mails criada por meio da ferramenta Soylent [Fisher and Dou-

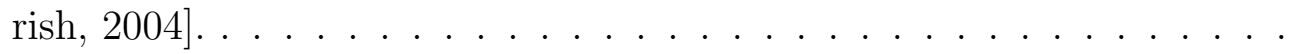

30. Processo de geração de mapas interativos de documentos: o sistema pode receber em (1) uma coleção de objetos não estruturados, em (2) uma tabela de dados estruturada, ou em (3) uma matriz de distâncias [Paulovich et al., 2007]. . . . . . . . . . . . . . .

31. Mapa criado com a ferramenta PEx, no qual pontos representam manchetes de notícias e as cores denotam a frequência do termo "bird flu", de acordo com a escala de cores no canto superior esquerdo. . . . . . .

32. Exemplo de rede heterogênea gerada a partir de dados de redes sociais do Orkut, na qual os círculos cinzas representam as comunidades; os quadrados azuis, os indivíduos do sexo masculino; os quadrados vermelhos, os indivíduos do sexo feminino; e as arestas conectam os indivíduos às suas comunidades. . . . . . . . . . . . . . . . . . . . . 
33. Projeção multidimensional da matriz de adjacência modificada do conjunto de dados do Orkut, na qual a cor indica a quantas comunidades relacionadas à Peugeot os indivíduos pertencem. . . . . . . . . . . . . .

34. Coordenação por identidade entre duas visões do conjunto de dados do Orkut. Os membros da comunidade "Eu odeio Fiat !!" foram selecionados na visão de rede heterogênea à esquerda, e os mesmos foram destacados na visão de projeção multidimensional à direita. Na visão de rede heterogênea, o círculo cinza representa a comunidade; os quadrados azuis, os indivíduos do sexo masculino; e os quadrados vermelhos, os indivíduos do sexo feminino. Na visão de projeção multidimensional, a cor indica a quantas comunidades relacionadas à Peugeot os indivíduos

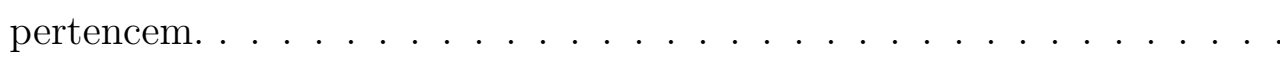

35. Coordenação relacional entre duas visões do conjunto de dados do Orkut. A comunidade "Counter-Strike Brasil (CS)" foi selecionada na visão à direita, e seus membros foram destacados na visão à esquerda. . . . . .

36. Janela da ferramenta PEx-Graph com uma rede social heterogênea aberta. 51

37. Janela do Wizard da ferramenta PEx-Graph que permite configurar se e como as arestas serão utilizadas para projetar. . . . . . . . . . . . 52

38. Janela do visualizador de atributos de vértices da ferramenta PEx-Graph, aberta ao selecionar um ou mais vértices com a ferramenta de visualização de atributos. . . . . . . . . . . . . . . . . . . .

39. Busca por "Volks" na projeção das comunidades do conjunto de dados do Orkut. As comunidades que continham o termo em algum dos atributos foram coloridas de azul.

40. Rede egocêntrica da comunidade "Volkswagen Gol" com os vértices expandidos.

41. Projeção das comunidades do conjunto de dados do Orkut, cujo tamanho e cor dos vértices reflete o grau de intermediação. A cor segue a escala de cores no canto superior esquerdo. As arestas conectam comunidades com pelo menos dez membros em comum. 
42. Rede heterogênea do conjunto de dados do Netlog, na qual os grupos são representados como círculos verdes, os usuários do sexo masculino como quadrados azuis, os usuários do sexo feminino como quadrados vermelhos, e as arestas conectam os membros às comunidades a que pertencem. . . . . . . . . . . . . . . . .

43. Subconjuntos da rede heterogênea do Netlog: (a) grupos com membros em comum tanto com o "Arsenal Fanz" quanto com o "Manchester United Til I Die", (b) grupos com membros em comum ao "Manchester United Til I Die", e (c) grupos com membros em comum ao "Arsenal Fanz". . .

44. Projeção multidimensional dos membros do conjunto de dados do Netlog: (a) coloridos por país, e (b) coloridos por idade. . . . . . . . . . .

45. Projeção multidimensional dos membros do conjunto de dados do Netlog exibindo as arestas entre membros que fazem parte de pelo menos dez grupos em comum. . . . . . . . . . . . . . . . .

46. Projeção multidimensional dos grupos do conjunto de dados do Netlog: (a) grupos com membros em comum com o "Arsenal Fanz", e (b) grupos com membros em comum com o "Manchester United Til I Die". . . . .

47. Rede heterogênea do conjunto de dados do Orkut, na qual os círculos cinzas representam as comunidades; os quadrados azuis, os indivíduos do sexo masculino; e os quadrados vermelhos, os indivíduos do sexo feminino. 62

48. Redes egocêntricas: (a) das três comunidades relacionadas à Volkswagen, e (b) das duas comunidades relacionadas à Peugeot. Os círculos cinzas representam as comunidades; os quadrados azuis, os indivíduos do sexo masculino; e os quadrados vermelhos, os indivíduos do sexo feminino.

49. Projeção multidimensional dos membros do conjunto de dados do Orkut utilizando a matriz somada dos atributos. A cor representa: (a) gênero, (b) estado civil, (c) aniversário, e (d) idade.

50. Projeção multidimensional dos membros do conjunto de dados do Orkut utilizando a matriz somada dos atributos. A cor e o tamanho representam: (a) grau de intermediação, e (b) grau de proximidade. . . . . . . . 
51. Coordenação relacional entre a projeção dos membros e a projeção das comunidades. As comunidades relacionadas à Peugeot foram selecionadas na projeção da direita e somente seus membros permaneceram visíveis na projeção da esquerda. . . . . . . . . . . . . . . . . . . .

52. Coordenação relacional entre a projeção dos membros e a projeção das comunidades. As comunidades relacionadas à Volkswagen foram selecionadas na projeção da direita e somente seus membros permaneceram visíveis na projeção da esquerda. . . . . . . . . . . . . . . . . . . .

53. Rede de citação de uma revisão sistemática. Os pontos vermelhos representam artigos excluídos; os azuis representam os incluídos; e os cinzas, artigos referenciados. . . . . . . . . . . . . . .

54. Rede de citação de uma revisão sistemática. Os artigos incluídos que não estão conectados aos demais merecem atenção. . . . . . . . . . . .

55. Resultado gráfico da segunda fase da avaliação. As barras indicam o número de usuários que classificaram cada uma das comunidades como sendo predominantemente masculina, predominantemente feminina, ou indefinida. As cinco comunidades referem-se a "Eu amo meu Honda Civic", "Pareço metida(o), mas sou legal", "Eu acredito no amor", "O que é para ser nosso ninguém tira", e "Tuning", respectivamente. . . . .

56. Notas atribuídas pelos usuários à facilidade de uso, ao conforto com a interface, e à utilidade do sistema. As notas variam de 1 a 5. . . . . . 


\section{Introdução}

Desde a década de trinta, pesquisadores em ciências sociais buscam compreender as relações humanas na sociedade com o auxílio de representações visuais. Com o advento do computador e, em particular, da computação gráfica, foi possível criar procedimentos que produzissem resultados visuais replicáveis, ou seja, diferentes pesquisadores, utilizando os mesmos dados, poderiam obter as mesmas imagens. Atualmente, o avanço da tecnologia e dos meios de comunicação, principalmente da internet, propicia o aumento da quantidade de dados disponibilizados diariamente e, consequentemente, da necessidade de exploração das informações contidas nesses dados. O grande volume e a alta complexidade dos dados dificultam tanto a análise computacional quanto a humana, intensificado a busca por soluções de mineração visual, que possibilitam ao usuário extrair modelos e interagir com representações gráficas dos dados. Assim, a área de visualização de informação está ganhando cada vez mais destaque e importância. Além disso, o número crescente de pessoas trocando informações e participando de comunidades em sites de relacionamento favoreceu o surgimento de uma nova forma de relação social, a qual tem despertado o interesse de estudiosos tanto de visualização de informação quanto de ciências sociais, possibilitando que um campo em particular ganhasse bastante atenção de ambas as áreas, o da visualização de redes sociais.

A forma mais comum de representar redes sociais é por meio de grafos, ou seja, diagramas compostos de vértices e arestas, os quais representam, respectivamente, os indivíduos da rede e as relações entre eles. Grafos são interessantes porque constituem uma forma de representação mais expressiva que tabelas atributo-valor e potencialmente mais eficiente que dados multirrelacionais [Washio et al., 2005]. Entretanto, as redes sociais possuem características adicionais às dos modelos clássicos estudados pela teoria dos grafos. Os dados provenientes dessas redes possuem alta complexidade, envolvendo atributos nos vértices e arestas, que podem variar de valores numéricos a 
textos e imagens, além de relacionamentos múltiplos entre os vértices. Além disso, os dados podem ser analisados em vários níveis, desde a caracterização global da rede até o indivíduo e seus vizinhos ou similares. A quantidade de dados e de elementos em muitas das redes podem exigir técnicas de amostragem e interfaces apropriadas para localizar regiões e objetos de interesse. Essas e outras características classificam as redes sociais como um tipo especial de redes complexas.

A motivação para o estudo desses dados é variada, mas o princípio é comum. Existe uma imensa quantidade de informação proveniente de relacionamentos humanos em sites de relacionamento, tais como Orkut ${ }^{1}$ e Myspace $^{2}$, dentre muitos outros, que pode ser empregada para os mais variados fins. Exemplos são o entendimento de relações sociais, busca de padrões de preferências para apoio aos setores de comércio e produção, detecção e investigação de atividades ilícitas, estudo e projeto de políticas públicas e outras políticas de distribuição de recursos, e avanço da ciência pelo estudo de redes de conhecimento.

Como a representação mais natural para uma rede social é um grafo, o estudo de visualização em grafos, bem como de mineração em grafos, desempenham papéis importantes no trabalho de investigação de formas de representação adequadas e inovadoras para esse tipo de exploração visual. Existem dezenas de técnicas empregadas para visualização e interação em grafos, sendo que a maioria delas preocupa-se em encontrar o melhor posicionamento dos vértices e arestas de modo a facilitar a extração de informações e padrões interessantes. Entretanto, em vários aspectos, uma rede social é um conjunto de dados multidimensional, isto é, cada elemento da rede pode ser definido por um conjunto de atributos. Embora as técnicas visuais mais modernas de redes sociais sejam efetivas para evidenciar relacionamentos entre indivíduos e grupos de indivíduos, elas geralmente falham em analisar os dados no que se refere aos seus demais atributos. Algumas técnicas desenvolvidas especificamente para redes sociais apresentam ideias que utilizam variações de forma, cor e tamanho dos vértices, além de definir regiões para posicionamento dos vértices com base em alguns atributos, como sexo e idade. Além disso, alguns trabalhos recentes propõem o uso de outras estratégias que diferem da forma tradicional de grafos, como posicionar matrizes no lugar dos vértices para permitir a identificação de relações não explícitas de outro modo.

Nesse contexto, o presente trabalho tem como objetivo apresentar novas aborda-

\footnotetext{
${ }^{1}$ http://www.orkut.com.br/

${ }^{2}$ http://www.myspace.com/
} 
gens de exploração visual de redes sociais baseadas em atributos, além de integrá-las às diferentes técnicas existentes para realizar visualização exploratória em grafos e redes sociais. A primeira abordagem implementada utiliza redes heterogêneas, isto é, grafos em que os vértices representam mais de um tipo de objeto, para visualizar as redes sociais, permitindo identificar comunidades e perfis de usuários em uma única representação. A segunda abordagem faz uso de várias técnicas de visualização multidimensional para posicionar os indivíduos no plano de acordo com seus atributos e relacionamentos, com o objetivo de favorecer o posicionamento de indivíduos correlacionados na mesma região do plano. Por fim, é possível gerar diferentes visualizações, utilizando tanto as abordagens anteriores quanto técnicas tradicionais de grafos, e coordená-las, de forma a examinar concomitantemente associações e atributos, revelando, assim, informações contidas nos dados não visíveis por qualquer uma das técnicas individualmente. O objetivo do conjunto de técnicas proposto é fornecer um ferramental adicional às técnicas previamente existentes que facilite localizar padrões de conexão em redes que tenham relação com características dos indivíduos, isto é, relacionar comunidades com propriedades individuais. Essa tarefa é essencial para a análise efetiva de redes sociais voluntárias.

As abordagens foram implementadas em uma ferramenta de código aberto denominada Projection Explorer (PEx), que foi estendida para realizar visualização exploratória de redes sociais. Para avaliar as novas técnicas, foram realizados estudos de caso e uma avaliação com usuário, que mostraram resultados satisfatórios. Os usuários conseguiram explorar com facilidade uma rede social do Orkut e encontraram tendências nos perfis dos membros de algumas comunidades.

O restante desta dissertação está dividido como segue: no Capítulo 2 são apresentados os conceitos básicos sobre grafos, assim como as principais técnicas para visualização e interação existentes na literatura; no Capítulo 3 são descritas técnicas utilizadas para visualização de redes sociais, bem como métricas para análise e ferramentas para exploração das mesmas; no Capítulo 4 são apresentadas as abordagens propostas; no Capítulo 5 são descritos os resultados obtidos; e no Capítulo 6 são apresentadas as conclusões e os trabalhos futuros. 


\section{Visualização de informação em grafos}

Grafos são estruturas usadas para modelar relações entre objetos de um conjunto. Formalmente, um grafo $G$ é uma dupla $(V(G), E(G))$, sendo $V(G)$ um conjunto não vazio de vértices e $E(G)$ um conjunto de pares de elementos de $V(G)$, sendo cada par uma aresta [Boccaletti et al., 2006]. Um vértice $v \in V(G)$ é dito adjacente a um vértice $u \in V(G)$ caso o par $(u, v) \in E(G)$. Um grafo $G$ é direcionado se cada par em $E(G)$ for ordenado. Um passeio em um grafo $G$ é uma sequência de vértices de $G$ em que cada vértice da sequência é adjacente ao anterior. Um caminho é um passeio cujos vértices são todos distintos. Um ciclo é um caminho no qual o primeiro vértice da sequência é adjacente ao último vértice da sequência. Um grafo é cíclico caso possua um ou mais ciclos, e é acíclico caso contrário. Um grafo é conexo se existe um caminho entre quaisquer dois vértices. Um subgrafo de um grafo $G(V, E)$ é um grafo $G^{\prime}\left(V^{\prime}, E^{\prime}\right)$ tal que $V^{\prime} \subseteq V$, e $E^{\prime} \subseteq E$. Uma árvore é um grafo conexo acíclico, isto é, um grafo no qual dois vértices são conectados por exatamente um caminho. Uma árvore geradora de um grafo $G$ é um subgrafo de $G$ que possui o mesmo conjunto de vértices de $G$ e forma uma árvore.

Computacionalmente, um grafo pode ser usado como um tipo abstrato de dado, o qual não é diretamente manipulado pelo usuário, mas armazena informações internamente. Outro uso comum de grafos é para representar visualmente relacionamentos ou padrões existentes entre objetos. Muitas situações cotidianas podem ser representadas intuitivamente utilizando pontos conectados por linhas, como redes de computadores, nas quais computadores são representados por pontos e as conexões físicas entre eles por linhas, e redes de amigos, nas quais as pessoas são representadas como pontos e as amizades como linhas. Assim, grafos são amplamente usados em diversas áreas, desde banco de dados e engenharia de software a biologia e medicina.

Os algoritmos para desenho de grafos procuram encontrar a melhor posição para os 
nós e arestas de modo que o resultado seja de fácil entendimento, permitindo ao usuário extrair informações úteis e compreender melhor a estrutura do grafo. No entanto, encontrar um posicionamento adequado é uma tarefa complexa. Vários estudos realizados com usuários mostram que certas regras podem facilitar a leitura de um grafo, como evitar cruzamentos entre as arestas, limitar o número de arestas por vértice, evitar a sobreposição de vértices, entre outros [Batini et al., 1985]. Além disso, também é interessante que uma técnica gere sempre o mesmo resultado para determinado conjunto de dado, o que pode auxiliar o usuário a criar um mapa mental do grafo. Em geral, essas regras são bastante simples, mas satisfazê-las pode ser uma tarefa bastante complicada, principalmente quando o número de vértices e arestas cresce. Muitos algoritmos têm sido desenvolvidos nesse sentido, mas cada um leva em consideração diferentes aspectos e critérios visuais em detrimento de outros. A escolha de quais regras utilizar, e de como implementá-las, levam a técnicas que, na maioria das vezes, funcionam bem somente para determinados tipos de grafos [Spritzer and Freitas, 2008]. A maioria das técnicas de traçado de grafos trata o problema como um processo de otimização, ou seja, tentam resolver um conjunto de equações minimizando um erro gerado a partir das restrições impostas pelo conjunto de regras escolhido. Essas técnicas baseadas em otimização são interessantes pois podem ser aplicadas em todos os tipos de grafos e permitem que o usuário acompanhe o processo de construção por meio de animações que desenham os passos intermediários do processo. Por outro lado, as técnicas baseadas em otimização geram diferentes representações para um mesmo conjunto de dados, além de possuírem um alto custo computacional.

Além das técnicas que geram representações visuais baseadas apenas na estrutura topológica do grafo, as quais se preocupam principalmente com aspectos estéticos, existem algumas poucas que se preocupam também com as informações semânticas contidas nos atributos dos nós e arestas. Essas informações, muitas vezes, podem ser de grande importância para entender o porquê das relações existentes entre os elementos e também para identificar novos padrões não expressos explicitamente.

Também é possível utilizar outras abordagens para aumentar a legibilidade dos grafos, como técnicas de interação, construção de representações tridimensionais, e geração de duas ou mais representações simultâneas, cada uma podendo utilizar uma técnica diferente.

O objetivo deste capítulo é discutir aspectos de grafos relevantes à sua utilização 
na visualização e análise de dados, e está dividido como segue: na Seção 2.1 são apresentadas as formas usuais de representação de grafos; na Seção 2.2 são apresentados conceitos relativos à representação de conhecimento usando grafos; na Seção 2.3 são apresentadas várias técnicas de visualização de grafos; na Seção 2.4 são discutidas as formas de interação no contexto da visualização de grafos; e na Seção 2.5 é apresentada uma breve introdução a redes complexas.

\subsection{Formas de representação de grafos}

Grafos podem ser representados de várias formas. As mais comuns são: matriz de adjacência, lista de adjacência, e lista de arestas.

A matriz de adjacência de um grafo $G$ com $n$ vértices é uma matriz $A, n \times n$, definida como:

$$
a_{i j}= \begin{cases}1 & \text { se } v_{i} \text { é adjacente a } v_{j} \\ 0 & \text { caso contrário. }\end{cases}
$$

Determinados grafos possuem pesos numéricos associados às arestas, os quais podem indicar diferentes propriedades dependendo dos dados sendo representados. Nesses casos, o valor de $a_{i j}$ indica o peso da aresta, se $v_{i}$ é adjacente a $v_{j}$.

A lista de adjacência de um grafo $G$ com $n$ vértices é formada por $n$ listas, uma para cada vértice. Cada lista contém os vértices adjacentes ao vértice em questão, podendo também armazenar os pesos das arestas.

A lista de incidência é uma lista de pares de vértices, sendo que cada par representa uma aresta do grafo. A lista também pode armazenar os pesos das arestas. Em grafos direcionados, a ordem do par indica a direção da aresta.

Uma forma menos usual de representação de grafos é a matriz Laplaciana. Dado um grafo $G$ com $n$ vértices, a matriz Laplaciana $L, n \times n$, é definida como:

$$
l_{i j}= \begin{cases}\operatorname{grau}\left(v_{i}\right) & \text { se } i=j \\ -1 & \text { se } i \neq j \text { e } v_{i} \text { é adjacente a } v_{j} \\ 0 & \text { caso contrário. }\end{cases}
$$

O grau de um vértice indica o número de arestas conectadas a ele. Em grafos direcionados, o grau do vértice pode considerar somente as arestas que partem do vértice 
(grau de saída) ou apenas as arestas que chegam ao vértice (grau de entrada). Em grafos cujas arestas contêm pesos, o grau do vértice também pode ser computado somando os pesos das arestas, e o valor de $l_{i j}$ é o oposto do peso (isto é, o valor negativo do peso), se $i \neq j$ e $v_{i}$ é adjacente a $v_{j}$.

A Figura 1 exibe uma representação visual de um grafo. Cada vértice é representado por um círculo numerado e as arestas são representadas por linhas que conectam pares de vértices. A Figura 2 exemplifica as diferentes formas de representação citadas anteriormente para o grafo da Figura 1. Na Figura 2(a), o grafo é representado como uma matriz de adjacência, na qual as linhas e colunas seguem a numeração dos vértices da Figura 1. Na Figura 2(b), o grafo é representado como uma lista de adjacência, sendo que a primeira coluna indica o vértice de acordo com a numeração do grafo de exemplo, e a segunda coluna contém as listas de vértices adjacentes a cada um. Na Figura 2(c), o grafo é representado como uma lista de incidência. E na Figura 2(d), o grafo é representado como uma matriz Laplaciana.

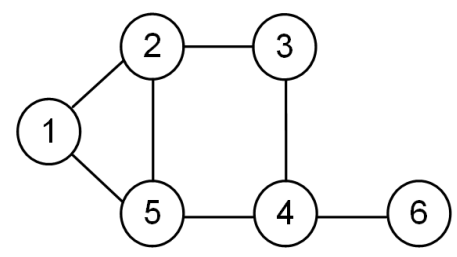

Figura 1: Exemplo de representação visual de um grafo. Os círculos numerados representam os vértices, e as linhas conectando-os representam as arestas.

\subsection{Representação de conhecimento em grafos}

A representação dos dados é fundamental na descoberta de padrões. Via de regra, os objetos tratados pelas técnicas de descoberta de padrões são representados em tabelas atributo-valor, existindo, no entanto, domínios e aplicações nos quais existem informações não apenas dos objetos, mas também das relações entre eles. Grafos permitem representar tanto os objetos quanto essas relações, situando-se, em termos de expressividade, entre as representações atributo-valor e relacional [Washio et al., 2005].

O exemplo a seguir, devido a Motta [da Motta, 2009], ilustra a expressividade de uma representação baseada em grafos. Na Figura 3 é apresentado um diagrama Entidade-Relacionamento (DER) de um banco de dados de publicações científicas, destacando que um mesmo artigo pode citar e pode ser citado por muitos artigos, e um autor pode participar de muitos artigos assim como um artigo ter muitos autores. 


$$
\left(\begin{array}{llllll}
0 & 1 & 0 & 0 & 1 & 0 \\
1 & 0 & 1 & 0 & 1 & 0 \\
0 & 1 & 0 & 1 & 0 & 0 \\
0 & 0 & 1 & 0 & 1 & 1 \\
1 & 1 & 0 & 1 & 0 & 0 \\
0 & 0 & 0 & 1 & 0 & 0
\end{array}\right)
$$

(a)

\begin{tabular}{|l|l|}
\hline 1 & 2,5 \\
\hline 2 & $1,3,5$ \\
\hline 3 & 2,4 \\
\hline 4 & $3,5,6$ \\
\hline 5 & $1,2,4$ \\
\hline 6 & 4 \\
\hline
\end{tabular}

(b)

\begin{tabular}{|l|}
\hline 1,2 \\
\hline 1,5 \\
\hline 2,3 \\
\hline 2,5 \\
\hline 3,4 \\
\hline 4,5 \\
\hline 4,6 \\
\hline
\end{tabular}

(c)

$$
\left(\begin{array}{rrrrrr}
2 & -1 & 0 & 0 & -1 & 0 \\
-1 & 3 & -1 & 0 & -1 & 0 \\
0 & -1 & 2 & -1 & 0 & 0 \\
0 & 0 & -1 & 3 & -1 & -1 \\
-1 & -1 & 0 & -1 & 3 & 0 \\
0 & 0 & 0 & -1 & 0 & 1
\end{array}\right)
$$

(d)

Figura 2: Diferentes formas de representação de um grafo: (a) matriz de adjacência, (b) lista de adjacência, (c) lista de incidência, (d) matriz Laplaciana.

Na Tabela 1 são representadas as informações dos artigos e dos autores, bem como os relacionamentos, representando coautoria. Essas informações podem ser representadas por grafos que modelam as relações de coautoria. A Figura 4(a) apresenta um grafo cujos vértices representam os autores e as arestas coautoria. A Figura 4(b) apresenta uma rede heterogênea na qual os vértices em forma de círculo representam os autores, os vértices em forma de quadrado representam os artigos, e as arestas representam o relacionamento entre autores e artigos.

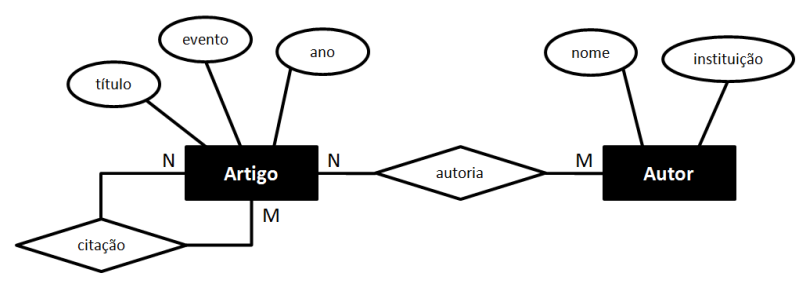

Figura 3: Diagrama Entidade-Relacionamento de um banco de dados de publicações científicas.

\subsection{Visualização de grafos}

Como a própria definição de grafo sugere, a abordagem mais intuitiva de representação desse tipo de estrutura utiliza pontos ou outra geometria para representar os vértices, 
Tabela 1: Banco de dados de publicações científicas: (a) artigo, (b) autor e (c) coautoria.

(a)

\begin{tabular}{c|c|c|c}
\hline id & título & evento & ano \\
\hline 1 & Finding community structure in very large networks & Physical Review E & 2004 \\
2 & Community structure in social and biological networks & PNAS & 2002 \\
3 & The Power of Choice in Network Growth & European Journal of Physics B & 2007 \\
4 & Explosive Percolation in Random Networks & Science & 2009 \\
\hline
\end{tabular}

(b)

\begin{tabular}{c|c|c}
\hline id & nome & instituição \\
\hline$a$ & Aaron Clauset & University of New Mexico \\
$b$ & Mark Newman & University of Michigan \\
$c$ & Cristopher Moore & University of New Mexico \\
$d$ & Michelle Girvan & University of Michigan \\
$e$ & Raissa D'Souza & University of California \\
$f$ & Paul Krapivsky & Boston University \\
$g$ & Dimitris Achlioptas & University of California \\
$h$ & Joel Spencer & New York University \\
\hline
\end{tabular}

(c)

\begin{tabular}{c|c}
\hline artigo & autor \\
\hline 1 & $a$ \\
1 & $b$ \\
1 & $c$ \\
2 & $d$ \\
2 & $b$ \\
3 & $e$ \\
3 & $f$ \\
3 & $c$ \\
4 & $g$ \\
4 & $e$ \\
4 & $h$ \\
\hline
\end{tabular}

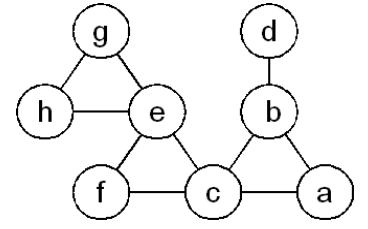

(a)

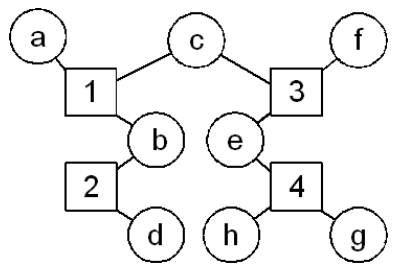

(b)

Figura 4: Rede de co-autoria: (a) apenas autores, (b) autores e artigos.

e linhas ou curvas que os conectam para representar as arestas existentes entre eles. A grande maioria dos algoritmos propostos utiliza essa abordagem, diferindo apenas na maneira em que as arestas e os vértices são posicionados.

Herman et al. descrevem uma série de técnicas clássicas para criação e navegação de grafos em visualização de informação [Herman et al., 2000]. Muitas técnicas se baseiam na construção de árvores. O algoritmo de Reingold-Tilford [Reingold and Tilford, 1981; Walker, 1990] é um algoritmo bastante conhecido de posicionamento baseado em árvore. A Figura 5 exibe uma árvore gerada com o algoritmo de ReingoldTilford. O algoritmo de posicionamento radial [Eades, 1992] dispõe os nós em círculos concêntricos de acordo com a profundidade na árvore. A Figura 6 exibe um exemplo de árvore radial.

Algoritmos de posicionamento hiperbólico são usados, na maioria, para representar árvores em duas ou três dimensões, permitindo observar o grafo com um efeito no qual os objetos ao centro são projetados em maiores detalhes, enquanto que objetos distantes 


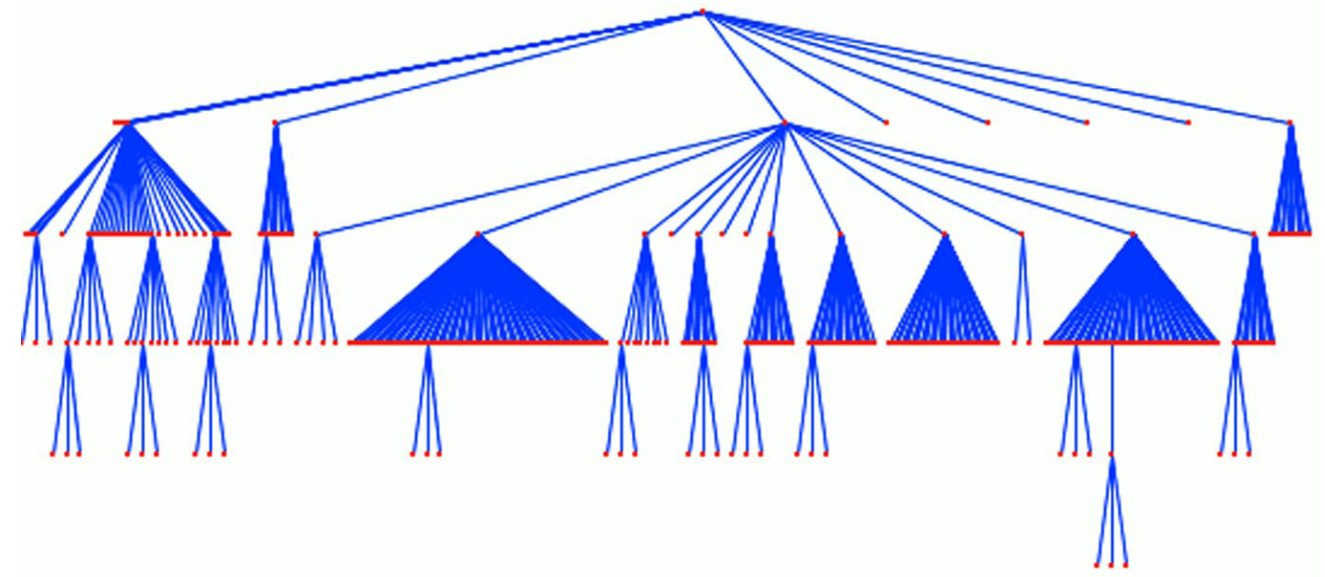

Figura 5: Árvore gerada a partir do algoritmo de Reingold-Tilford [Reingold and Tilford, 1981; Walker, 1990].

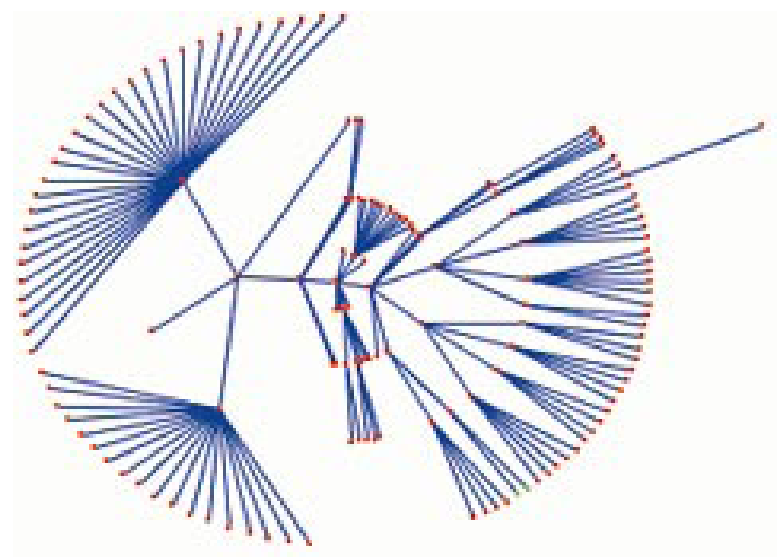

Figura 6: Exemplo de árvore radial [Eades, 1984]. 
do centro são mostrados progressivamente menores e as arestas são apresentadas como curvas [Lamping and Rao, 1999]. A grande vantagem desse tipo de visualização é a possibilidade de representar grafos com uma quantidade grande de vértices e arestas usando interação para analisar áreas de interesse. A Figura 7 exibe um exemplo de posicionamento hiperbólico.

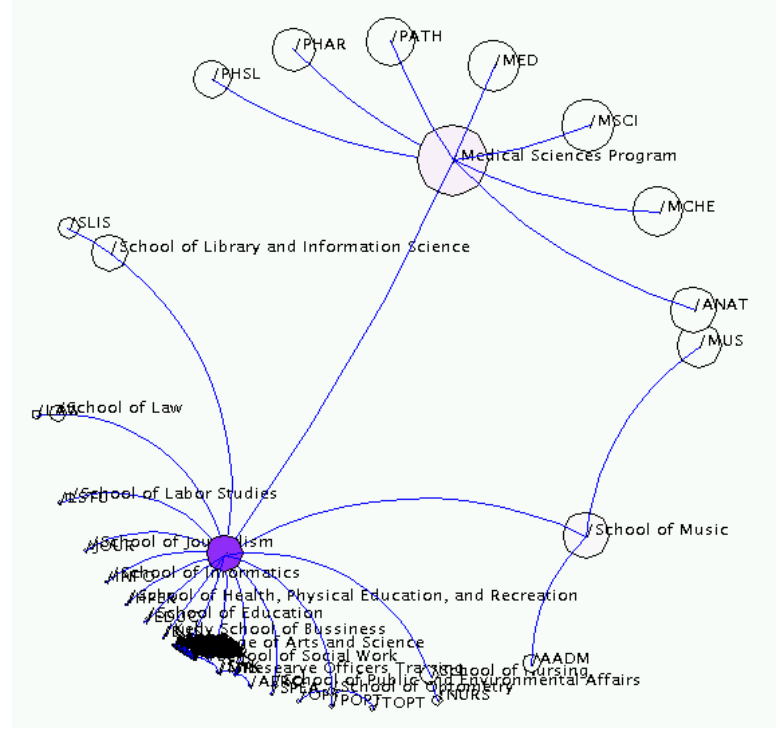

Figura 7: Exemplo de visualização de grafo baseado no posicionamento hiperbólico [Zhou, 2004].

Em geral, os algoritmos de posicionamento baseados em árvores possuem baixo custo computacional. Assim, para outros tipos de grafos, é possível calcular uma árvore geradora e utilizar um dos algoritmos de posicionamento baseados em árvore existentes. No entanto, essa abordagem não leva em consideração todas as arestas do grafo original, podendo gerar confusão visual. Por isso, outras abordagens para representar os demais tipos de grafos são mais adequadas.

Algoritmos de posicionamento baseados em força são incrementais, tratando o grafo como um sistema físico [Eades, 1984]. Esses algoritmos atribuem forças aos vértices e arestas, os quais movimentam-se de modo a minimizar a energia do sistema até atingir o equilíbrio. Os resultados obtidos com essa abordagem são visualmente bons, apesar do alto custo computacional. A Figura 8 mostra um exemplo de posicionamento baseado em força utilizando o algoritmo proposto por Eades.

Algoritmos de posicionamento ortogonal sempre posicionam as arestas na horizontal ou na vertical de modo a reduzir tanto a área ocupada pelo grafo quanto o número 


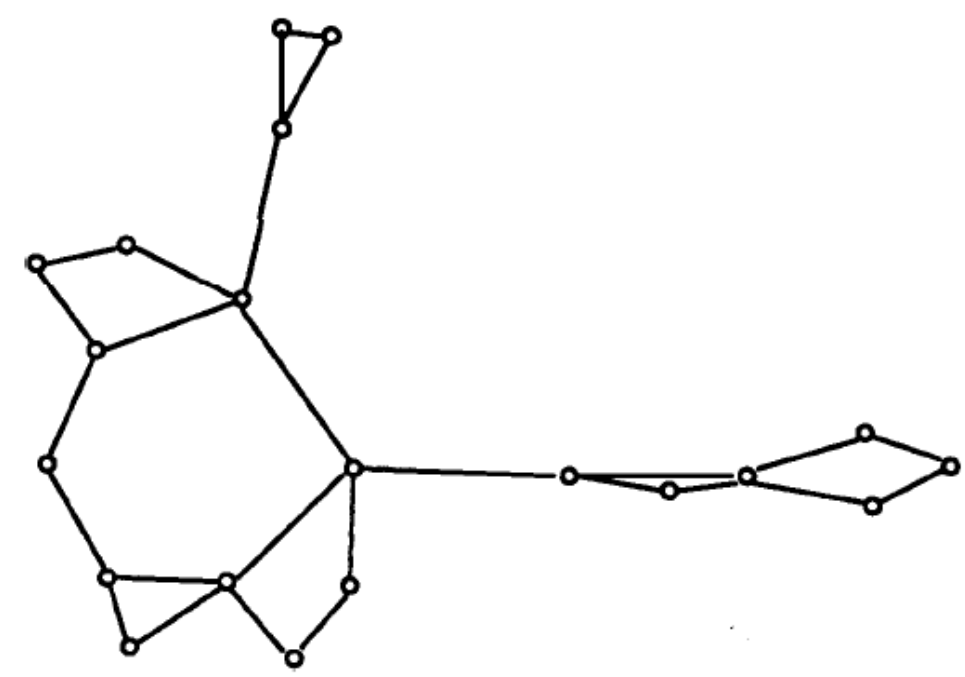

Figura 8: Exemplo de posicionamento baseado em força proposto por Eades [Eades, 1984].

de cruzamentos entre arestas. A Figura 9 exemplifica essa abordagem utilizando o algoritmo proposto por Tamassia e Tollis [Tamassia and Tollis, 1989].

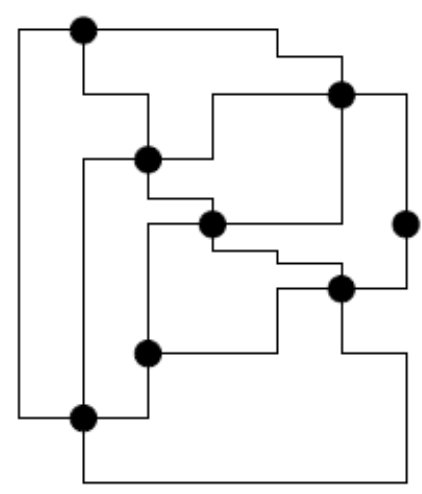

Figura 9: Exemplo de posicionamento ortogonal baseado no algoritmo de Tamassia e Tollis [Tamassia and Tollis, 1989].

Outra abordagem para o traçado de grafos é o posicionamento hierárquico, no qual os nós são posicionados em camadas, sendo útil para representar diagramas organizacionais que possuem estrutura hierárquica. Essa abordagem é muito semelhante à estrutura de árvore, mas trata apenas de grafos direcionados. Um algoritmo clássico dessa abordagem é o de Sugiyama et al. [Sugiyama et al., 1981].

Os algoritmos de posicionamento espectral utilizam os autovetores da matriz Laplaciana do grafo para minimizar uma função de energia, aplicada a cada aresta. Tal abordagem assemelha-se aos algoritmos baseados em força, mas a função de energia a ser minimizada nesse caso é local, substituindo as forças de atração das arestas, enquanto 
nos algoritmos baseados em força é global. Os trabalhos de Pisanski e Shawe-Taylor [Pisanski and Shawe-Taylor, 2000], e Koren [Koren, 2003] apresentam os principais algoritmos que utilizam essa abordagem.

Uma abordagem alternativa bastante interessante para o traçado de grafos é a baseada em propriedades topológicas do grafo, isto é, a abordagem procura detectar as diferentes estruturas contidas no grafo, como árvores e componentes conectados, e, de acordo com as propriedades topológicas encontradas, utiliza um algoritmo mais apropriado, como baseado em árvore ou em força. Assim, essa abordagem combina várias outras, sendo utilizada no algoritmo de Archambault et al. [Archambault et al., 2007].

Recentemente, novos trabalhos têm buscado solucionar o problema da escalabilidade, pois representações de grafos que contêm muitos vértices e arestas utilizando as técnicas já apresentadas podem ter problemas de obstrução e confusão visual, devido ao grande número de cruzamentos entre arestas e ao grande espaço ocupado. Entre esses trabalhos, encontra-se o Treemap [Shneiderman, 1992], específico para árvores, o qual representa os vértices do grafo como retângulos aninhados de acordo com sua hierarquia, e sistemas que representam a matriz de adjacência do grafo [Abello and Korn, 2002]. A Figura 10 [SmartMoney, 2008] mostra um exemplo de um aplicativo web para visualização do valor das ações das principais empresas americanas dividido hierarquicamente em setores e indústrias. As cores indicam alta ou baixa no preço de ações, e o tamanho indica a participação da empresa no mercado. A Figura 11 [Fekete, 2005] exibe uma matriz de adjacência de um grafo de coautoria em artigos científicos, no qual os eixos representam autores e os valores na matriz indicam o número de artigos realizados em co-autoria. Foi utilizada uma técnica de interação para destacar uma região da matriz.

Também é possível utilizar múltiplas representações simultâneas de um grafo, de forma que diferentes técnicas possam ser aplicadas em cada uma delas. Como as diferentes abordagens apresentam suas vantagens e desvantagens, ao utilizar várias delas, as deficiências de uma podem ser supridas pelos pontos fortes de outras [Keim and Kriegel, 1996]. Com o objetivo de facilitar ainda mais o entendimento, algumas técnicas podem ser aplicadas sobre as múltiplas visões de modo que ações realizadas em uma visualização sejam refletidas nas demais. Essas técnicas são denominadas técnicas de coordenação e o campo da visualização exploratória que estuda como 


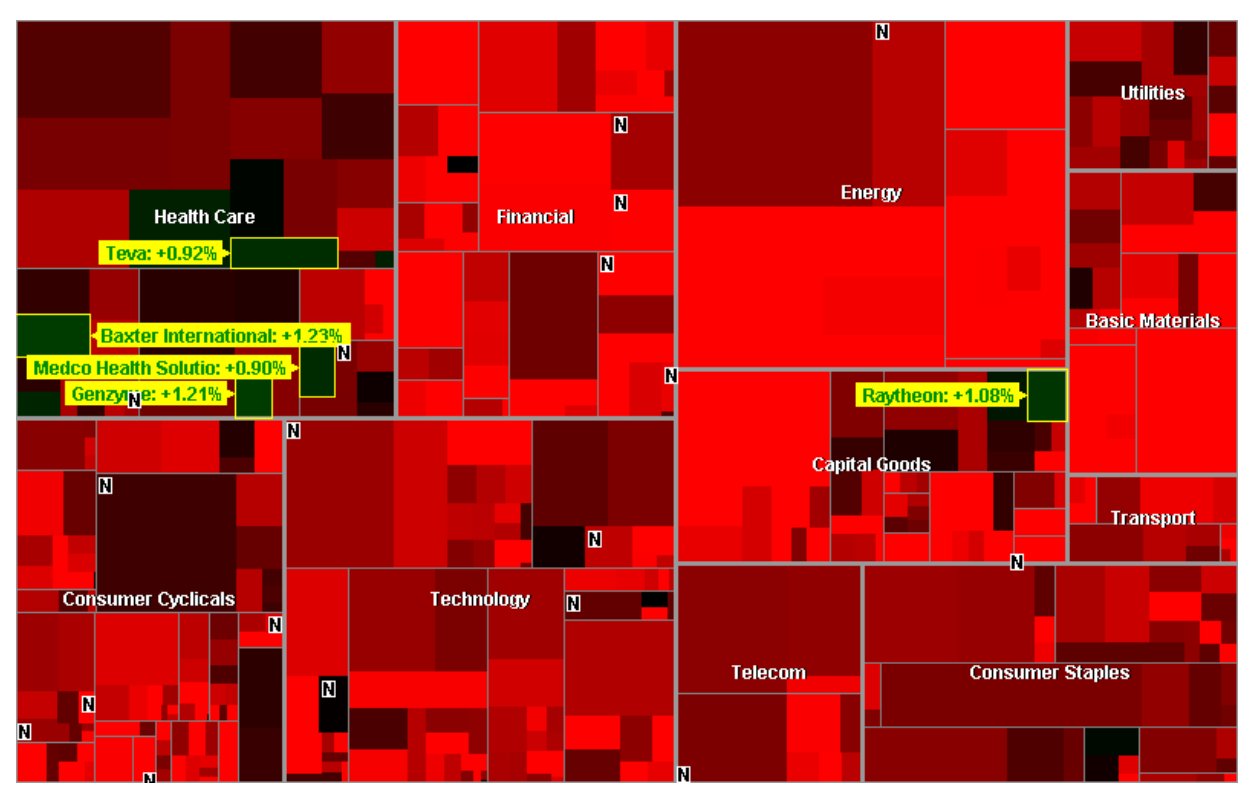

Figura 10: Aplicativo para visualização do valor das ações das principais empresas americanas utilizando a técnica Treemap [SmartMoney, 2008].

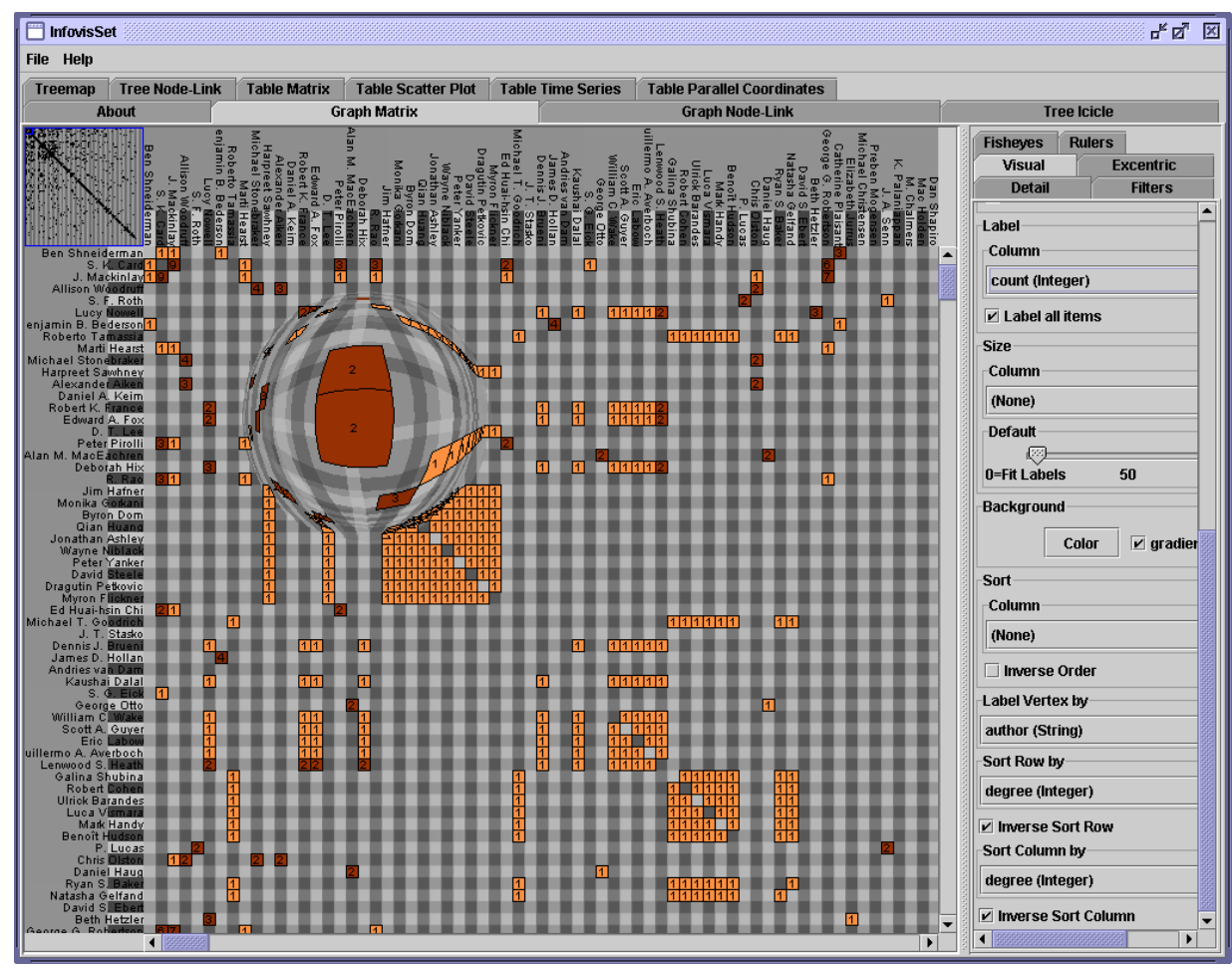

Figura 11: Matriz de adjacência de um grafo de co-autoria em artigos científicos [Fekete, 2005]. 
combinar eficientemente as informações contidas nas múltiplas visões é denominado Múltiplas Visões Coordenadas (CMV - Coordinated and Multiple Views).

Outra possibilidade de apresentar grafos é combinar em uma mesma visualização diferentes abordagens, dando origem a técnicas híbridas. Um exemplo é o Elastic Hierarchies [Zhao et al., 2005], exibido na Figura 12. Como é possível observar, essa técnica constrói uma representação visual de grafos utilizando tanto diagramas com nós e arestas quanto Treemaps.

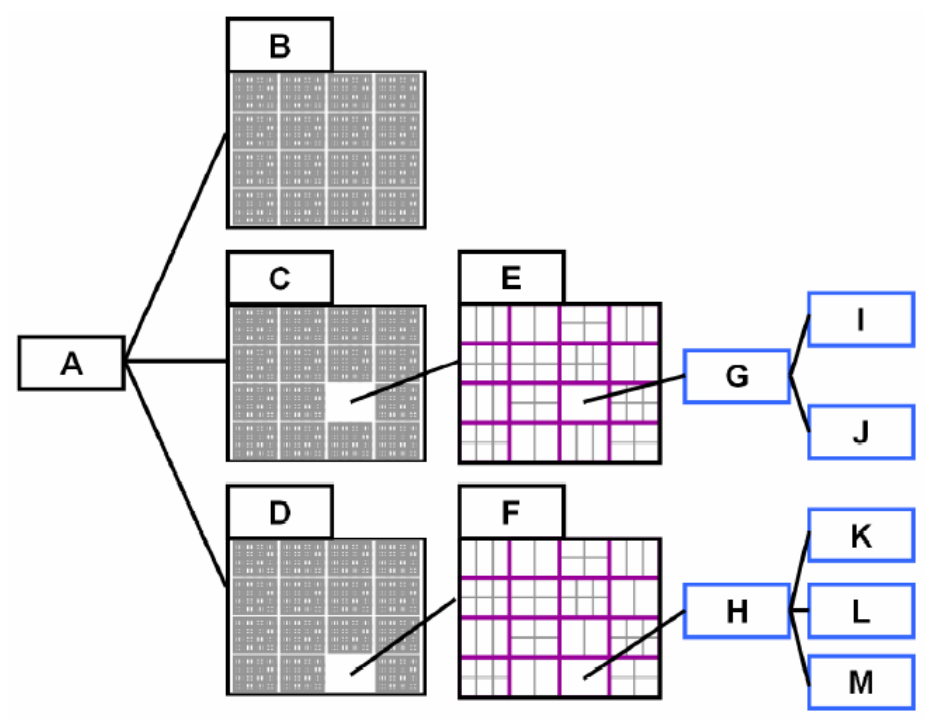

Figura 12: Elastic Hierarchies: exemplo de técnica híbrida na qual é possível representar grafos utilizando tanto nós e arestas quanto Treemaps [Zhao et al., 2005].

Muitas vezes, a estrutura do grafo permite criar agrupamentos de vértices baseados nas arestas que os conectam. Dessa forma, outra abordagem para lidar com grafos que possuem muitos vértices e arestas é criar agrupamentos menores e expandi-los à medida que o usuário necessitar. Abello et al. [Abello et al., 2006] descrevem uma ferramenta, denominada ASK-GraphView, que permite realizar agrupamento e navegação interativa de grafos com até 16 milhões de arestas. A ferramenta agrupa certos nós que estão conectados a um mesmo nó, e exibe um grafo simplificado, no qual cada nó representa um agrupamento. O usuário pode, então, navegar pela estrutura hierárquica expandindo interativamente agrupamentos individuais. A Figura 13 ilustra essa ferramenta. Uma ferramenta semelhante é apresentada por Loubier et al. [Loubier et al., 2007], a qual agrupa os nós em classes, que são obtidas pelo algoritmo de agrupamento de Markov, exibindo como resultado um grafo de classes, que podem ser expandidas. A ferramenta também cria grafos com características temporais, dividindo os dados em intervalos de tempo e gerando um grafo para cada intervalo, permitindo analisar a evo- 
lução ocorrida. Alguns modelos específicos para lidar com grafos com características evolutivas ao longo do tempo são propostos por Leskovec et al. [Leskovec et al., 2005]. Huang et al. [Huang et al., 2005] descrevem um framework para filtragem, agrupamento e visualização de grafos. Cada uma das etapas permite intervenção do usuário para que os parâmetros sejam ajustados de acordo com os dados.

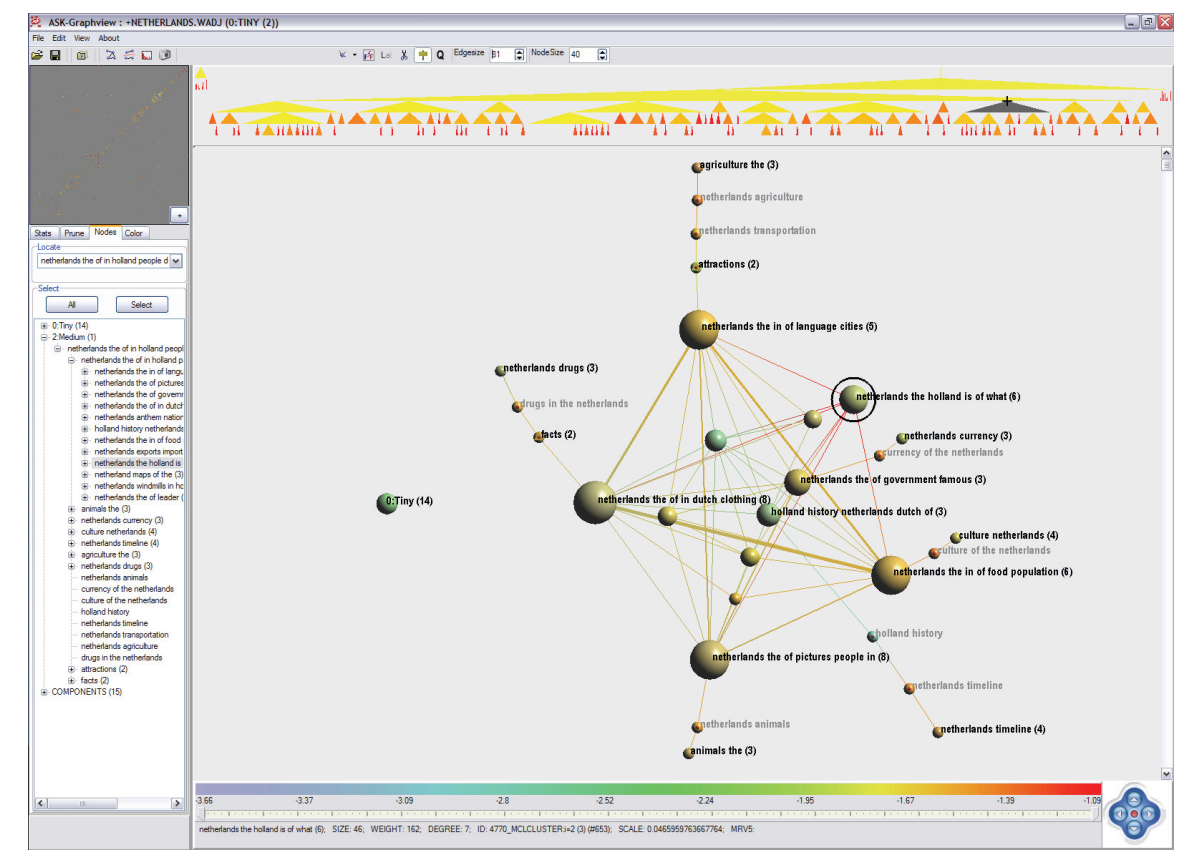

Figura 13: ASK-GraphView: ferramenta que utiliza agrupamentos para visualizar grafos que contêm uma grande quantidade de vértices e arestas [Abello et al., 2006].

As abordagens apresentadas até agora baseiam-se apenas na estrutura topológica do grafo para gerar representações visuais. Algumas poucas abordagens têm sido criadas para visualizar grafos baseadas nos dados contidos nos vértices e nas arestas. Em muitas situações, esses dados são tão importantes quanto a própria estrutura topológica do grafo, pois ajudam a extrair novas informações não representadas explicitamente nos relacionamentos. Uma contribuição nessa linha é o trabalho de Wattenberg [Wattenberg, 2006]. A Figura 14 exibe o PivotGraph [Wattenberg, 2006], uma ferramenta para visualizar grafos e seus atributos. Os atributos são visualizados dois a dois em um gráfico de dispersão, sendo que o tamanho dos pontos indica a quantidade de vértices com os mesmos valores para ambos os eixos, a cor dos vértices indica a razão entre os graus de entrada e de saída, a espessura das arestas indica a quantidade de relacionamentos entre dois pontos, e a cor das arestas indica a razão entre o número de relacionamentos pelo número de vértices. 


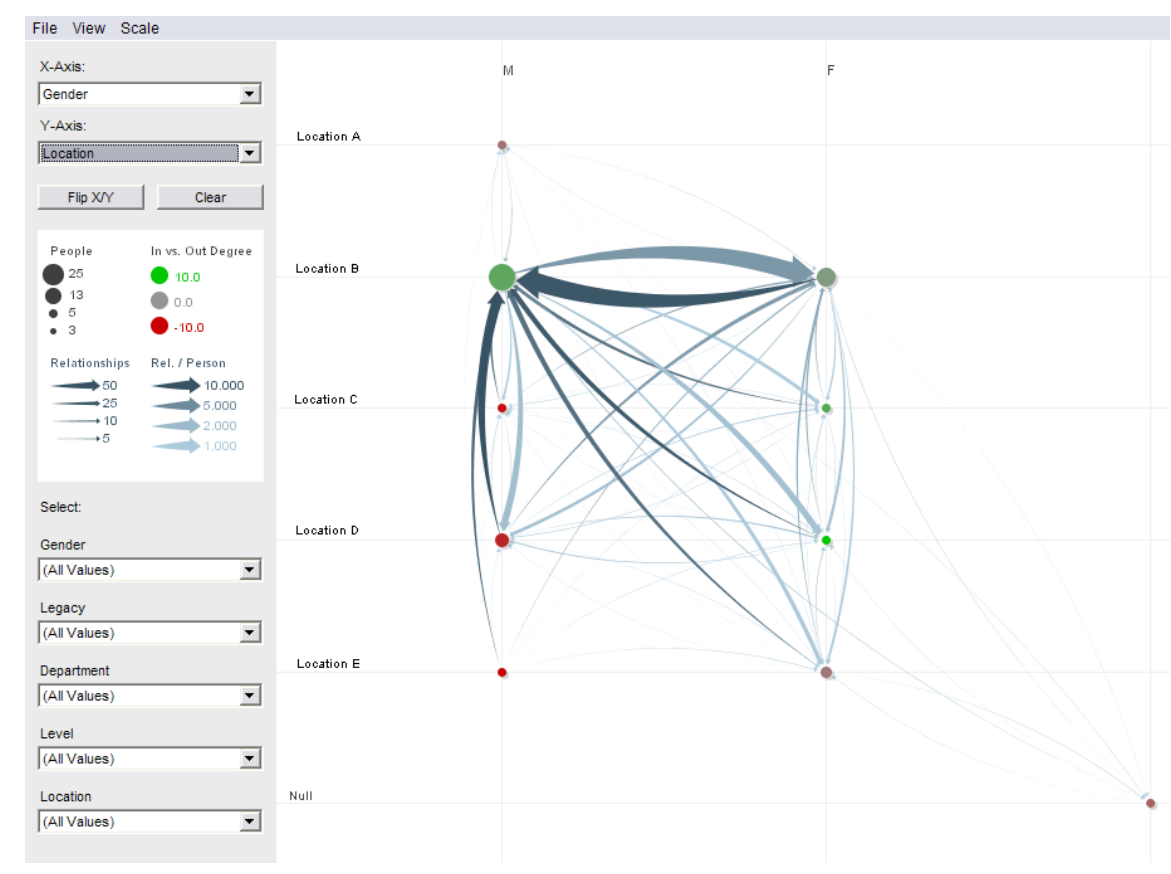

Figura 14: PivotGraph: ferramenta para gerar representações visuais de grafos baseadas nos dados contidos nos vértices e nas arestas [Wattenberg, 2006].

\subsection{Interação em visualização de grafos}

Para que o usuário seja capaz de explorar os dados, além de compreender e extrair informações relevantes dos mesmos, mecanismos de interação são extremamente importantes. Como as representações de grafos, em geral, possuem problemas decorrentes do posicionamento dos vértices e das arestas, as técnicas de interação se tornam parte essencial da visualização. Alguns mecanismos clássicos de interação na área de visualização de informação incluem seleção, escala, busca e filtro.

A seleção permite que o usuário escolha diretamente na representação visual um vértice ou grupo de vértices ou uma aresta ou um grupo de arestas de interesse, de modo que as informações sobre os objetos selecionados sejam exibidas. Além disso, é por meio da seleção que o usuário consegue manipular um objeto, como arrastá-lo.

A escala permite que o usuário visualize em maiores detalhes determinada região da representação visual, ampliando-a simplesmente, ou exibindo informações adicionais a respeito dos objetos ali contidos. Como a visualização pode exceder o espaço disponível na tela, principalmente quando a escala é aplicada, é fundamental que o usuário possa deslocar-se sobre a apresentação, de modo a visualizar outras áreas que não estão sendo exibidas.

A busca possibilita que o usuário forneça alguma informação que permita identificar 
objetos de interesse, destacando-os na visualização. Já o filtro permite definir um conjunto de critérios para restringir quais objetos serão exibidos na tela. O filtro é bastante útil para controlar o excesso de objetos sendo exibidos.

Outro conceito de técnicas de interação bastante utilizado é o de "foco+contexto" [Leung and Apperley, 1994; Keahey and Robertson, 1996]. As técnicas dessa categoria exibem uma visão detalhada de uma região de interesse da representação visual, enquanto o restante da visualização é exibido em um nível menor de detalhes. Uma das técnicas mais utilizadas dessa categoria é o denominado "olho de peixe" [Sarkar and Brown, 1994], que é o mecanismo de interação que representa uma lente sobre a visualização, utilizado na matriz de adjacência da Figura 11.

Novas abordagens de visualização de grafos têm sido propostas utilizando as técnicas de interação como parte do processo de representação visual. As ferramentas baseadas em agrupamento apresentadas na Seção 2.3 utilizam essa ideia, pois o grafo apresentado inicialmente contém objetos não exibidos explicitamente, sendo necessário que o usuário utilize as ferramentas de interação, principalmente seleção, para visualizar outros vértices que haviam sido agrupados.

Uma técnica baseada em força para manipulação interativa de grafos é apresentada por Spritzer e Freitas [Spritzer and Freitas, 2008]. Segundo essa técnica, é possível, além de visualizar os grafos, realizar consultas diretamente sobre a apresentação visual, posicionando ímãs que atraem ou repelem os nós de acordo com os critérios definidos. A Figura 15 exemplifica essa técnica de interação, na qual as circunferências maiores representam as áreas de influência dos imãs posicionados no centro de cada uma. Como é possível observar, os vértices são atraídos para dentro das áreas de influência caso satisfaçam a condição imposta pelos respectivos ímãs.

Uma outra ferramenta para visualização e análise de grafos é o GUESS [Adar, 2006]. A proposta dessa ferramenta é combinar análise e visualização em um pacote para análise exploratória de dados em grafos, de forma que seja possível realizar a análise juntamente com a visualização. Diferentemente da ferramenta apresentada por Spritzer e Freitas, o GUESS não modifica a posição dos vértices e arestas, apenas seus atributos visuais, como cor ou visibilidade, além de permitir obter valores de grau, densidade e centralidade. O GUESS também implementa vários algoritmos de posicionamento de diferentes abordagens. A Figura 16 exibe um exemplo de grafo visualizado por meio do GUESS. 


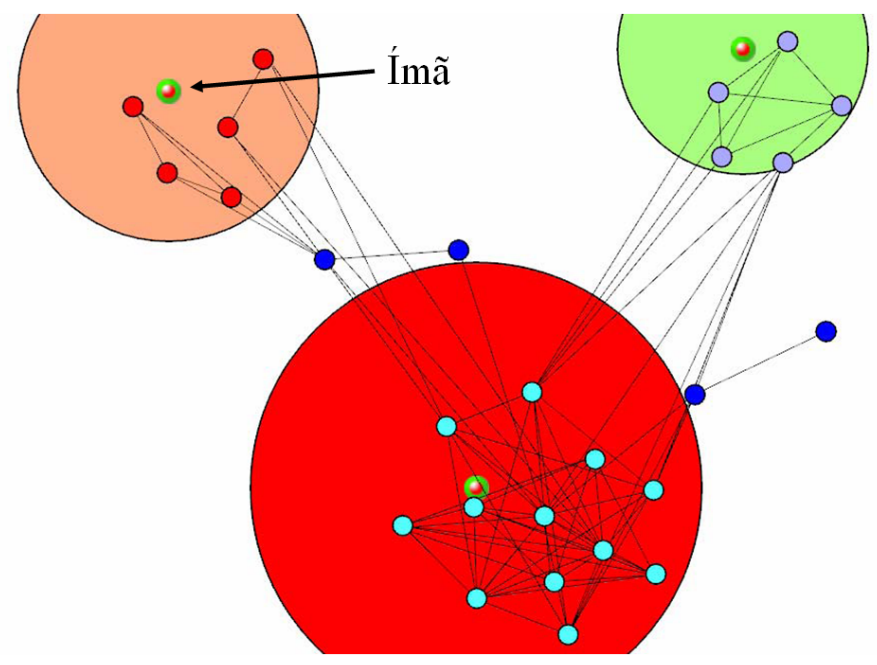

Figura 15: Técnica de interação na qual ímãs posicionados pelo usuário atraem ou repelem os vértices de acordo com critérios definidos [Spritzer and Freitas, 2008].

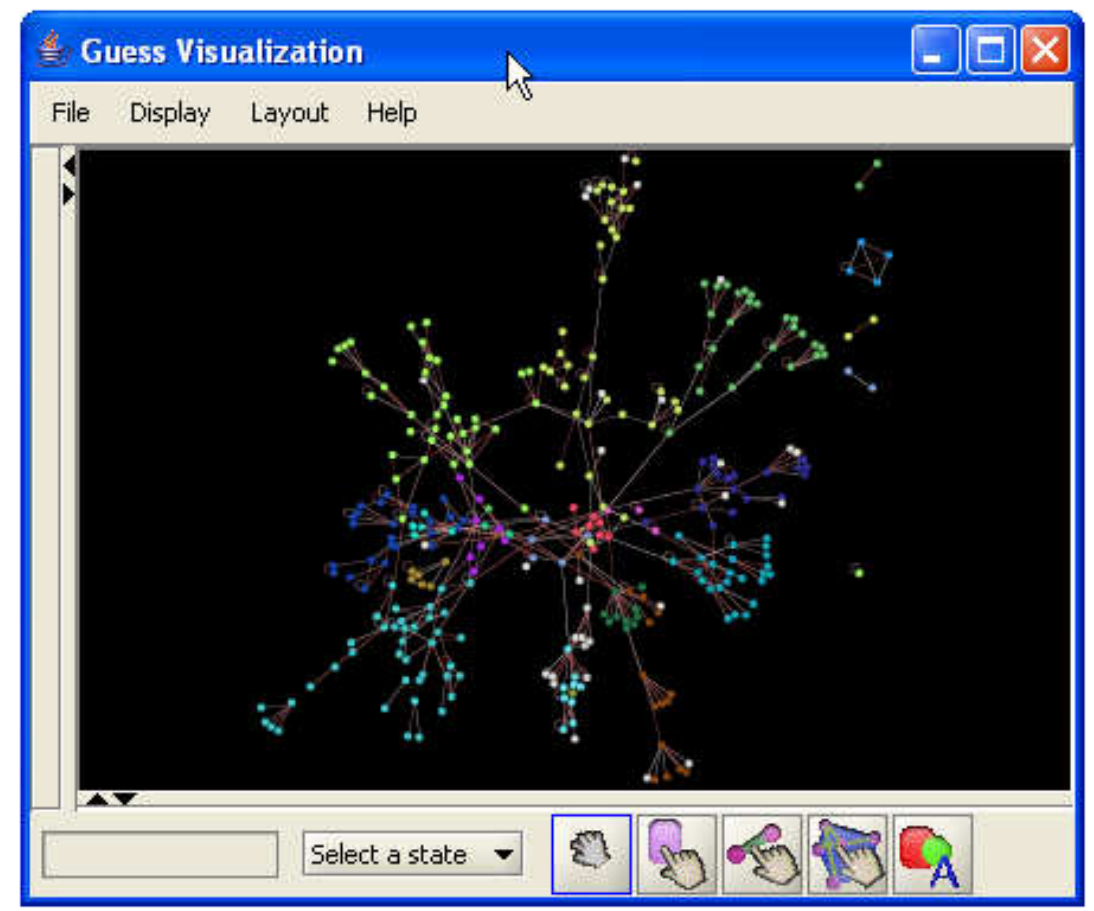

Figura 16: GUESS: ferramenta para análise exploratória de dados em grafos que engloba algoritmos de posicionamento de diferentes abordagens e faz uso de técnicas de interação [Adar, 2006]. 
Existem também vários pacotes e bibliotecas que auxiliam na criação de programas para visualização de grafos. A Tom Sawyer Software ${ }^{3}$ apresenta cinco pacotes disponíveis em várias linguagens de programação que permitem desenvolver programas de visualização e análise de grafos com diferentes algoritmos de posicionamento e interação.

Outra biblioteca bastante completa é a $\mathrm{JUNG}^{4}$, capaz de gerar diversos tipos de grafos diferentes, além de possuir uma quantidade muito grande de algoritmos de posicionamento. Essa biblioteca é desenvolvida em Java, sendo amplamente utilizada em várias áreas para desenvolver ferramentas específicas.

As técnicas de visualização e interação apresentadas neste capítulo foram desenvolvidas e são utilizadas, principalmente, para exploração de grafos cujas características diferem dos modelos clássicos tratados na teoria dos grafos. Tais grafos recebem o nome de redes complexas. Uma breve introdução a redes complexas é apresentada na próxima seção.

\subsection{Introdução a redes complexas}

Muitos sistemas naturais e tecnológicos são compostos por um grande número de unidades dinâmicas que se inter-relacionam. Alguns exemplos incluem sistemas biológicos, químicos, redes neurais e a internet. Esses sistemas podem ser visualizados por meio de grafos, nos quais as unidades dinâmicas são representadas pelos vértices e as interações entre as unidades são representadas pelas arestas. Pesquisas recentes em diversas áreas têm revelado que a maioria das redes formadas por esses sistemas possui propriedades topológicas não triviais, isto é, que não ocorrem em grafos simples, como pequena distância entre os vértices, alto coeficiente de agrupamento e a presença de estruturas de comunidade [Boccaletti et al., 2006]. Redes que possuem essas características diferem dos modelos clássicos tratados na teoria dos grafos, sendo denominadas redes complexas. Dessa forma, a teoria de redes complexas procura tratar de grafos com grande número de vértices e arestas, bem como de suas propriedades estatísticas [Newman, 2003].

Além das propriedades citadas, um efeito interessante que ocorre em redes reais é o dito "mundo-pequeno" (small-world). Um experimento realizado por Milgram [Mil-

\footnotetext{
${ }^{3}$ http://www.tomsawyer.com/

${ }^{4} \mathrm{http}: / /$ jung.sourceforge.net/
} 
gram, 1967] mostrou que existem arestas nas redes que atuam como atalhos, isto é, que conectam diferentes regiões, diminuindo o caminho entre indivíduos aparentemente distantes. Para realizar o experimento, pessoas foram selecionadas aleatoriamente em duas cidades dos Estados Unidos. Para cada pessoa selecionada, foi entregue um envelope contendo o nome de um destinatário, o qual pertencia a alguma cidade do outro lado do país. Foi solicitado, então, que cada participante enviasse o envelope ao destinatário caso o conhecesse; caso contrário, que escrevesse o próprio nome em uma lista e a enviasse junto com o envelope a algum conhecido que, em sua opinião, teria maior probabilidade de conhecer o destinatário. Muitos envelopes se perderam, mas os que chegaram passaram na mão de aproximadamente seis pessoas. Atualmente, esse efeito tem sido verificado diretamente em um grande número de redes complexas.

O experimento realizado por Milgram permite obter outra conclusão muito interessante. Além de demonstrar que existem atalhos nas redes, o experimento também demonstrou que as pessoas são boas em encontrá-los, pois os participantes não tinham nenhum conhecimento adicional sobre a rede social da qual faziam parte, ao contrário, eles conheciam apenas seus amigos e, talvez, alguns amigos de seus amigos.

Outra característica importante de redes complexas está relacionada a uma medida conhecida como coeficiente de agrupamento (clustering coefficient), descrita na Seção 3.2. O coeficiente de agrupamento indica a probabilidade de dois vértices, ambos conectados a um terceiro vértice, estarem conectados entre si. Esse coeficiente assume um valor consideravelmente maior em diversas redes reais do que em grafos de mesmo tamanho gerados aleatoriamente.

Muitas redes complexas são denominadas livres de escala (scale-free) devido à distribuição das conexões entre os vértices. De forma geral, essa distribuição indica que, independente do quanto a rede cresça, vértices com muitas conexões continuarão com muitas conexões e vértices com poucas conexões continuarão com poucas conexões. Além disso, a distribuição também indica a presença de poucos nós muito conectados e uma grande quantidade de elementos com poucas conexões, o que não ocorre em grafos gerados aleatoriamente, em que todos os nós apresentam aproximadamente a mesma quantidade de conexões. Uma consequência direta dessa distribuição é o efeito devastador causado sobre a rede pela remoção de nós muito conectados, o que pode até mesmo torná-la desconexa.

Muito embora alguns dos trabalhos aqui mencionados tratem do problema de análise 
de atributos de vértices e arestas, o presente trabalho amplia a importância desses atributos na análise de grafos, em particular daqueles que representam redes sociais.

O Capítulo 3 discute especificamente sobre redes sociais, que compõem um subconjunto dos sistemas tratados na teoria de redes complexas. Assim, muitas das medidas para redes sociais que são descritas na Seção 3.2 também podem ser aplicadas para os demais tipos de redes complexas. Outras propriedades sobre a dinâmica e a estrutura de redes complexas são apresentadas por Boccaletti et al. [Boccaletti et al., 2006] e por Newman [Newman, 2003]. 


\section{Análise visual de redes sociais}

Há muitas décadas, pesquisadores da área de ciências sociais buscam formas de compreender quais são e como ocorrem as relações humanas na sociedade. Atualmente, o crescente avanço das tecnologias de comunicação, a popularização da internet, e o número de pessoas utilizando serviços, fornecendo informações e participando de comunidades online propiciam o estudo de um campo particular da visualização de informação, o da visualização de redes sociais. Essas redes possuem características muito semelhantes às de redes complexas, citadas na Seção 2.5, sendo frequentemente tratadas como tal.

Diversos trabalhos têm sido publicados descrevendo métodos para realizar exploração visual de redes sociais. A abordagem mais intuitiva e, consequentemente, a mais comum, utiliza grafos como forma de representação desse tipo de dado, pois redes sociais possuem a característica intrínseca de serem formadas por nós e arestas, sendo que os nós representam os indivíduos da rede e as arestas o relacionamento entre eles. Em ciências sociais, diagramas para visualização de redes sociais são chamados de sociogramas.

Freeman relata a história da visualização de redes sociais dentro do contexto sociológico, descrevendo os meios pelos quais a informação pode ser codificada [Freeman, 2000]. Desde os primeiros estudos na área de análise de redes sociais, representações visuais têm desempenhado um papel fundamental, propiciando aos pesquisadores novas ideias e interpretações sobre as estruturas das redes, e ajudando-os a transmiti-las. Trabalhos pioneiros na área, como os de Moreno [Moreno, 1932, 1934, 1953], já faziam uso de imagens para revelar informações importantes sobre padrões de relacionamentos. Moreno defende em seus trabalhos que o processo de análise deve começar pela visualização da rede, a qual consiste em um método de exploração que permite posicionar todos os indivíduos e as relações existentes entre eles, e que somente por meio de representações visuais é possível realizar a análise estrutural de uma comunidade. A 
Figura 17 exibe uma rede social apresentada no primeiro trabalho de Moreno [Moreno, 1932]. Como é possível observar, a representação utilizada possui a mesma estrutura de um grafo. Os outros trabalhos de Moreno [Moreno, 1934, 1953] apresentam ideias mais elaboradas, como arestas dirigidas, variações na forma, cor e tamanho dos vértices, além de definir regiões para posicionamento dos pontos baseadas em propriedades dos indivíduos. Assim, todo o arcabouço e experiência de visualização e análise de dados expressos como grafos podem ser empregados para a exploração de rede sociais [Herman et al., 2000]. Abordagens utilizando tais elementos têm sido desenvolvidas para analisar domínios específicos, como redes de co-autoria em publicações científicas, comunicações por e-mail, e comunidades virtuais em sites de relacionamento.

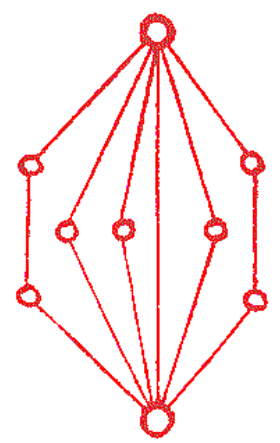

Figura 17: Exemplo de representação de rede social desenhada a mão [Moreno, 1932].

Um estudo realizado por Huang et al. descreve como as pessoas interpretam representações visuais de redes sociais [Huang et al., 2006]. O resultado da pesquisa sugere que os usuários têm a tendência de acreditar que nós no centro ou no topo são mais importantes, e nós próximos pertencem à mesma comunidade. Ao serem questionados sobre como as propriedades visuais podem ajudar ou atrapalhar o entendimento da rede social, os usuários responderam que o posicionamento dos nós e das arestas deve ser organizado de acordo com os papéis que os indivíduos representam na rede e de acordo com os objetivos da visualização, e que os nós não devem ser distribuídos igualmente no plano, ao invés disso, a distância entre eles deve refletir seu relacionamento. Assim, são propostas algumas recomendações e hipóteses sobre o comportamento de leitura das pessoas, como reduzir o número de cruzamentos entre arestas, destacar nós importantes usando cores e tamanhos diferentes, separar nós importantes, não distribuir nós aleatoriamente, agrupar nós que pertencem ao mesmo conjunto, separar grupos espacialmente, entre outros.

Este capítulo tem por objetivo relatar um estudo de ferramentas para análise de 
redes sociais, e apresenta, na Seção 3.1, as diferentes técnicas utilizadas para visualizar redes sociais; na Seção 3.2, as métricas utilizadas para análise de redes sociais; e na Seção 3.3, alguns sistemas disponíveis para exploração de redes sociais.

\subsection{Visualização de redes sociais}

Conforme visto na Seção 2.3, diversas abordagens podem ser utilizadas para a representação visual de grafos. Para representação de redes sociais, algumas abordagens adicionais foram propostas de modo que determinadas propriedades dos indivíduos sejam realçadas.

Uma das primeiras abordagens criadas para representar redes sociais dispõe os nós em uma espécie de alvo, no qual cada região contém indivíduos com determinada quantidade de relacionamentos, sendo posicionados no centro os que possuem maior número [Northway, 1940]. Essa abordagem é muito semelhante ao algoritmo de posicionamento radial, mas difere no sentido em que o alvo utiliza o número de conexões como base para o posicionamento, enquanto o algoritmo radial utiliza a profundidade na árvore. A Figura 18 exibe um exemplo de sociograma criado por meio dessa abordagem. Nesse exemplo, o grafo é dirigido, o que significa que, se a seta parte de James e chega em Tim, James considera Tim um amigo. Como é possível observar, indivíduos posicionados no centro são mais "populares", ou seja, vários outros indivíduos estão conectados a eles, enquanto os que estão afastados do centro quase não são considerados amigos por ninguém, mesmo considerando outros como amigos.

O algoritmo de posicionamento circular posiciona os vértices em espaços regulares ao redor de uma circunferência [Mitchell, 1994]. A Figura 19 exibe um exemplo de rede social representada desse modo. Como é possível observar, essa abordagem pode não ser muito interessante em alguns casos, pois os elementos são dispostos de modo que a identificação de grupos e de indivíduos mais conectados não é imediata.

Algoritmos baseados em grupos utilizam técnicas de redução de dimensionalidade para posicionar os pontos de forma que elementos conectados fiquem próximos e elementos não conectados fiquem distantes. Essas técnicas estão relacionadas com a proposta deste trabalho, que tem como um de seus objetivos incorporá-las a outras abordagens de visualização de redes sociais. Freeman [Freeman, 1999] exibe alguns exemplos de visualização de redes sociais utilizando essas técnicas. A Figura 20 exemplifica essa abordagem. Como é possível observar, vértices conectados entre si aparecem próximos 


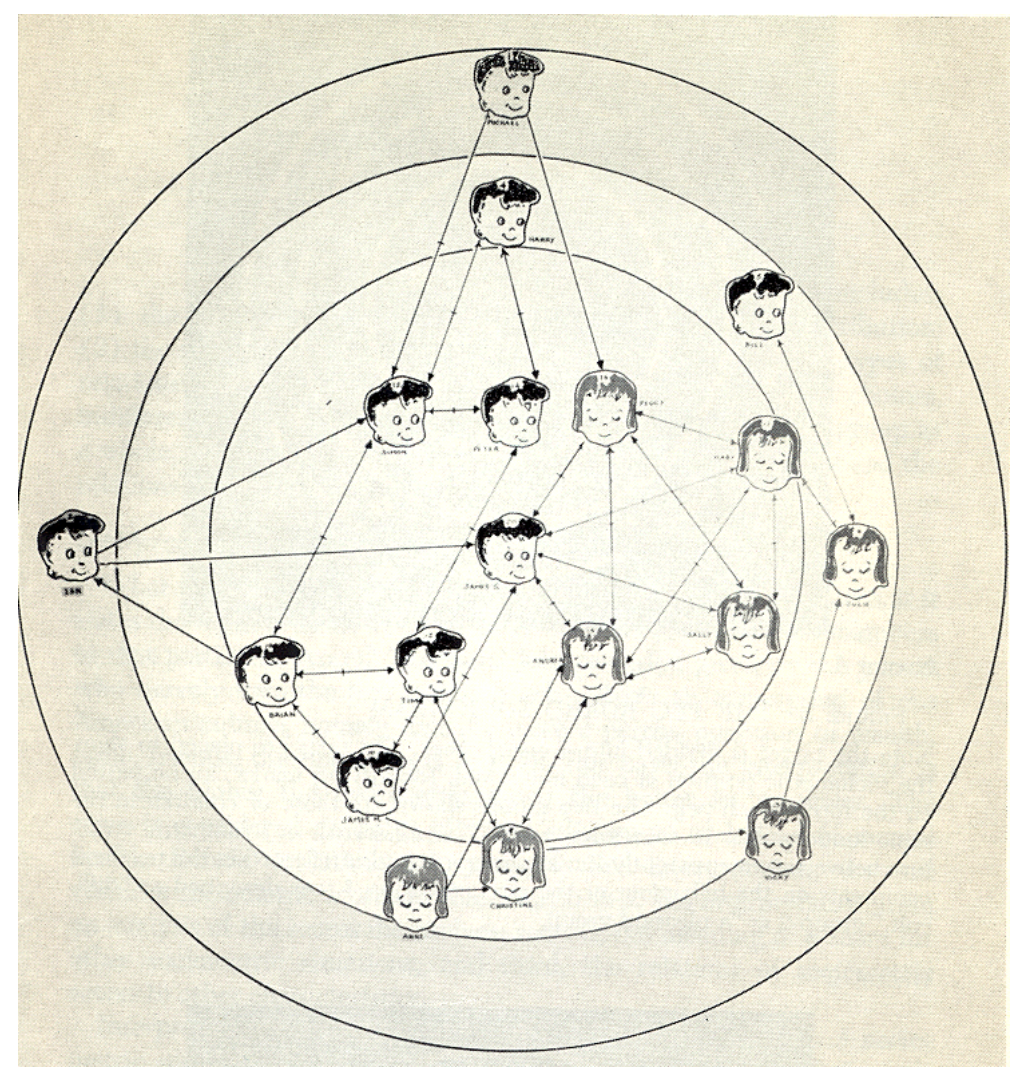

Figura 18: Sociograma criado utilizando a abordagem baseada em alvo [Northway, 1952].

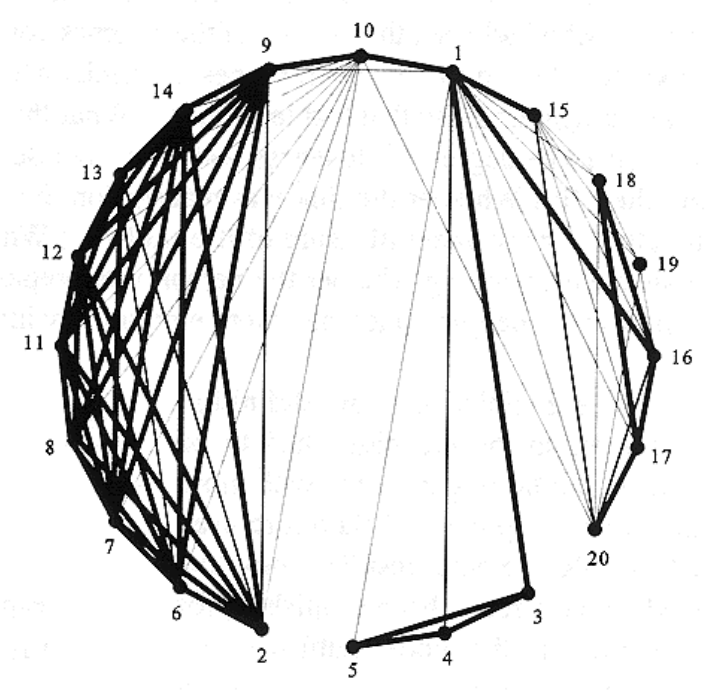

Figura 19: Exemplo de sociograma visualizado utilizando a abordagem circular [Mitchell, 1994]. 
uns dos outros, formando grupos.

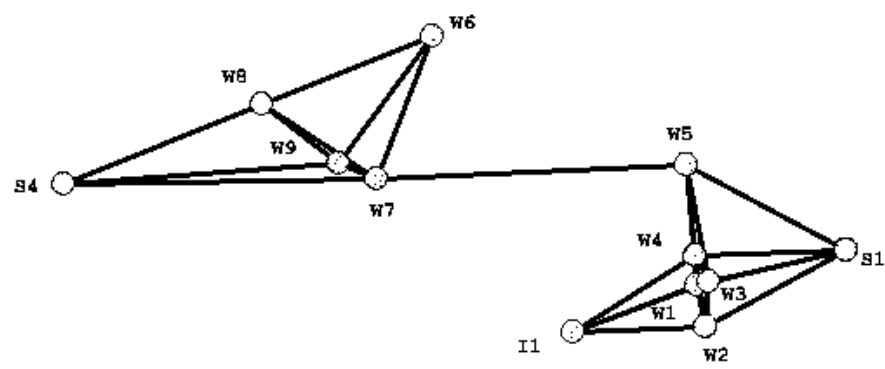

Figura 20: Exemplo de sociograma baseado em grupos, em que os vértices conectados entre si aparecem próximos uns dos outros [Freeman, 1999].

Outras abordagens utilizam variações dos algoritmos de posicionamento para grafos, muitas vezes para visualizar redes denominadas egocêntricas, na qual um indivíduo é posicionado no centro e sua rede de relacionamentos é construída ao seu redor. A Figura 21 mostra um exemplo de sociograma construído por meio de uma variação do algoritmo de posicionamento radial, cujo objetivo é visualizar a rede social de um indivíduo no Myspace ${ }^{5}$.

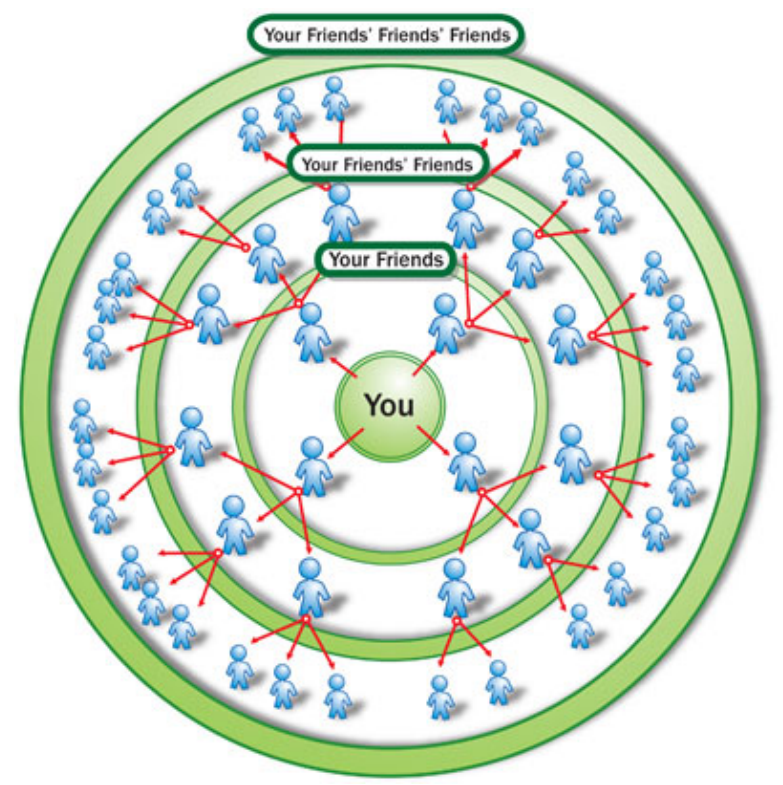

Figura 21: Sociograma de um indivíduo no Myspace, construído utilizando uma variação do algoritmo de posicionamento radial [Roos, 2007].

Assim como a maioria dos trabalhos apresentados no Capítulo 2, essas abordagens posicionam os indivíduos da rede de acordo com os seus relacionamentos, dando pouca atenção para os atributos dos indivíduos. No entanto, é possível utilizá-las em conjunto

\footnotetext{
${ }^{5}$ http://www.myspace.com/
} 
com as abordagens propostas neste trabalho, que procuram analisar a rede de acordo com os atributos dos indivíduos.

\subsection{Métricas para análise de redes sociais}

A análise de redes sociais pode ser útil para investigar padrões de parentesco, estruturas de comunidade, e outras relações sociais formais ou informais [Marcus et al., 2007]. Uma análise comum envolve descobrir os papéis exercidos pelos indivíduos na rede, como líderes, seguidores e pessoas populares. Outra análise envolve determinar a condição da rede como um todo, o que permite, por exemplo, identificar problemas organizacionais ou possíveis atividades ilegais. Com o objetivo de realizar essas análises em redes sociais, diversas métricas podem ser utilizadas, algumas delas criadas especificamente para esse problema.

O grau do vértice, visto na Seção 2.1, é um métrica comumente utilizada e simples de ser computada.

A densidade é uma medida que indica o quanto a rede está conectada, sendo definida pela razão entre o número de arestas existentes pelo total de arestas possíveis.

O grau de intermediação (betweenness centrality) é uma medida que indica o quanto um determinado vértice pertence ao caminho mínimo entre dois outros vértices. O caminho mínimo entre dois vértices é o caminho de menor custo que existe entre eles, sendo o custo dado pelo número de arestas que é necessário percorrer para sair de um vértice e chegar a outro ou, havendo pesos associados às arestas, pela soma dos pesos de cada aresta percorrida. Um vértice tem alto grau de intermediação se os caminhos mínimos entre muitos pares de outros vértices passam por ele.

O grau de proximidade (closeness centrality) mede o quanto um vértice está próximo de todos os demais vértices da rede. Quanto maior o caminho mínimo entre um determinado vértice e os demais vértices da rede, menor será o valor do grau de proximidade desse vértice. Caso existam vértices que não possam ser alcançados a partir de determinado vértice por não haver um caminho entre eles, o valor do grau de proximidade desse vértice diminui. O grau de proximidade pode ser calculado tanto em grafos direcionados quanto em grafos não-direcionados.

O comprimento de caminho médio (average path length) calcula a média das distâncias entre um determinado vértice e todos os demais vértices.

O comprimento de caminho característico (characteristic path length) calcula 
a média das distâncias entre todos os pares de vértices.

A eficiência global (global efficiency) indica a taxa na qual os vértices podem ser alcançados a partir de cada um dos demais vértices da rede. Um valor alto de eficiência global indica que o caminho entre dois vértices quaisquer da rede é, em geral, curto.

O coeficiente de agrupamento (clustering coefficient) é uma medida da porcentagem de triângulos fechados na vizinhança imediata de um determinado vértice. Em outras palavras, se um vértice $A$ está conectado a um vértice $B$, e o vértice $B$ está conectado a um vértice $C$, o coeficiente de agrupamento do vértice $B$ indica a probabilidade do vértice $A$ estar conectado ao vértice $C$.

A homogeneidade mede o quanto os vértices compartilham os mesmos valores de determinados atributos. Por exemplo, se um dos atributos de uma rede social for "nacionalidade" e o valor assumido por esse atributo em todos os vértices for "brasileiro", então a rede é altamente homogênea para esse atributo.

A razão externo-interno (E-to-I ratio) mede o número de indivíduos de um grupo conectados com indivíduos de fora do grupo versus o número de indivíduos do mesmo grupo conectados entre si. Nesse caso, um grupo é um conjunto de indivíduos que possuem valor igual para determinado atributo. Por exemplo, a razão externointerno do atributo "nacionalidade" igual a "brasileiro" é 1:1 se os brasileiros estiverem conectados igualmente com brasileiros e com não-brasileiros; é 0:1 se os brasileiros estiverem conectados apenas com brasileiros; é 1:0 se os brasileiros estiverem conectados somente com não-brasileiros; e é 0:0 se os brasileiros não estiverem conectados com ninguém.

Existem diversas outras métricas e propriedades utilizadas para analisar redes sociais. Wasserman e Faust [Wasserman and Faust, 1994] discutem muitas dessas métricas e propriedades, além de apresentarem vários métodos e modelos estatísticos que podem ser utilizados com esse objetivo.

\subsection{Ferramentas para exploração de redes sociais}

Novas ferramentas específicas para exploração de redes sociais utilizam os mesmos algoritmos de posicionamento e ferramentas de interação apresentados nas Seções 2.3 e 2.4, além das abordagens apresentadas na Seção 3.1. Entretanto, por serem específicas para exploração de redes sociais, as estratégias aqui mencionadas possuem mecanismos de análise baseados em atributos de indivíduos e de suas relações dentro das redes. 
Huisman e Duijn [Huisman and Duijn, 2005] descrevem as características de várias dessas ferramentas, detalhando o funcionamento de algumas. Uma lista de programas pode ser encontrada no site do INSNA ${ }^{6}$ (International Network for Social Network Analysis). Em geral, essas ferramentas utilizam as métricas apresentadas na Seção 3.2 para realizar a análise das redes sociais. O NetDraw é um programa para visualizar grandes redes sociais, gerando representações visuais baseadas nos atributos dos indivíduos da rede, além de possuir alguns poucos mecanismos de análise. Os programas StoCNET, MultiNet, UCINet e Agna realizam análises estatísticas sobre as redes sociais, mas o StoCNET não gera representação visual. Outros programas são voltados para a análise da evolução de redes sociais, como o Blanche e o Condor, capazes de simular as evoluções ocorridas nas redes. Já o SNA (Social Network Analysis) [Butts, 2007] é uma biblioteca para $R^{7}$ capaz de realizar análises estatísticas em redes sociais e gerar representações visuais para as mesmas.

Apesar do grande número de opções de programas e bibliotecas disponíveis, alguns autores defendem que ainda há a necessidade de se criar novas técnicas e formas de representação visual em decorrência do aumento dos serviços de redes sociais na internet, cada um apresentando diferentes tipos de relacionamento. Heer e Boyd [Heer and Boyd, 2005] apresentam uma nova ferramenta, denominada Vizster, cujo objetivo é permitir que usuários finais identifiquem padrões e tenham uma visão mais abrangente sobre as comunidades das quais fazem parte. O algoritmo de posicionamento utilizado é baseado em força. A Figura 22 exibe a janela do programa com uma rede social. À esquerda, é apresentada a rede egocêntrica de um usuário do site de relacionamento Friendster ${ }^{8}$, na qual as arestas indicam amizade. À direita é exibido um painel que apresenta o perfil de um usuário selecionado na rede.

Mutton [Mutton, 2004] segue uma linha mais específica apresentando uma ferramenta para inferir e visualizar redes sociais no IRC (Internet Relay Chat). Para inferir as redes sociais, um programa foi usado para coletar todas as mensagens que transitavam pelos canais. Os usuários que enviavam mensagens diretamente a outros foram conectados num grafo, assim como aqueles que enviavam mensagens para o canal, mas recebiam uma resposta de outros usuários em um instante próximo. Para visualizar a rede foram utilizados algoritmos de posicionamento baseados em força.

\footnotetext{
${ }^{6}$ http://www.insna.org/

${ }^{7} \mathrm{R}$ é uma ferramenta e uma linguagem de programação para computação estatística, e está disponível gratuitamente no endereço http://www.r-project.org/.

${ }^{8}$ http://www.friendster.com/
} 


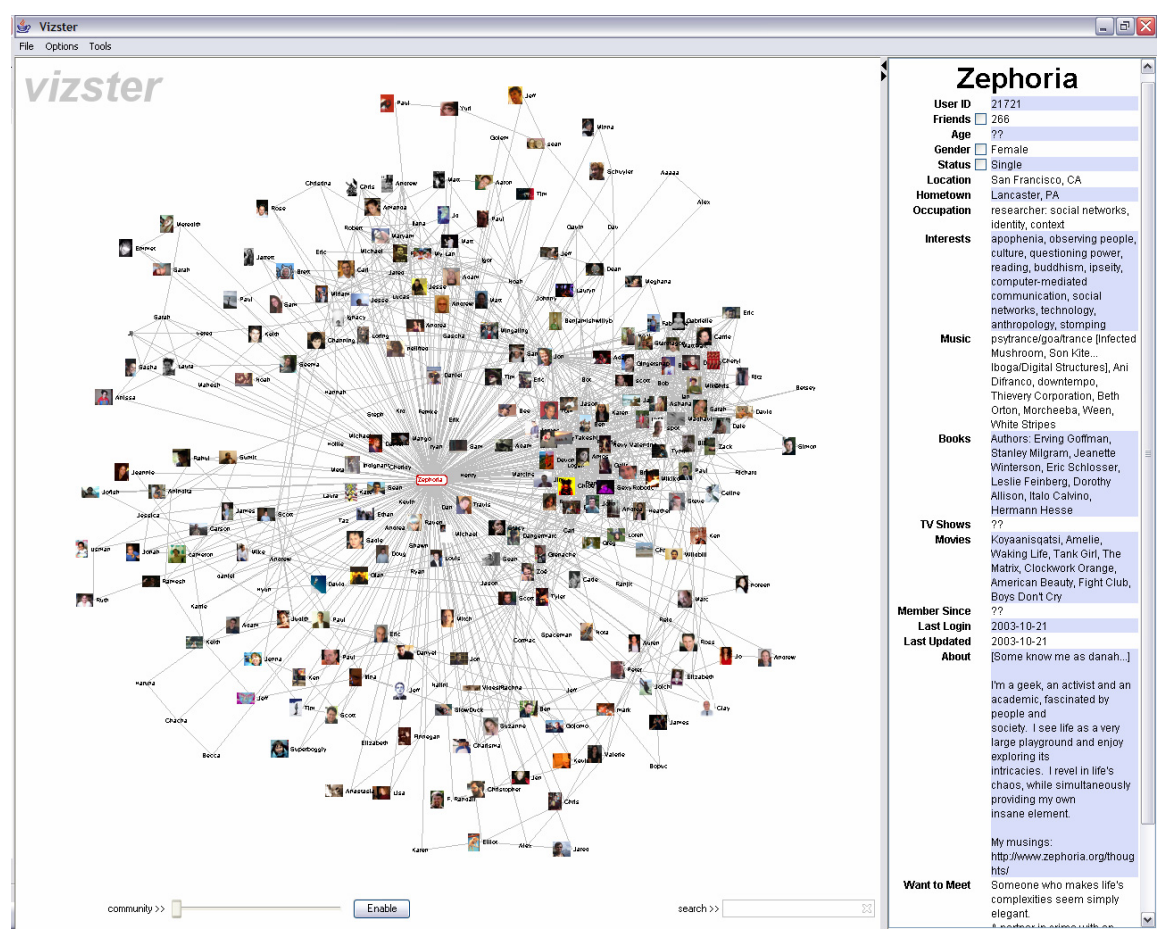

Figura 22: Janela da aplicação Vizster exibindo a rede egocêntrica de um usuário do site de relacionamento Friendster, na qual as arestas indicam amizade. O painel da direita exibe o perfil de um usuário selecionado na rede [Heer and Boyd, 2005].

Henry et al. [Henry and Fekete, 2006; Henry et al., 2007] apresentam duas ferramentas para visualizar redes sociais. A primeira ferramenta, MatrixExplorer, permite visualizar as redes como um conjunto de nós e arestas em coordenação com uma representação em forma de matriz de adjacência. A visualização como um conjunto de nós e arestas pode ser criada utilizando vários algoritmos clássicos de grafos, enquanto a visualização como matriz de adjacência organiza as linhas e colunas para revelar componentes conectados. A Figura 23 mostra um exemplo de grafo representado de ambas as formas, à esquerda como uma matriz de adjacência e à direita como um conjunto de vértices e arestas, sendo que as cores representam agrupamentos definidos interativamente pelo usuário. A segunda ferramenta, denominada NodeTrix, representa a rede como um conjunto de nós e arestas, sendo que os nós são exibidos como matrizes de adjacência. Cada nó pode representar, por exemplo, uma comunidade. As conexões entre os membros da comunidade são representadas na matriz de adjacência, e as conexões entre indivíduos de comunidades diferentes são representadas como arestas do grafo. A Figura 24 exemplifica essa abordagem.

Namata et al. [Namata et al., 2007] também apresentam uma ferramenta, denominada DualNet, capaz de gerar representações visuais coordenadas. Essa aplicação 


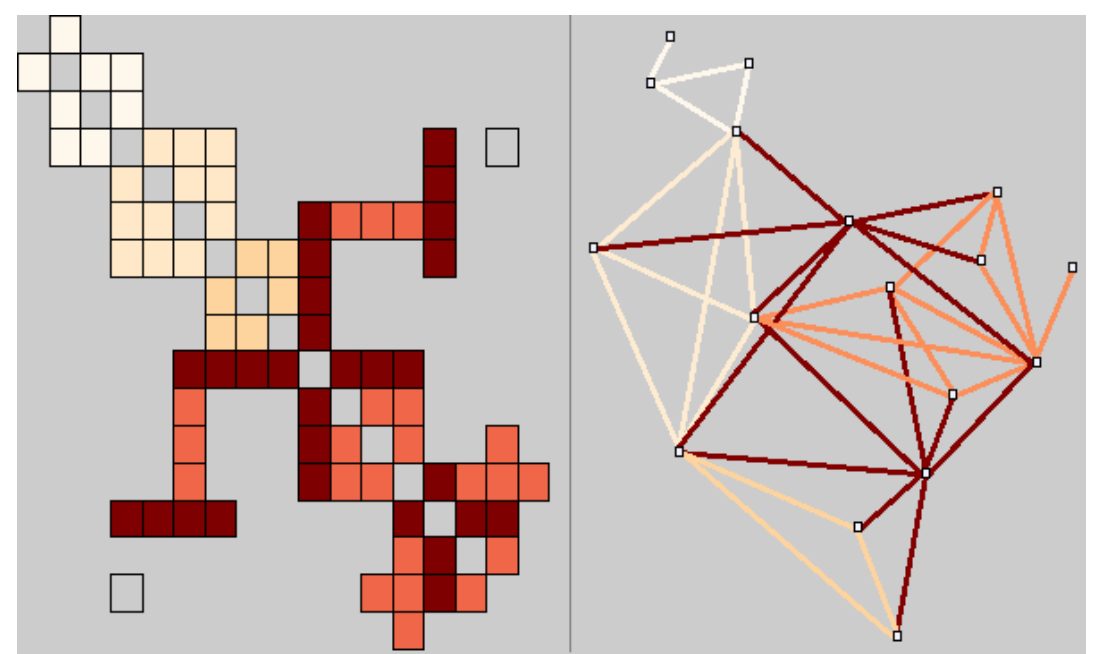

Figura 23: Exemplo de rede criada com a ferramenta MatrixExplorer. À esquerda é apresentada uma representação da rede como uma matriz de adjacência, e à direita uma representação como um conjunto de nós e arestas [Henry and Fekete, 2006].

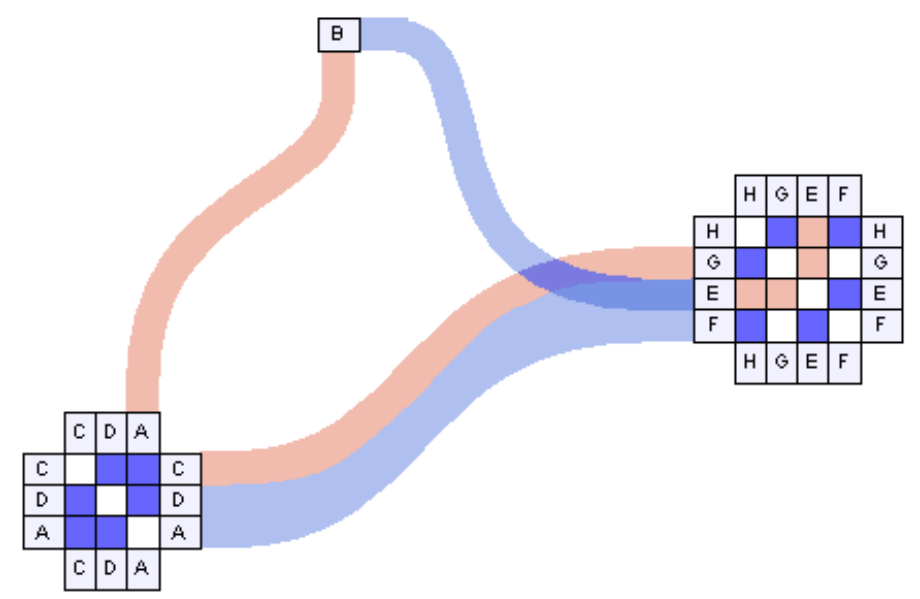

Figura 24: Exemplo de rede criada com a ferramenta NodeTrix, sendo que cada matriz representa uma comunidade, as conexões entre indivíduos de uma mesma comunidade são representadas na matriz de adjacência, e as conexões entre indivíduos de comunidades diferentes são representadas como arestas do grafo. A cor representa algum atributo da aresta [Henry et al., 2007]. 
trata a rede como um conjunto de sub-redes, cada uma podendo ser visualizada e manipulada independentemente em painéis distintos, com representações e controles apropriados, além de permitir a coordenação entre os painéis. A Figura 25 exibe uma janela da aplicação contendo dois sociogramas com diferentes abordagens, sendo que no sociograma da esquerda o nó "senior specialist" agrupa um conjunto de indivíduos que estão selecionados no sociograma da direita.

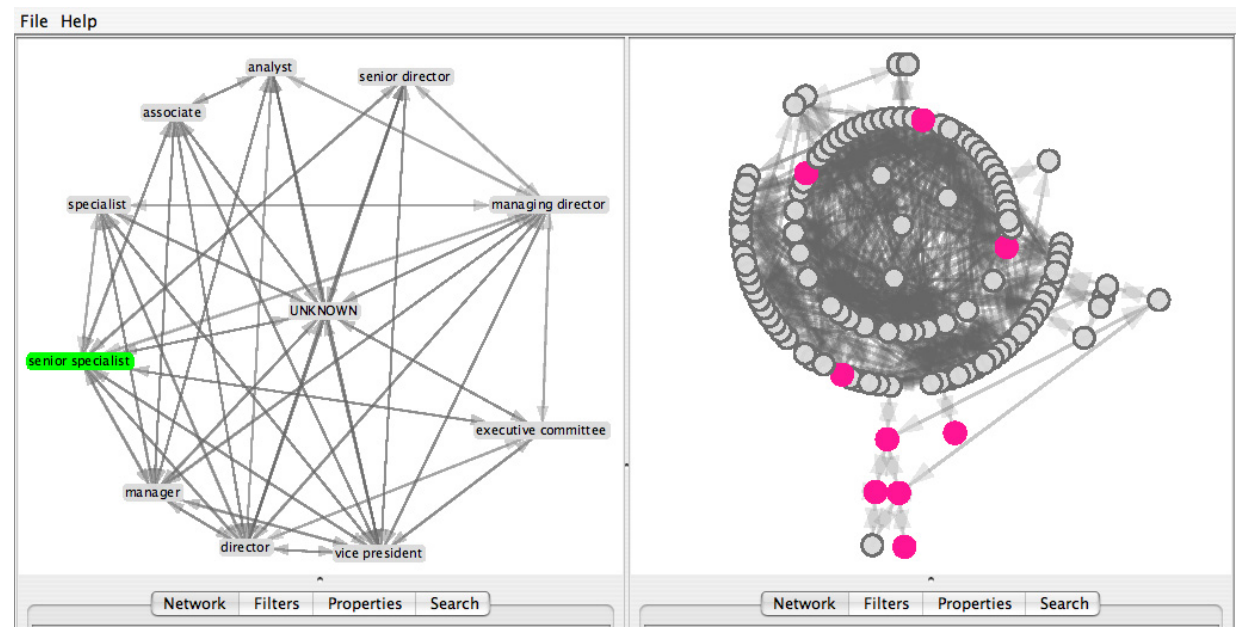

Figura 25: Janela da ferramenta DualNet, na qual o nó do sociograma da esquerda agrupa um conjunto de indivíduos selecionados no sociograma da direita [Namata et al., 2007].

Um trabalho interessante é descrito por Shen et al. [Shen et al., 2006]. A ferramenta desenvolvida por eles, denominada Ontovis, é capaz de construir redes heterogêneas (redes nas quais os vértices representam mais de um tipo de objeto). Inicialmente, a ferramenta exibe dois grafos: um grafo completo, contendo todos os vértices de todos os tipos; e um grafo ontológico, em que cada vértice representa um tipo de objeto e as arestas representam a interação entre os diferentes tipos, obtida por meio de uma análise do grafo completo. A partir do grafo ontológico, contendo os diferentes tipos de objetos, os usuários podem construir um grafo derivado do grafo completo incluindo somente vértices cujos tipos estão selecionados no grafo ontológico. O tamanho dos vértices pode refletir alguma medida, como grau ou centralidade do vértice, e a cor indica o tipo do vértice. A Figura 26 ilustra uma rede criada com o OntoVis.

Li e Lin [Li and Lin, 2009] propõem um mecanismo para abstração de informação em redes sociais heterogêneas. Eles extraem combinações lineares das conexões de um vértice de interesse e calculam medidas de dependência estatística entre as combinações e o vértice. Após realizar uma filtragem, eles geram um subgrafo a partir das 


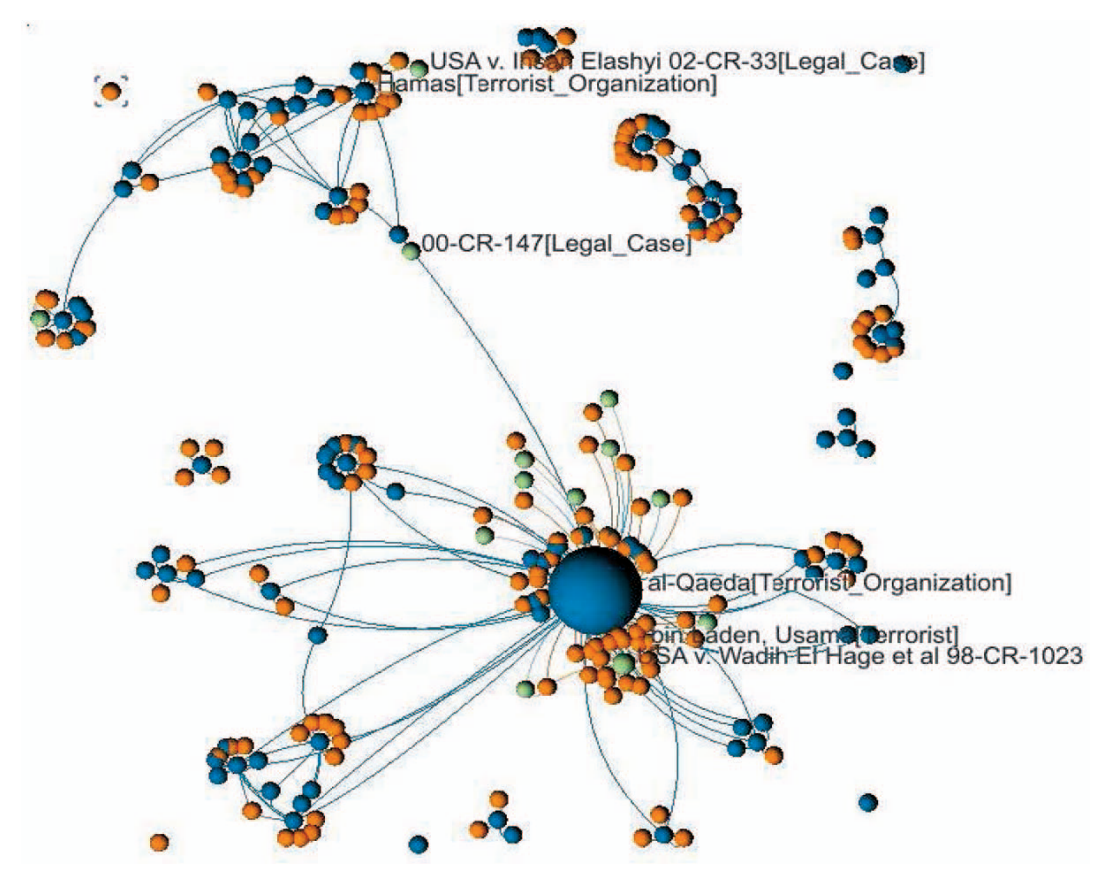

Figura 26: Exemplo de sociograma de redes terroristas criado com o OntoVis, no qual nós em laranja representam terroristas, nós em azul organizações terroristas e nós em verde casos legais relacionados com atentados terroristas [Shen et al., 2006].

combinações lineares de modo a focar em relações de interesse.

Outro trabalho bastante relevante é o de Gloor et al. [Gloor et al., 2009], que apresentam uma ferramenta para visualização de redes sociais em que o posicionamento dos vértices é baseado na similaridade entre as mensagens trocadas pelos atores. $\mathrm{O}$ algoritmo utilizado é baseado em força, mas a força de atração entre dois atores é proporcional à similaridade do conteúdo das mensagens trocadas entre eles. A similaridade é calculada pela contagem e ponderação da frequência dos termos usando a tf-idf (term frequency-inverse document frequency).

Velardi et al. [Velardi et al., 2008] apresentam uma abordagem para posicionamento dos vértices baseada nos interesses dos atores da rede. Nesse caso, os autores utilizam um sistema de extração de termos e detecção de tópicos sobre mensagens publicadas pelos atores em blogs ou sobre suas publicações científicas. Após a detecção dos tópicos, para cada mensagem ou publicação, um vetor é extraído no qual cada elemento reflete uma medida de sobreposição do conteúdo do texto com os tópicos detectados. Para cada ator da rede, o centroide dos vetores das suas publicações é calculado e utilizado para computar a sua similaridade com os demais atores da rede por meio de alguma medida de distância. As similaridades, então, são utilizadas como pesos das arestas entre os atores, posicionados por meio de um algoritmo baseado em força. 
Smith et al. [Smith et al., 2009] propõem uma abordagem baseada nos atributos dos vértices para computar um grau de similaridade entre eles. Para cada atributo, uma rede pode ser gerada na qual o peso das arestas reflete o grau de similaridade calculado para aquele atributo. Bezerianos et al. [Bezerianos et al., 2010] também apresentam uma ferramenta para visualizar redes sociais levando em consideração os atributos da rede, no entanto, os atributos são visualizados sempre dois a dois, em um gráfico de dispersão avançado, com filtragem e animações tridimensionais.

Perer e Scheiderman [Perer and Shneiderman, 2006] descrevem uma ferramenta que calcula medidas de centralidade dos vértices, criando um ranking, que permite que o usuário selecione os indivíduos de interesse, mantendo-os no grafo e colorindo-os de acordo com sua posição no ranking. A ferramenta também cria visões coordenadas, uma contendo um gráfico de dispersão dos vértices, onde cada eixo representa uma medida de centralidade calculada, e a outra exibe o grafo. Dessa forma, é possível colorir os vértices no grafo de acordo com faixas de valores selecionadas no gráfico de dispersão.

Aris e Shneiderman [Aris and Shneiderman, 2006] descrevem uma ferramenta, denominada NVSS (Network Visualization by Semantic Substrates), que permite definir regiões para posicionar os vértices de acordo com os valores de um atributo. Cada região forma um gráfico de dispersão e pode ter diferentes atributos nos eixos. Também é possível filtrar os vértices pelos demais atributos e controlar a exibição das arestas, tanto entre quanto intra regiões.

Outra linha de pesquisa envolvendo visualização de redes sociais considera a evolução das redes ao longo do tempo. Falkowski et al. [Falkowski et al., 2006] propõem uma abordagem para analisar a evolução de comunidades online em nível de subgrupo. Inicialmente, a rede é analisada de modo a gerar agrupamentos baseados na conectividade entre os indivíduos. Cada agrupamento é tratado, então, como uma instância de comunidade, sendo uma comunidade formada por várias instâncias. A similaridade entre as instâncias de comunidades é calculada pelo número de membros em comum. As instâncias de comunidades são exibidas como um grafo, no qual o tamanho do nó representa o número de membros pertencentes àquela instância de comunidade, e cada cor representa uma comunidade. É criado um grafo para cada período de tempo analisado. Por meio de barras de rolagem é possível observar o comportamento da rede ao longo do tempo. Também é possível observar um histórico do comportamento das 
comunidades, no qual o eixo $x$ representa o tempo. A Figura 27 ilustra um exemplo desse comportamento das comunidades ao longo do tempo, sendo que um trecho do histórico está destacado e sendo observado em maiores detalhes à direita.

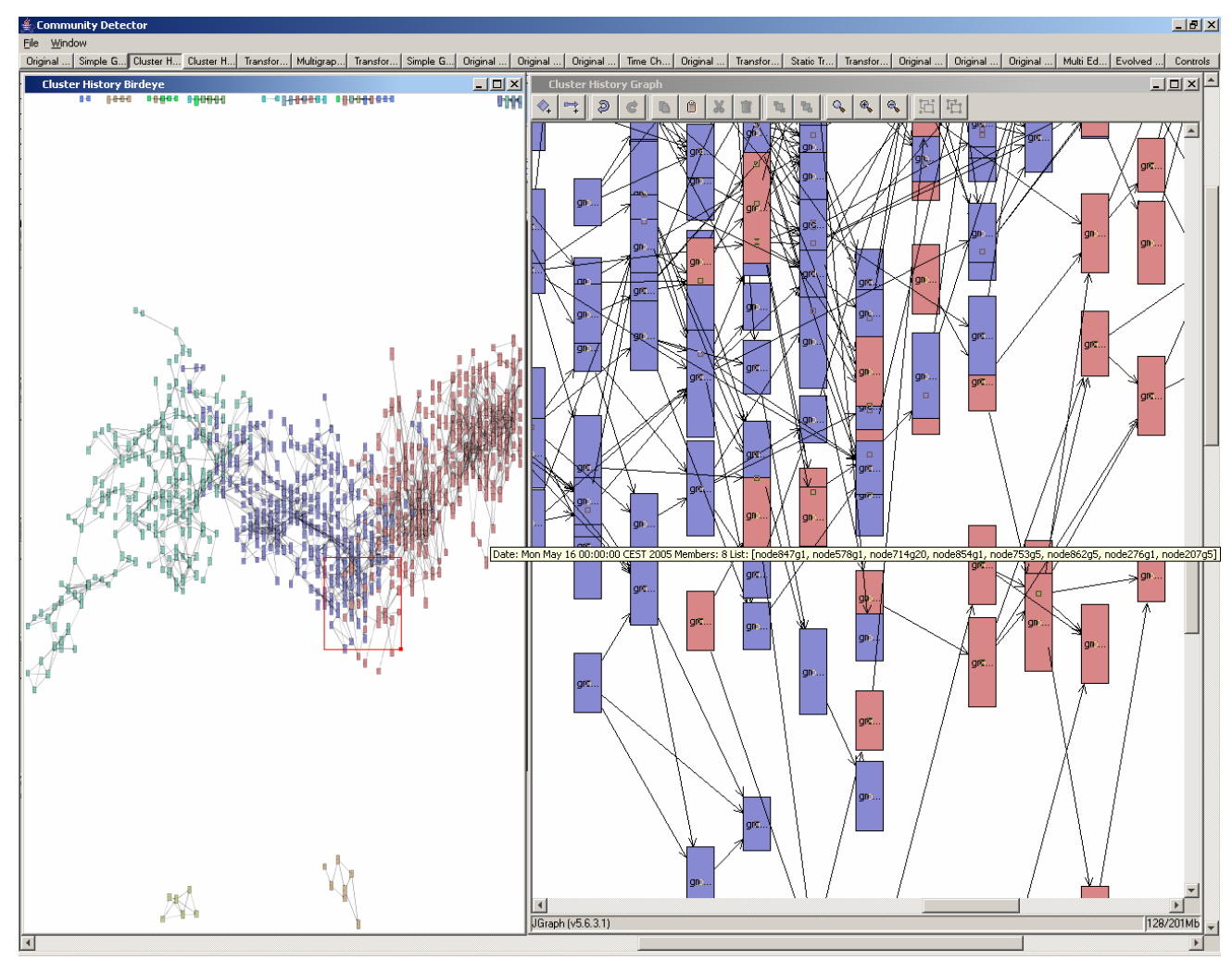

Figura 27: Exemplo de visualização da evolução de redes sociais ao longo do tempo [Falkowski et al., 2006].

Kang et al. [Kang et al., 2007] também descrevem uma ferramenta, C-Group, para visualizar a evolução de redes sociais ao longo do tempo, mas com uma abordagem diferente. Os vértices da rede são separados em grupos de acordo com os valores dos seus atributos, ou seja, se dois vértices possuem o mesmo valor para determinado atributo, eles estão no mesmo grupo. Os indivíduos da rede, então, são visualizados dois a dois, e seus grupos são posicionados em uma de três possíveis regiões: uma região compartilhada, se ambos os indivíduos pertencem ao grupo; uma região pertencente somente ao indivíduo 1, caso o indivíduo 1 faça parte do grupo, mas o indivíduo 2 não; e uma região pertencente somente ao indivíduo 2 , caso o indivíduo 2 faça parte do grupo, mas o indivíduo 1 não. Da mesma forma que na abordagem apresentada por Falkowski et al. [Falkowski et al., 2006], as mudanças ocorridas podem ser visualizadas por meio de barras de rolagem. No entanto, não é possível visualizar o histórico por meio de um único grafo. A Figura 28 apresenta um exemplo de visualização utilizando 
a ferramenta C-Group.

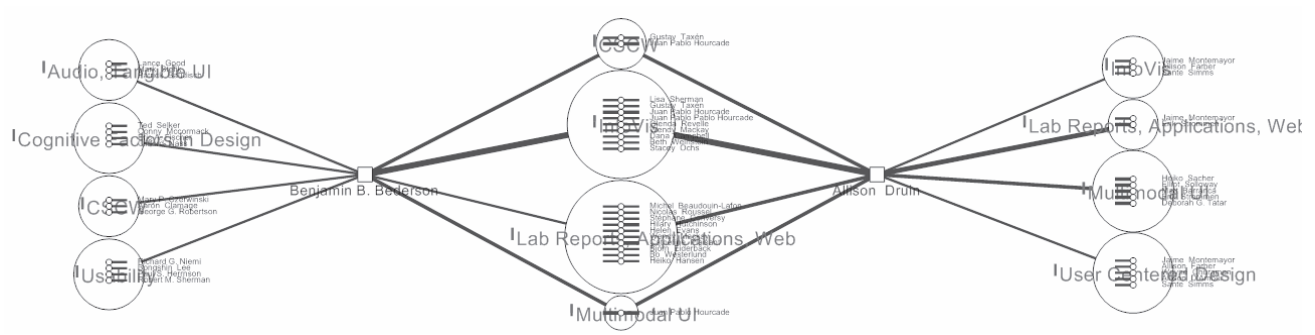

Figura 28: Exemplo de visualização com a ferramenta C-Group, que apresenta dois vértices e três regiões de grupos. À esquerda, os grupos do vértice "Benjamin B. Bederson"; à direita, os grupos do vértice "Allison Druin"; e no centro, os grupos comuns a ambos [Kang et al., 2007].

Outra abordagem para visualizar relações ao longo do tempo é proposta por Viégas et al. [Viegas et al., 2004]. A ferramenta PostHistory gera redes sociais como grafos com base nos e-mails recebidos e enviados pelos contatos. Por meio de um painel contendo um calendário e outro contendo as relações existentes entre os membros, é possível selecionar um membro para destacar todos os e-mails enviados por ele no calendário. Além disso, também é possível criar um grafo de relacionamentos a partir dos remetentes dos e-mails.

Fisher e Dourish [Fisher and Dourish, 2004] apresentam um aplicativo semelhante, denominado Soylent, para analisar alguns aspectos das atividades dos usuários de modo a descobrir informações sociais e temporais. A Figura 29 exibe uma rede de e-mails criada com a ferramenta desenvolvida. Como é possível observar, essa ferramenta também permite restringir a visão somente a um determinado período de tempo. $\mathrm{O}$ mesmo trabalho descreve também um segundo aplicativo, TellMeAbout, cujo intuito é ser usado no cotidiano em empresas, a qual utiliza o Soylent para descrever como indivíduos, objetos ou grupos estão situados, socialmente e temporalmente.

O ContactMap [Whittaker et al., 2004] é voltado para o uso pessoal. Essa ferramenta visa integrar comunicação e informação por meio da visualização de redes sociais individuais. A ideia principal é permitir que os usuários saibam quem pertence à sua própria rede social, exibindo detalhes sobre os contatos e informações sobre disponibilidade, tarefas a serem realizadas, documentos transferidos, além de exibir as conexões existentes entre diferentes contatos na rede.

Uma ideia bem diferente é discutida por Fujimura et al. [Fujimura et al., 2006]. Por meio de pesquisas, argumentam que pequenos agrupamentos de pessoas em congressos e outros eventos são um componente básico para a formação de uma comunidade. 


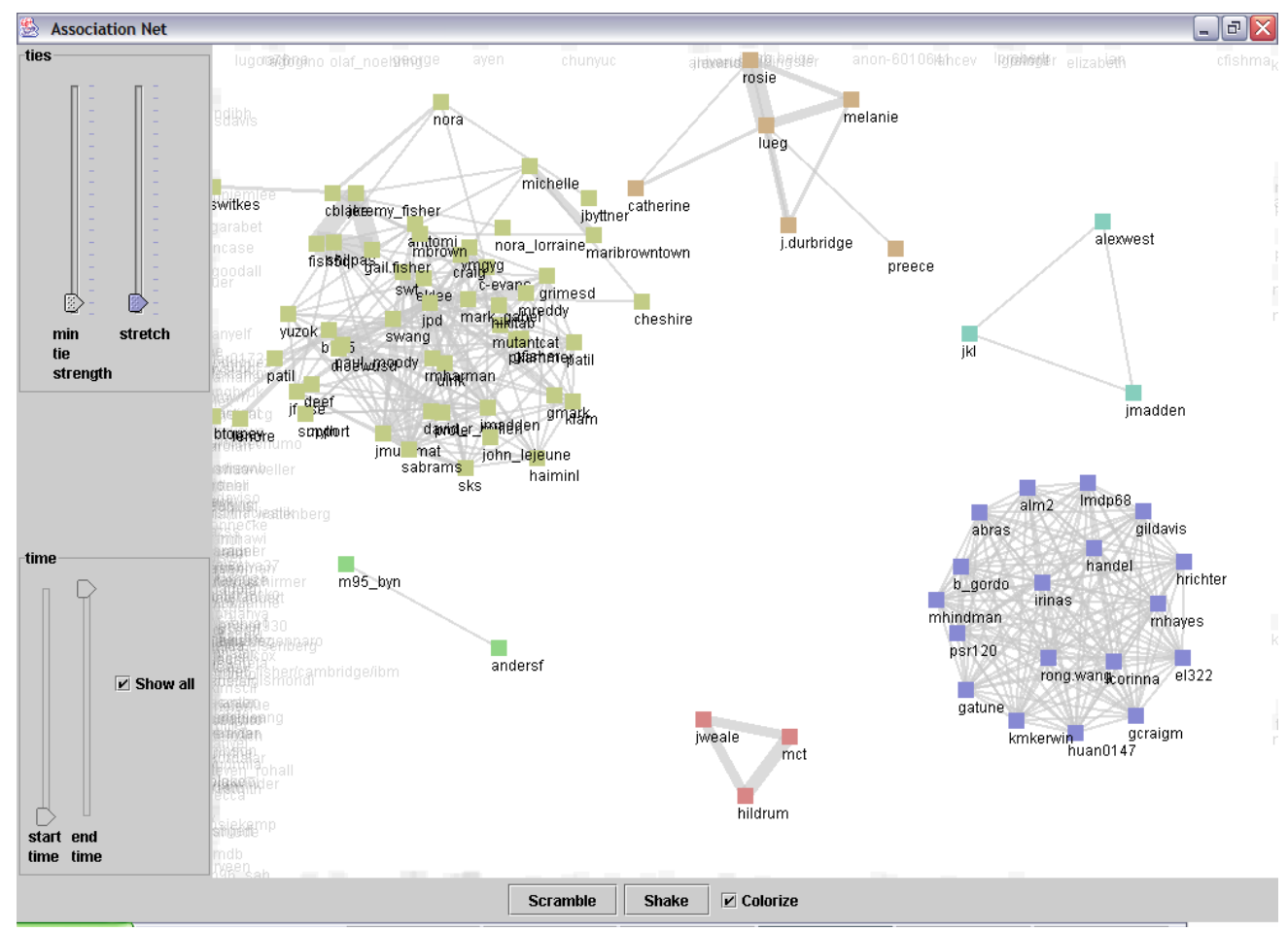

Figura 29: Rede de e-mails criada por meio da ferramenta Soylent [Fisher and Dourish, 2004].

Como muitos desses agrupamentos ocorrem em volta de mesas, criaram um sistema chamado Tabletop Community, que permite visualizar as interações sociais ao redor das mesmas. Os usuários podem registrar o estado e atmosfera de cada interação e o sistema, então, visualiza o estado de toda a comunidade como uma rede interativa na forma de um grafo no qual os nós correspondem às mesas e as arestas correspondem às interações ocorridas entre elas.

Embora todos os trabalhos descritos apresentem propostas interessantes e alguns levem em consideração determinados atributos da rede, nenhum deles tem como objetivo analisar os perfis dos indivíduos. A proposta deste trabalho é aliar a análise dos relacionamentos dos indivíduos à análise dos seus atributos, de modo que seja possível associar as conexões da rede ao perfil dos indivíduos. Essa proposta é denominada neste trabalho visualização multidimensional de redes sociais e as suas contribuições são apresentadas no próximo capítulo. 


\section{Exploração visual multidimensional de redes sociais}

Existe grande motivação para o trabalho de visualização na exploração de redes sociais. A análise exploratória dessas redes tende a revelar universos de informações previamente inesperadas ou desconhecidas e é um assunto de grande relevância, tratado com interesse em muitas áreas da estatística, da sociologia, e da computação. Por exemplo, é sugerido que as opiniões expressas por membros de redes sociais eletrônicas influenciam as reações do mercado.

A estrutura e as medidas que refletem a organização topológica das redes podem fornecer informações importantes para o processo de exploração de redes sociais, sendo que muitos sistemas já admitem a análise visual dessas medidas e também o seu uso na melhoria da visualização, conforme mencionado no Capítulo 3. Porém, também é necessário acoplar ao processo a análise baseada em conteúdo, que pode revelar relacionamentos e identificar características entre os atores da rede. Faz parte do trabalho de análise investigar as duas vertentes dos dados. Isso, entretanto, raramente é visto em sistemas que lidam com visualização de redes.

Assim, este trabalho apresenta três abordagens para permitir (i) a visualização de redes com diferentes tipos de vértices; (ii) a visualização de redes baseadas em conteúdo, quando os vértices são descritos por um vetor de atributos - nesse caso, a proximidade entre os vértices é um indicativo da similaridade entre eles; e (iii) a análise simultânea de diferentes visualizações, utilizando tanto as abordagens anteriores quanto técnicas tradicionais de grafos, por meio de coordenação. O resultado deste trabalho visa adicionar uma contribuição relevante também ao repertório das técnicas de análise de dados multidimensionais com informação relacional associada.

As três abordagens foram implementadas em uma ferramenta desenvolvida pelo 
grupo de visualização do ICMC-USP, denominada Projection Explorer (PEx) [Paulovich et al., 2007], uma plataforma de código aberto capaz de gerar visualizações baseadas em conteúdo através do posicionamento de pontos no plano. Este trabalho estende a ferramenta para permitir a visualização de redes sociais, fazendo uso de suas estruturas de dados e de algumas características de exploração.

A Seção 4.1 introduz alguns conceitos sobre projeções multidimensionais e apresenta a ferramenta PEx, e a Seção 4.2 descreve as abordagens propostas.

\subsection{Projeções multidimensionais e o PEx}

Dados multidimensionais são aqueles que possuem duas ou mais dimensões, sendo que cada dimensão corresponde a um atributo do conjunto de dados. Assim, um item do conjunto de dados, também chamado de instância ou objeto de dado, com $m$ atributos, pode ser visto como um ponto definido no espaço $m$-dimensional.

Técnicas tradicionais de visualização têm uma aplicação limitada sobre conjuntos de dados que possuem alta dimensionalidade. Técnicas de projeção multidimensional são utilizadas nesse contexto para reduzir o número de dimensões do conjunto de dados, mapeando os mesmos em um espaço de baixa dimensionalidade, em geral, de uma a três dimensões. O processo de mapeamento procura preservar as informações de distância entre os objetos. Formalmente, seja $X=\left\{x_{1}, x_{2}, \ldots, x_{n}\right\}$ um conjunto formado por $n$ pontos de $m$ dimensões, com $\delta\left(x_{i}, x_{j}\right)$ uma medida de dissimilaridade (distância) entre dois pontos $i$ e $j$. Seja também $Y=\left\{y_{1}, y_{2}, \ldots, y_{n}\right\}$ um conjunto de pontos definido em um espaço de $p$ dimensões, com $p \in\{1,2,3\}$, e $d\left(y_{i}, y_{j}\right)$ uma distância entre dois pontos $i$ e $j$ no espaço de $p$ dimensões. Uma técnica de projeção multidimensional é descrita como uma função injetora $f: X \rightarrow Y$ que minimiza a diferença entre $\delta$ e $d$, ou seja, que faz $\left|\delta\left(x_{i}, x_{j}\right)-d\left(f\left(x_{i}\right), f\left(x_{j}\right)\right)\right|$ aproximar zero [Tejada et al., 2003]. As técnicas de projeção podem ser organizadas em dois grupos, dependendo se a função $f$ é linear ou não-linear.

As técnicas de projeção lineares geram combinações lineares dos atributos para defini-los em uma nova base ortogonal de dimensão inferior. Uma técnica de projeção linear muito utilizada é a Principal Component Analysis (PCA) [Jolliffe, 2002]. Já as técnicas de projeção não-lineares são técnicas iterativas que procuram minimizar uma função de perda de informação, tratando o problema como um processo de otimização. Dessa forma, é possível que o usuário acompanhe o processo, parando o mesmo quando 
achar conveniente, e adicione novas instâncias de dado realizando algumas iterações adicionais. Além disso, como as funções de minimização das técnicas não-lineares dependem apenas da relação de distância entre as instâncias de dado, caso uma matriz de distâncias seja fornecida, os dados originais não são necessários. Uma técnica de projeção não-linear implementada pelo grupo de visualização do ICMC é o Least-Squares Projection (LSP) [Paulovich et al., 2006], que alcança um bom balanço entre escalabilidade e precisão, sendo adequado para projetar espaços não-lineares em um tempo computacional razoável, mesmo para conjuntos de dados relativamente grandes. Outra técnica implementada pelo grupo é a Neighbor-Joining (NJ) [Cuadros et al., 2007], que é baseada na construção de árvores filogenéticas e agrupa no mesmo ramo as instâncias de dado mais similares de acordo com alguma medida de distância.

A Figura 30 ilustra o processo de geração de mapas interativos por meio de técnicas de projeção multidimensional. Como é possível observar, a fonte de dados pode ser uma coleção de objetos não estruturados, representada por (1), uma tabela de dados estruturada, representada por (2), ou uma matriz de distâncias, representada por (3). Caso seja uma coleção de objetos não estruturados, é possível extrair um vetor numérico de características de cada objeto do conjunto, que pode ser obtido por meio de diferentes técnicas, dependendo do tipo de objeto. Em documentos de texto, por exemplo, um vetor de características pode ser obtido pela contagem da frequência de cada palavra ou expressão relevante presente no conjunto de documentos. A partir dos vetores de características, é possível construir uma tabela de dados estruturada, na qual cada linha representa uma instância de dado e cada coluna uma característica extraída. A partir da tabela de dados estruturada, realiza-se o cálculo das distâncias entre os objetos de dados. Como cada objeto de dado pode ser visto como um ponto em um espaço multidimensional, as distâncias podem ser calculadas entre pares de pontos por meio de alguma medida de distância conhecida, como a distância euclidiana ou a similaridade do cosseno [Faloutsos and Lin, 1995]. Uma vez calculadas as distâncias, constrói-se uma matriz de distâncias, que pode ser a própria fonte de dados, e que é utilizada para projetar as instâncias em duas ou três dimensões. O resultado desse processo é um mapa de documentos, o qual deve permitir alguma interação do usuário, como extração de associações, tópicos, agrupamentos, entre outros.

Uma ferramenta capaz de gerar mapas interativos de documentos e outros dados utilizando técnicas de projeção multidimensional foi desenvolvida pelo grupo de visu- 
(1)

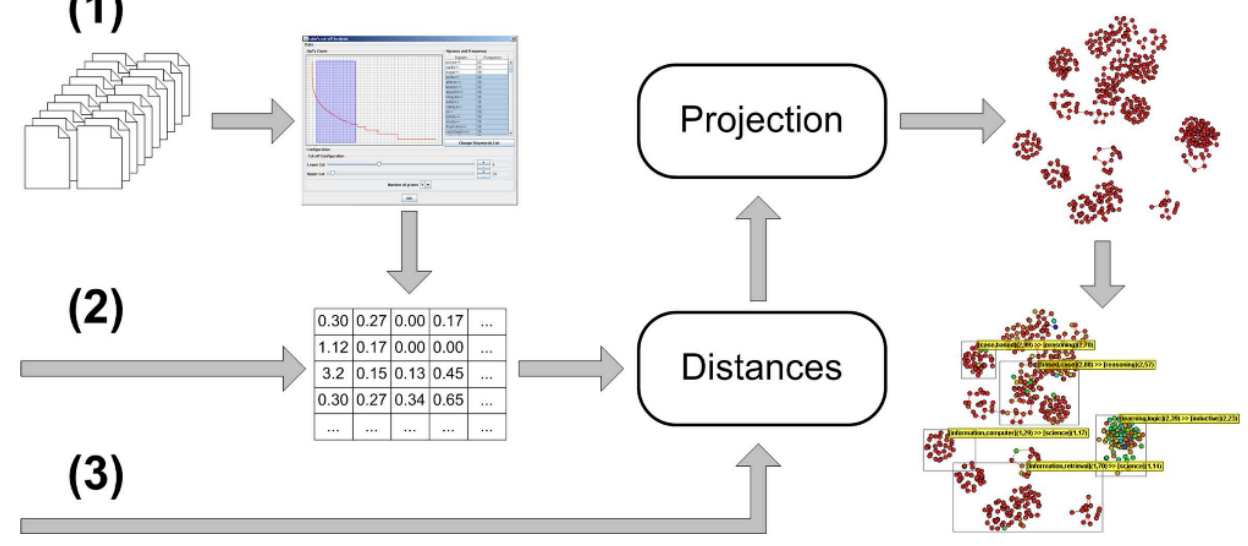

Figura 30: Processo de geração de mapas interativos de documentos: o sistema pode receber em (1) uma coleção de objetos não estruturados, em (2) uma tabela de dados estruturada, ou em (3) uma matriz de distâncias [Paulovich et al., 2007].

alização do ICMC-USP. O Projection Explorer (PEx) [Paulovich et al., 2007], como é denominada a ferramenta, tem como principal objetivo a exploração visual de coleções de documentos de texto, sendo que cada documento é apresentado como um ponto no plano e a proximidade entre os pontos denota a similaridade entre os respectivos documentos. Além disso, o PEx possui diversos mecanismos para auxiliar no processo de exploração dos dados, como busca por termos no corpo dos documentos, atribuição de cores e tamanhos diferentes aos pontos segundo algum critério, e extração de tópicos associados a conjuntos de documentos. A Figura 31 apresenta um exemplo de visualização gerada com o PEx, na qual cada ponto refere-se a uma notícia de jornal coletada na internet, e a cor foi gerada a partir de uma busca por "bird flu" e representa a frequência do termo no corpo do documento. Além disso, também foi extraído o tópico dos documentos usando uma estratégia de detecção de coocorrência de termos. Como é possível observar, o tópico extraído reflete o resultado da busca.

Muitas das técnicas aplicadas no PEx para visualizar coleções de documentos podem ser utilizadas para visualizar dados de outras naturezas. Trabalhos mais recentes expandiram os resultados para visualização de coleções de séries temporais e coleções de imagens. Uma funcionalidade interessante nesse contexto é a de múltiplas visões. Com ela é possível criar e interagir com várias visualizações simultaneamente, havendo a possibilidade de aplicar diferentes técnicas, tanto sobre o mesmo conjunto de dados, quanto sobre conjuntos diferentes. 


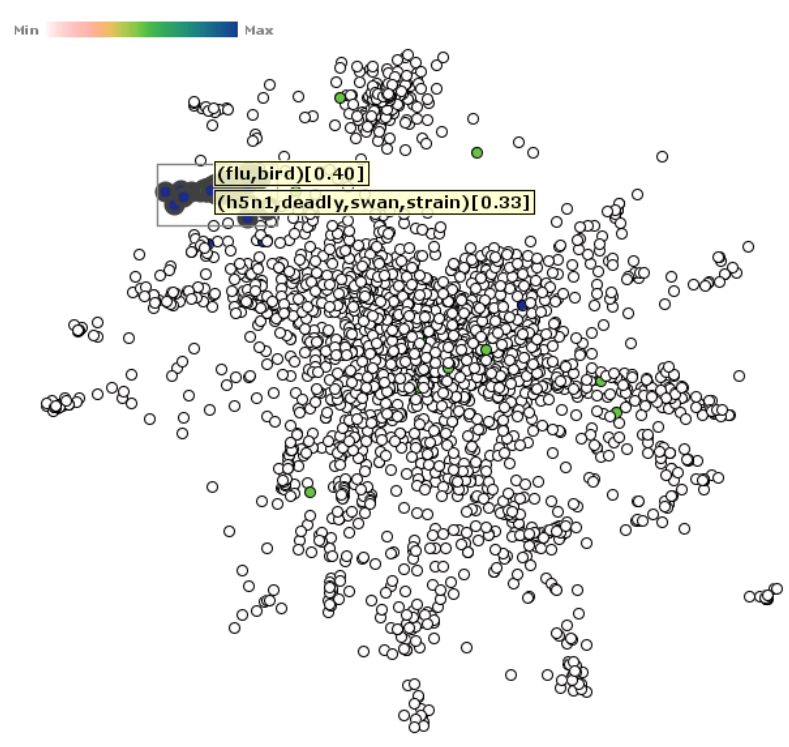

Figura 31: Mapa criado com a ferramenta PEx, no qual pontos representam manchetes de notícias e as cores denotam a frequência do termo "bird flu", de acordo com a escala de cores no canto superior esquerdo.

\subsection{Abordagens propostas e o PEx-Graph}

A seguir são apresentadas as três abordagens propostas, a saber: (i) redes heterogêneas, (ii) projeções multidimensionais, e (iii) múltiplas visões coordenadas. A Subseção 4.2.4 apresenta a extensão da ferramenta PEx para grafos e redes sociais, denominada PExGraph.

\subsubsection{Redes heterogêneas}

Redes heterogêneas são representadas como grafos nos quais os vértices representam mais de um tipo de objeto. Por meio de uma rede heterogênea, é possível representar dados relacionais, como tabelas $n-m$ de banco de dados. Nesse caso, as arestas podem conectar tanto objetos do mesmo tipo quanto objetos de tipos diferentes.

Ao utilizar redes heterogêneas com funcionalidades de interação típicas em análise de redes sociais, é possível amplificar a capacidade de exploração, voltada aos interesses do usuário. Uma das funcionalidades mais interessantes nesse contexto é a possibilidade de criar redes egocêntricas de vértices de interesse. Além disso, também é importante utilizar atributos visuais para os vértices, como forma, cor e tamanho, para representar os atributos dos dados.

Para ilustrar esta e as próximas abordagens, foi utilizado um conjunto de dados do site de relacionamentos Orkut. O conjunto de dados, coletado e cedido pelo IBOPE 
Media $^{9}$, contém uma tabela de indivíduos formada por um identificador e os atributos "gênero", "estado civill", "aniversário" e "idade"; uma tabela de comunidades formada por um identificador e um atributo "nome"; e uma tabela que associa os indivíduos às comunidades a que pertencem.

A Figura 32 exibe uma rede heterogênea gerada com o conjunto de dados do Orkut, na qual os vértices cinzas em forma de círculo representam as comunidades; os vértices azuis em forma de quadrado, os indivíduos do sexo masculino; os vértices vermelhos em forma de quadrado, os indivíduos do sexo feminino; e as arestas conectam os indivíduos às suas comunidades. Os vértices foram posicionados de acordo com as suas conexões utilizando uma estratégia de projeção multidimensional apresentada na próxima subseção. Para esse exemplo, foram geradas as redes egocêntricas das três comunidades ao centro, que representam "Ferrari", "Opala" e "Preparação e Mecânica Carros", da esquerda para a direita.

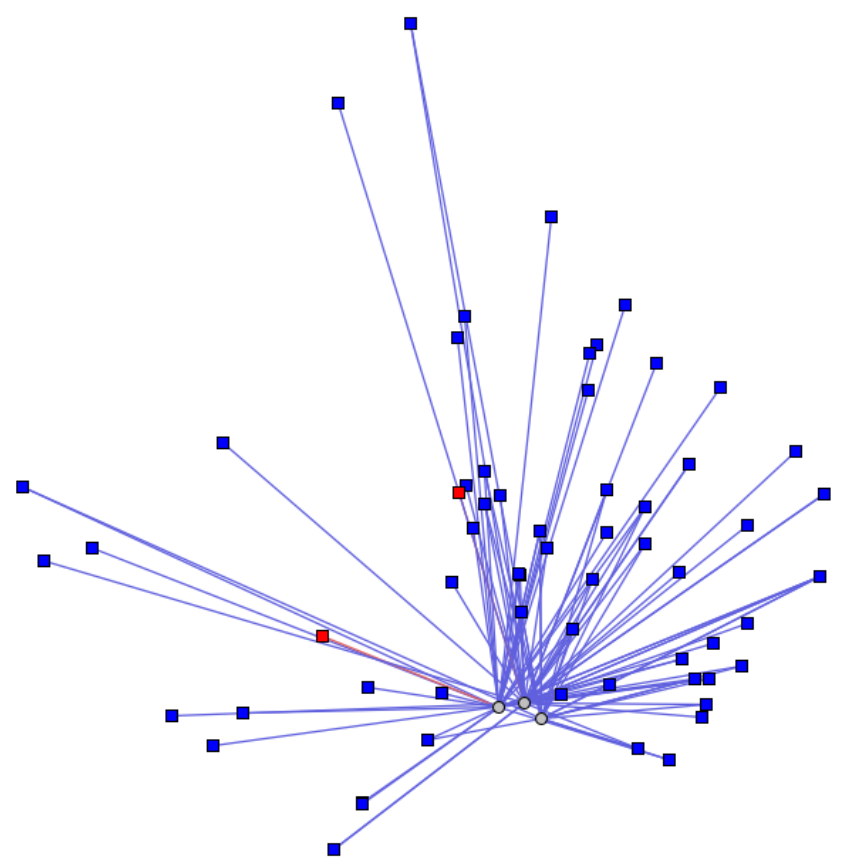

Figura 32: Exemplo de rede heterogênea gerada a partir de dados de redes sociais do Orkut, na qual os círculos cinzas representam as comunidades; os quadrados azuis, os indivíduos do sexo masculino; os quadrados vermelhos, os indivíduos do sexo feminino; e as arestas conectam os indivíduos às suas comunidades.

\footnotetext{
${ }^{9}$ http://www.ibope.com.br/
} 


\subsubsection{Projeções multidimensionais}

Cada indivíduo de uma rede social, tipicamente representado por um vértice, pode ser descrito por um vetor de atributos, ou como um ponto em um espaço de alta dimensionalidade. Utilizando projeção multidimensional, é possível posicionar os indivíduos no plano de acordo com os valores dos seus atributos.

Essa abordagem permite investigar grupos de indivíduos que possuem valores de atributos similares por meio de sua proximidade no plano. Em uma situação na qual as conexões também estão relacionadas com a similaridade entre os vértices, esse posicionamento produzirá menor cruzamento entre as arestas, caso contrário, poderá haver muitos cruzamentos.

O procedimento para esta abordagem cria uma matriz de distância para cada atributo do conjunto de dados e uma para os relacionamentos. As matrizes de distância dos atributos contêm um valor de dissimilaridade para cada par de vértices que reflete a diferença entre eles. Para atributos numéricos, é calculada sua diferença numérica; para atributos de data e hora, calcula-se a diferença em milissegundos; e para atributos nominais, é usada a distância de Levenshtein [Navarro, 2001], que conta o número mínimo de inserções, remoções ou substituições de caracteres necessárias para transformar uma cadeia de caracteres em outra. Para os relacionamentos, existem duas opções: a primeira é calcular uma matriz contendo os caminhos mais curtos entre cada par de vértices; a segunda é criar uma matriz de adjacência modificada $A^{\prime}$ a partir da matriz de adjacência original $A$, de modo que $a_{i j}^{\prime}=\max -a_{i j}$, onde max é o maior valor em $A$. Então, as matrizes de distância são normalizadas entre 0 e 1 e somadas. Por fim, a matriz resultante é usada na projeção. É possível somar somente as matrizes de interesse.

A Figura 33 exemplifica a projeção dos indivíduos do conjunto de dados do Orkut utilizando somente a matriz de adjacência modificada $A^{\prime}$. Os relacionamentos indicam se dois indivíduos pertencem a alguma comunidade em comum. A técnica de projeção utilizada neste e nos demais exemplos é chamada IDMAP [Minghim et al., 2006]. No conjunto de dados há indivíduos em duas diferentes comunidades relacionadas à marca de carro Peugeot. Assim, os vértices estão coloridos de acordo com o número de comunidades relacionadas à Peugeot das quais os indivíduos fazem parte. Indivíduos que não pertencem a nenhuma dessas comunidades aparecem em branco; indivíduos que pertencem a uma delas, em bege; e a duas, em verde escuro. Como é possível observar, 
os vértices que representam os indivíduos que pertencem a comunidades relacionadas à Peugeot estão separados daqueles que não pertencem a nenhuma.

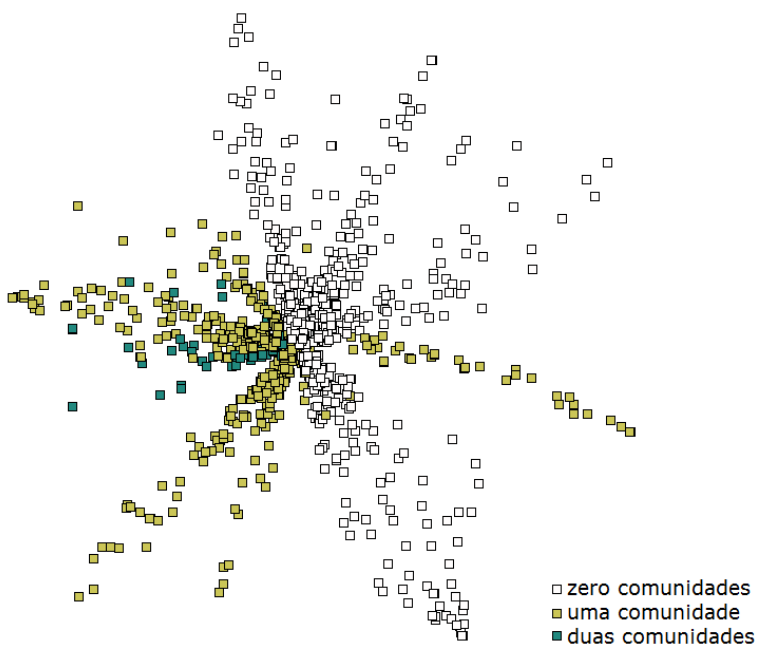

Figura 33: Projeção multidimensional da matriz de adjacência modificada do conjunto de dados do Orkut, na qual a cor indica a quantas comunidades relacionadas à Peugeot os indivíduos pertencem.

\subsubsection{Coordenação por identidade e coordenação relacional}

Múltiplas Visões Coordenadas (CMV - Coordinated and Multiple Views) refere-se à possibilidade de visualizar e interagir com várias visões simultaneamente, de modo que ações realizadas em uma delas sejam ecoadas para as demais, facilitando a exploração concomitante de padrões.

É possível utilizar uma técnica de coordenação, denominada coordenação por identidade, para criar um relacionamento direto entre os mesmos vértices contidos em diferentes visualizações. Quando um vértice ou um conjunto de vértices é selecionado em uma representação visual, os mesmos vértices são destacados nas outras representações. Assim, utilizando técnicas tradicionais de grafos aliadas às abordagens propostas, a coordenação por identidade permite identificar grupos de indivíduos tanto pela similaridade entre os objetos quanto pelas conexões da rede.

A Figura 34 mostra um exemplo de coordenação por identidade entre duas visões diferentes. A visão de rede heterogênea à esquerda exibe a rede egocêntrica da comunidade "Eu odeio Fiat !!". O círculo cinza representa essa comunidade; os vértices em forma de quadrado azul representam indivíduos do sexo masculino; e os vértices em forma de quadrado vermelho, os do sexo feminino. A visão de projeção multidimensional à direita é a mesma da Figura 33, e a cor indica em quantas comunidades 
relacionadas à Peugeot os indivíduos pertencem. Nesse caso, ao selecionar os membros da comunidade "Eu odeio Fiat !!" na visão de rede heterogênea, os mesmos vértices foram destacados na visão de projeção multidimensional, permitindo verificar que nenhum deles pertence a qualquer comunidade relacionada à Peugeot.
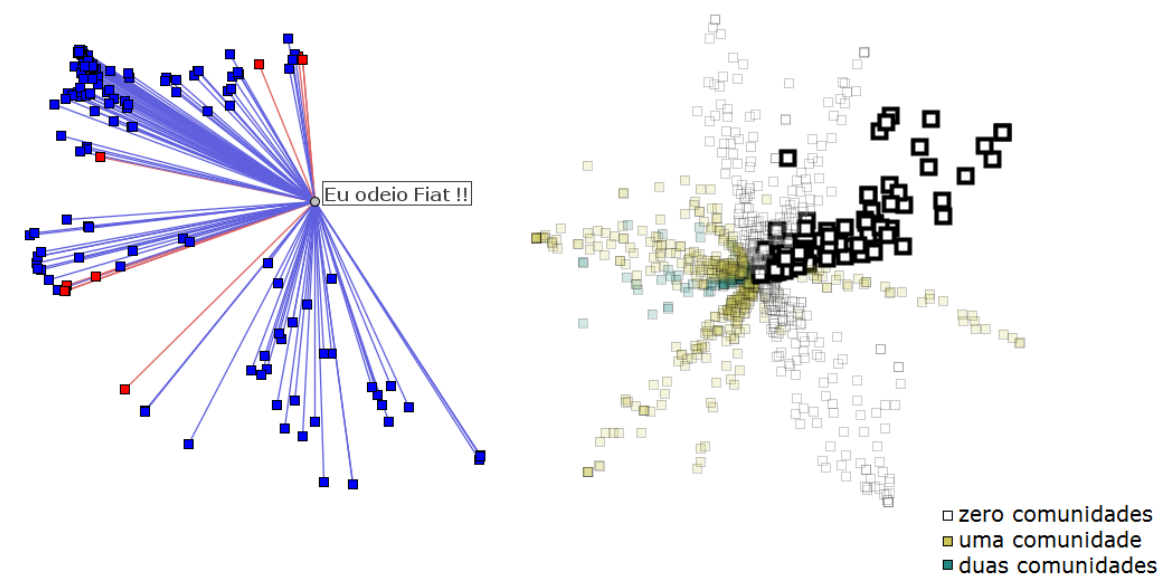

Figura 34: Coordenação por identidade entre duas visões do conjunto de dados do Orkut. Os membros da comunidade "Eu odeio Fiat !!" foram selecionados na visão de rede heterogênea à esquerda, e os mesmos foram destacados na visão de projeção multidimensional à direita. Na visão de rede heterogênea, o círculo cinza representa a comunidade; os quadrados azuis, os indivíduos do sexo masculino; e os quadrados vermelhos, os indivíduos do sexo feminino. Na visão de projeção multidimensional, a cor indica a quantas comunidades relacionadas à Peugeot os indivíduos pertencem.

Outra técnica de coordenação interessante é chamada de coordenação relacional, que cria uma associação do tipo $n-m$, ou seja, de muitos para muitos, entre vértices em diferentes representações visuais. Por exemplo, é possível criar duas visões, uma contendo somente os indivíduos da rede e a outra contendo somente as comunidades, e então associar os indivíduos às comunidades a que pertencem.

A Figura 35 exemplifica a técnica de coordenação relacional. A visão à esquerda foi gerada projetando somente os indivíduos do conjunto de dados do Orkut utilizando a matriz somada dos atributos. Nessa projeção, a cor indica o estado civil dos indivíduos. A visão à direita foi gerada projetando somente as comunidades do conjunto de dados do Orkut utilizando a matriz de caminhos mais curtos. Os relacionamentos indicam se duas comunidades possuem algum membro em comum. A coordenação relaciona indivíduos a comunidades de modo que, ao selecionar um ou mais indivíduos, suas comunidades são destacadas, e ao selecionar uma ou mais comunidades, seus membros são destacados. Nesse exemplo, a comunidade "Counter-Strike Brasil (CS)" foi selecionada e seus membros foram destacados. 


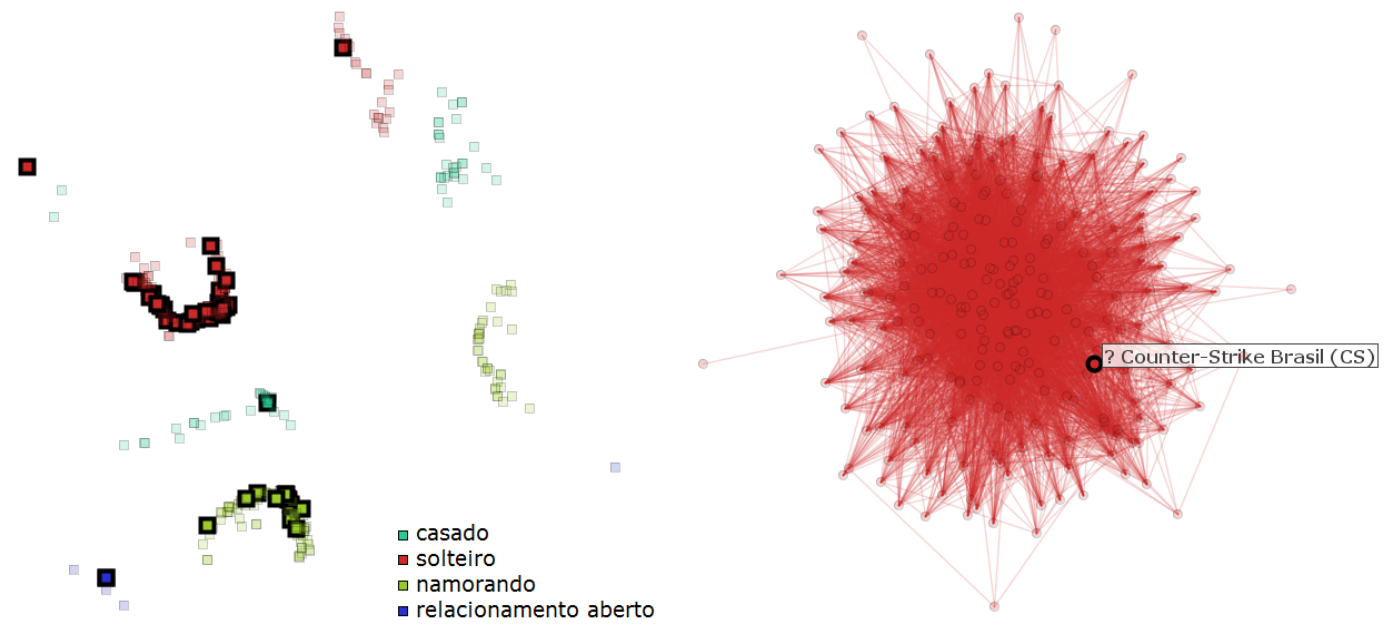

Figura 35: Coordenação relacional entre duas visões do conjunto de dados do Orkut. A comunidade "Counter-Strike Brasil (CS)" foi selecionada na visão à direita, e seus membros foram destacados na visão à esquerda.

A seguir, a incorporação dessas funcionalidades à ferramenta PEx é descrita.

\subsubsection{PEx-Graph}

As abordagens propostas foram implementadas na ferramenta Projection Explorer (PEx), que foi modificada para realizar visualização exploratória de grafos e redes sociais. A Figura 36 exibe a janela da ferramenta modificada, denominada PEx-Graph, com uma rede social heterogênea aberta. Esta seção descreve algumas das suas funcionalidades mais importantes.

A barra de ferramentas indicada pela letra "A" possui botões com funcionalidades básicas, como criar uma nova rede, abrir, salvar, além de zoom (escala) e um botão para executar um algoritmo de posicionamento baseado em força. As opções indicadas pela letra "B" permitem manter visível somente um ou mais vértices selecionados, além de fazer buscas textuais nos atributos dos vértices. A barra vertical à direita, indicada pela letra "C", apresenta diferentes opções de seleção de vértices, incluindo seleção de vizinhos mais próximos, geração de subgrafos, visualização de atributos, entre outras. As opções indicadas pela letra " $\mathrm{D}$ " permitem modificar os atributos visuais dos vértices, selecionar conjuntos de arestas, e o slider "Weight" permite controlar a exibição das arestas de acordo com seu peso. A lista indicada pela letra "E", à esquerda, contém os diferentes valores assumidos pelo atributo selecionado na caixa indicada por "H", sendo possível fazer busca e selecionar vértices a partir da mesma. A lista indicada pela letra " $F$ " contém os vizinhos mais próximos de um vértice selecionado. A visualização 


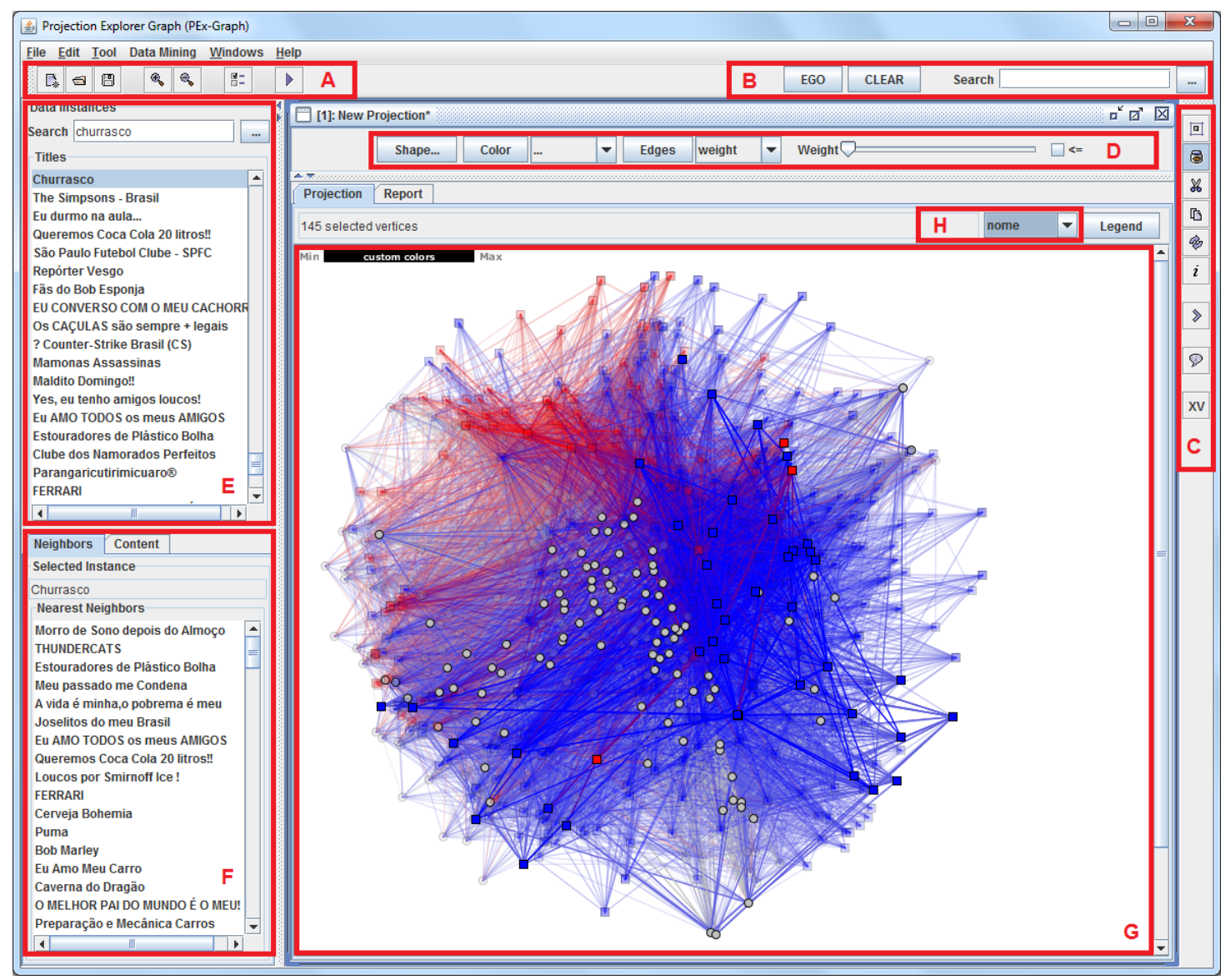

Figura 36: Janela da ferramenta PEx-Graph com uma rede social heterogênea aberta.

é exibida no espaço indicado pela letra "G". Ao passar o mouse sobre os vértices, é possível visualizar os valores assumidos por eles para o atributo selecionado na caixa indicada por "H".

Para criar uma nova projeção, utiliza-se um Wizard, que permite que o usuário siga um passo-a-passo com diferentes opções de configuração. A Figura 37 exibe uma etapa do Wizard, na qual é possível configurar se e como as arestas serão utilizadas para projetar. No Wizard também é possível escolher a técnica de projeção e configurar seus parâmetros. O arquivo de entrada deve estar no formato "vna", que declara os vértices e seus atributos, e especifica os conjuntos de arestas como uma lista de incidência.

As técnicas de interação implementadas no PEx-Graph incluem seleção, escala e busca, discutidas na Seção 2.4. O PEx-Graph fornece diferentes ferramentas de seleção. A seleção comum permite destacar um ou mais vértices do grafo. A seleção de vizinhos mais próximos destaca não apenas os vértices selecionados, mas também os seus vizinhos mais próximos no grafo. A geração de subgrafos permite criar outra visão contendo somente o subgrafo selecionado. A visualização de atributos exibe uma tabela 


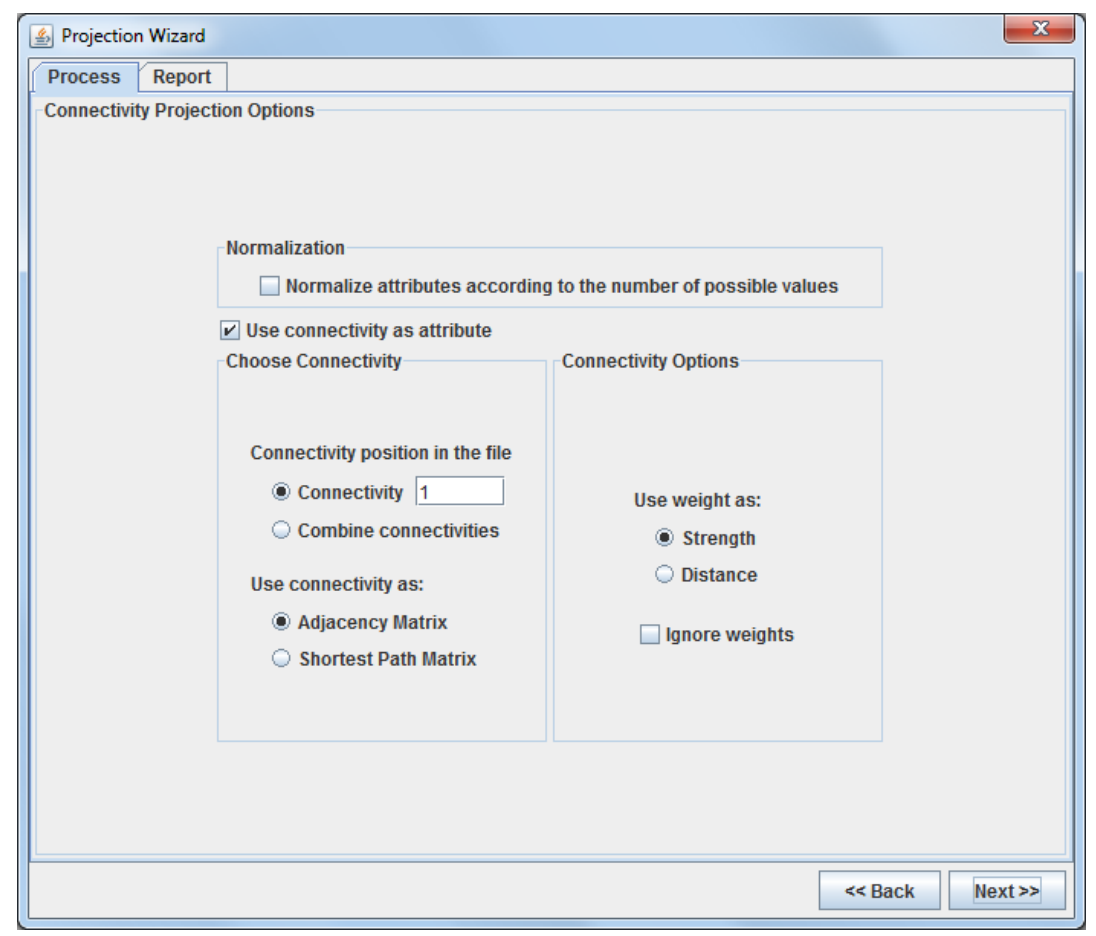

Figura 37: Janela do Wizard da ferramenta PEx-Graph que permite configurar se e como as arestas serão utilizadas para projetar.

de atributos para os vértices selecionados. A seleção de coordenação destaca vértices em outras visões de acordo com a técnica de coordenação utilizada, conforme explicado na Subseção 4.2.3. Por fim, a seleção de rótulos exibe um rótulo ao lado de cada vértice selecionado contendo os valores assumidos por eles para o atributo marcado na caixa indicada por "H" na Figura 36. A seleção de vizinhos mais próximos também pode ser configurada para selecionar somente os vizinhos que os vértices selecionados possuem em comum. Todas as ferramentas de seleção funcionam de duas formas: clicando e arrastando com o botão esquerdo do mouse, formando um retângulo em torno dos vértices a serem selecionados; ou clicando com o botão direito do mouse e desenhando uma forma livre, dentro da qual encontram-se os vértices a serem selecionados. A seleção de vizinhos mais próximos também funciona clicando sobre um vértice de interesse, sendo possível selecionar outros vértices pressionando a tecla shift e clicando sobre os demais. Uma vez aplicada a seleção, é possível clicar no botão "Keep" para manter visíveis somente os vértices selecionados, permitindo avaliá-los em detalhes (o botão de "Clear" ao lado exibe todos os vértices novamente).

A Figura 38 mostra a tabela aberta ao selecionar dois vértices com a ferramente de visualização de atributos. Para cada vértice, é exibida uma guia no topo da janela contendo o valor do vértice para o atributo selecionado na caixa "H" da Figura 36. 
Nesse exemplo, o valor é o identificador do vértice. A tabela na área central possui duas colunas: a da esquerda possui os nomes dos atributos e a da direita os valores assumidos por eles.

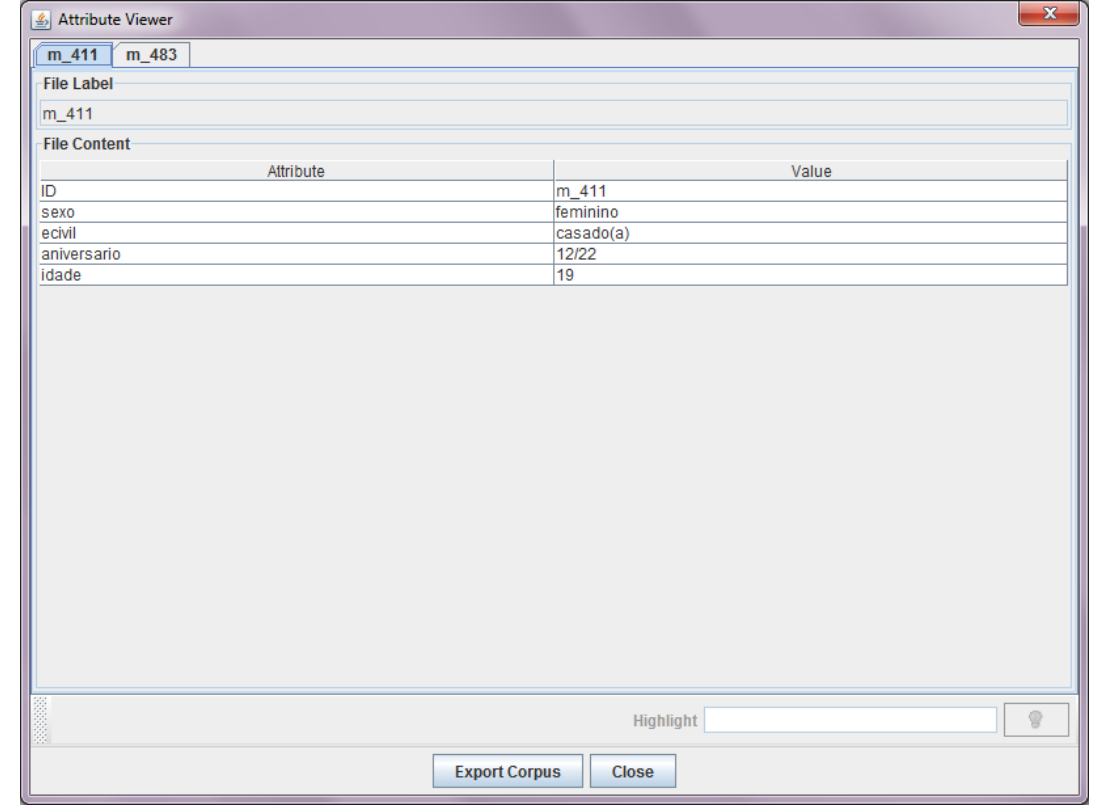

Figura 38: Janela do visualizador de atributos de vértices da ferramenta PEx-Graph, aberta ao selecionar um ou mais vértices com a ferramenta de visualização de atributos.

Um exemplo de seleção de rótulo pode ser visto na Figura 35, na qual a comunidade "Counter-Strike Brasil (CS)" foi selecionada com essa ferramenta.

O PEx-Graph também permite mover os vértices. Ao habilitar a devida opção, é possível selecionar um ou mais vértices utilizando a seleção comum ou de vizinhos mais próximos, e em seguida clicar sobre um dos vértices selecionados e arrastar. Todos os vértices selecionados, então, serão arrastados.

A ferramenta de busca é textual no PEx-Graph, sendo realizada sobre os atributos dos vértices. A Figura 39 exibe a projeção das comunidades do conjunto de dados do Orkut. Após realizar uma busca por "Volks", as comunidades que possuem o termo em algum atributo (as comunidades possuem apenas o atributo "nome" além do identificador) foram coloridas de azul.

Também é possível fazer uma busca na lista dos valores assumidos por um atributo (indicada pela letra "E" na Figura 36). Ao clicar sobre um valor, todos os vértices que assumem aquele valor são selecionados na visualização. Isso é útil, pois permite filtrar a visualização por valor de atributo, bastando clicar no botão "Keep" após selecionar um valor. 


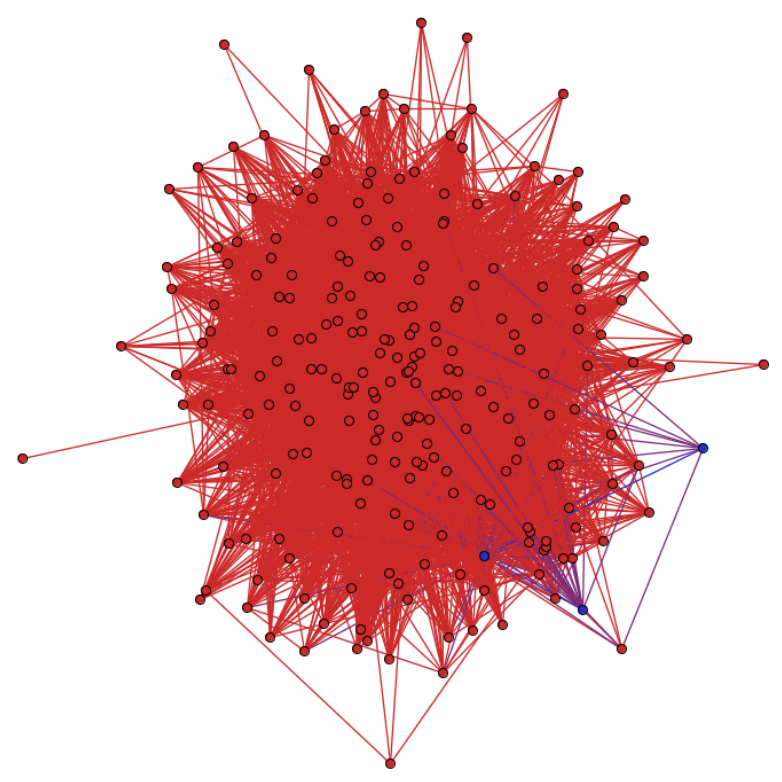

Figura 39: Busca por "Volks" na projeção das comunidades do conjunto de dados do Orkut. As comunidades que continham o termo em algum dos atributos foram coloridas de azul.

Outra funcionalidade interessante do PEx-Graph permite expandir os vértices, transformando-os em retângulos e exibindo o rótulo em seu interior. A Figura 40 exibe a rede egocêntrica da comunidade "Volkswagen Gol" com os vértices expandidos. A rede egocêntrica foi gerada a partir da projeção das comunidades do conjunto de dados do Orkut selecionando a comunidade "Volkswagen Gol" com a ferramenta de seleção de vizinhos mais próximos e pressionando em seguida o botão de "Keep".

O PEx-Graph permite modificar a cor, a forma, e o tamanho dos vértices de acordo com os valores de seus atributos. Também é possível carregar vários conjuntos de arestas, sendo possível exibir apenas um por vez. A partir de cada conjunto de arestas, o PEx-Graph pode calcular quatro métricas para análise de redes sociais: grau, grau de intermediação, grau de proximidade e coeficiente de agrupamento. Pode-se, então, utilizar os valores calculados para modificar os atributos visuais dos vértices. A Figura 41 exibe a projeção das comunidades do conjunto de dados do Orkut, cujo tamanho e cor dos vértices reflete o grau de intermediação. A comunidade mais central segundo essa métrica é a "The Simpsons - Brasil". A cor segue a escala de cores no canto superior esquerdo. As arestas conectam comunidades com pelo menos dez membros em comum.

Para coordenar duas ou mais visões, basta criar ou abrir as redes que se deseja coordenar, e selecionar a coordenação desejada no menu "Tool" (por identidade ou 


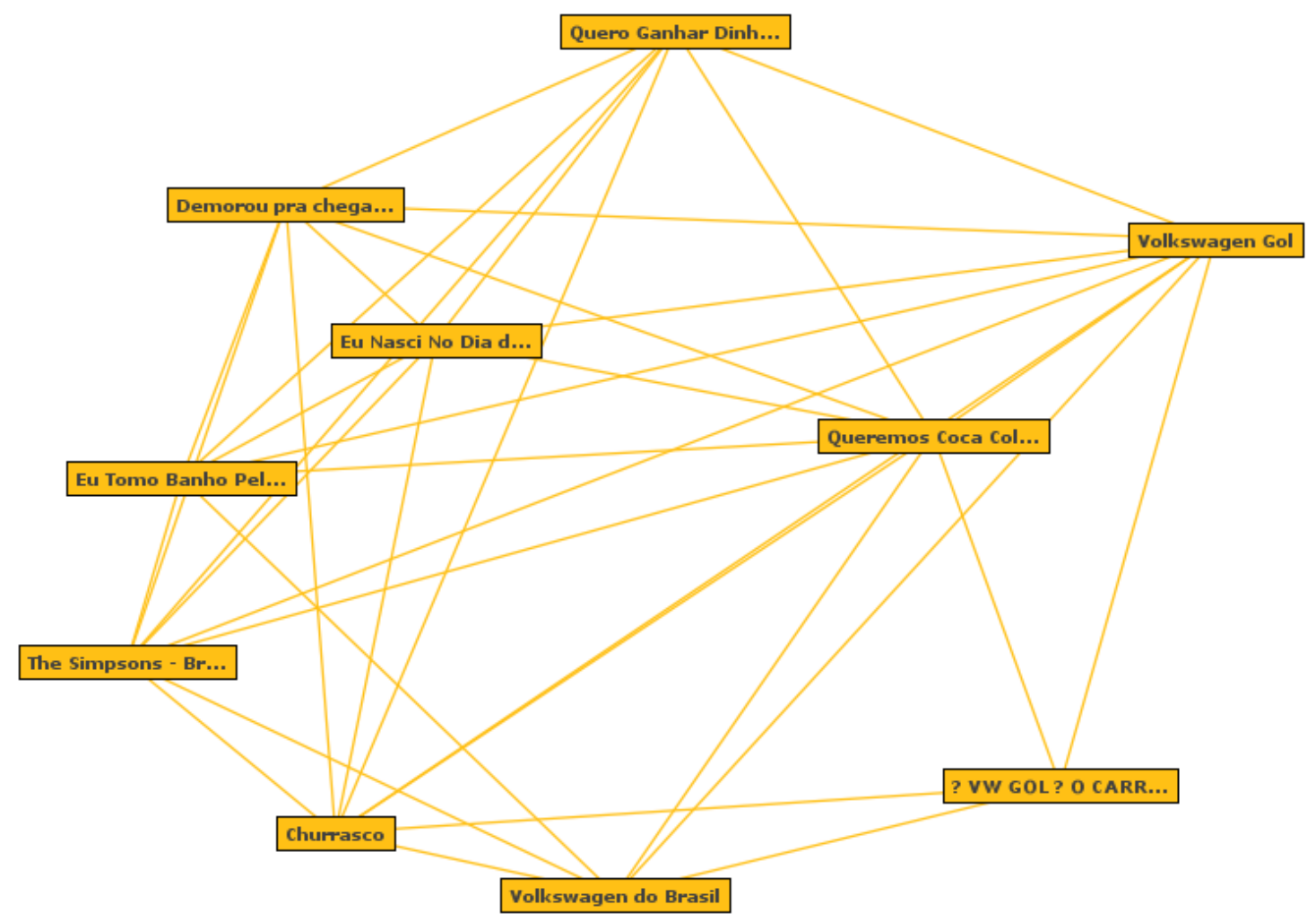

Figura 40: Rede egocêntrica da comunidade "Volkswagen Gol" com os vértices expandidos.

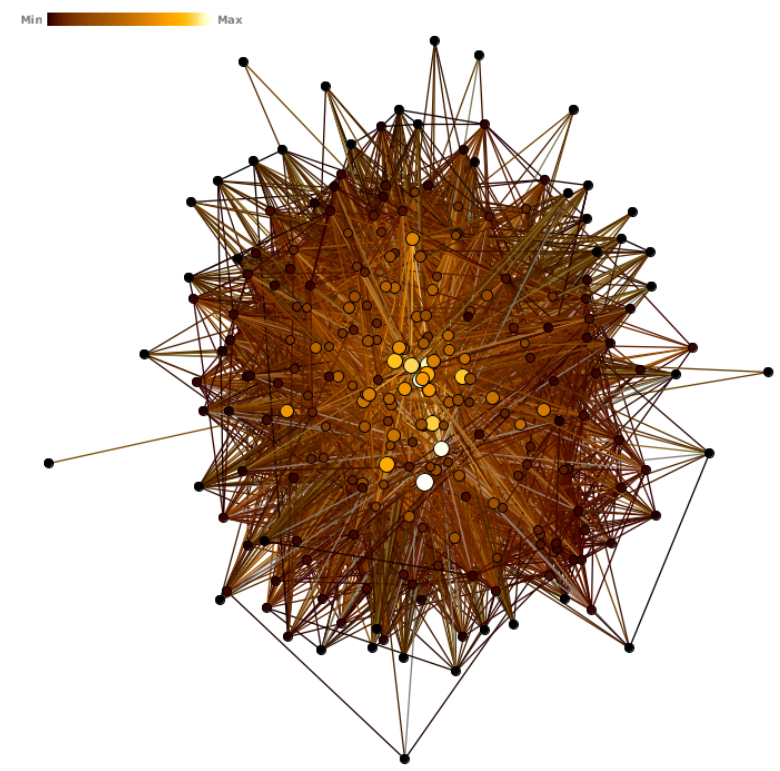

Figura 41: Projeção das comunidades do conjunto de dados do Orkut, cujo tamanho e cor dos vértices reflete o grau de intermediação. A cor segue a escala de cores no canto superior esquerdo. As arestas conectam comunidades com pelo menos dez membros em comum.

relacional). No caso da coordenação por identidade, os vértices com o mesmo identificador serão associados. No caso da coordenação relacional, é necessário fornecer um 
arquivo contendo uma relação de pares de identificadores, que associa diferentes vértices em diferentes visões. Utiliza-se, então, a seleção de coordenação para selecionar vértices em uma visão e destacar os vértices associados nas demais.

Com a implementação dessas funcionalidades, foram adicionadas, ao ferramental para exploração de redes sociais, ideias que podem melhorar a identificação de comunidades e a identificação de padrões entre indivíduos que a elas pertencem. A ferramenta PEx-Graph, bem como um vídeo ilustrando a utilização pode ser encontrado no site do grupo (http://infoserver.lcad.icmc.usp.br/) no item "Tools".

O próximo capítulo apresenta resultados de análise usando a ferramenta, tanto na forma de estudos de caso quanto nas conclusões obtidas por meio de uma avaliação com usuários. 


\section{Resultados}

Neste capítulo são apresentados os resultados obtidos com o uso da ferramenta PExGraph e das abordagens propostas nela implementadas na forma de estudos de caso e avaliação com usuários. A Seção 5.1 apresenta três estudos de caso, e a Seção 5.2 apresenta uma avaliação realizada com usuários e os resultados obtidos.

\subsection{Estudos de caso}

Alguns estudos de caso foram conduzidos para avaliar as abordagens propostas e a ferramenta PEx-Graph. As próximas subseções apresentam três desses estudos de caso. O primeiro é referente a um conjunto de dados obtido a partir do site de relacionamentos Netlog ${ }^{10}$. O segundo utiliza o mesmo conjunto de dados do Orkut dos exemplos da seção anterior. O terceiro estudo de caso utiliza a ferramenta para visualizar uma rede de citação com o objetivo de apoiar uma das etapas do processo de revisão sistemática, que é um modo de sumarizar toda pesquisa relevante e disponível sobre uma questão de interesse.

\subsubsection{Netlog}

Para este estudo de caso, foram coletados dados dos membros de dois grupos do site de relacionamentos Netlog. Os grupos são "Arsenal Fanz" e "Manchester United Til I Die". Os membros possuem os seguintes atributos: "gênero", "país", "idade" e "aniversário". Os demais grupos de cada membro também foram coletados.

A Figura 42 mostra uma rede heterogênea do conjunto de dados do Netlog. O posicionamento inicial foi aleatório e então os vértices foram reposicionados por meio de um algoritmo baseado em força. Os grupos são representados como círculos verdes, os usuários do sexo masculino como quadrados azuis, e os usuários do sexo feminino

\footnotetext{
${ }^{10}$ http://www.netlog.com/
} 
como quadrados vermelhos. As arestas conectam os membros às comunidades a que pertencem. Os dois grupos principais, "Arsenal Fanz" e "Manchester United Til I Die", estão indicados pelos seus nomes.

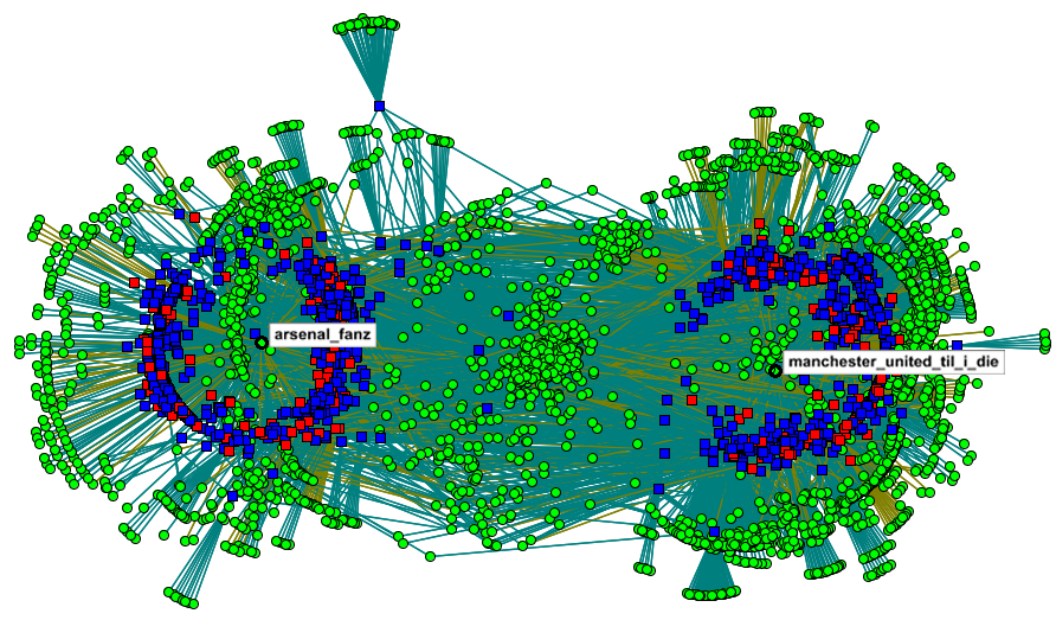

Figura 42: Rede heterogênea do conjunto de dados do Netlog, na qual os grupos são representados como círculos verdes, os usuários do sexo masculino como quadrados azuis, os usuários do sexo feminino como quadrados vermelhos, e as arestas conectam os membros às comunidades a que pertencem.

A Figura 43(a) exibe um subconjunto dos grupos do centro da Figura 42, alguns dos quais estão marcados com um rótulo. Entre eles estão: "Italy", "Salva L'Amore", "Friends 4 U", "Linkin Park" e "Al Pacino". A Figura 43(b) exibe os grupos dos quais os membros do "Manchester United Til I Die" fazem parte. Além dos vários grupos diretamente relacionados ao time de futebol Manchester United, também há dois grupos relacionados ao jogador Cristiano Ronaldo e outros como "Top Gear" e "Nirvana". Os grupos relacionados ao "Arsenal Fanz" são mostrados na Figura 43(c). Como no caso anterior, há vários grupos relacionados ao time de futebol Arsenal, outros relacionados a futebol em geral ("ACMilan" e "World Football"), além de outros, como "Final Fantasy".

A Figura 44 mostra uma projeção multidimensional dos membros do conjunto de dados do Netlog, considerando tanto seus atributos quanto seus relacionamentos, que refletem o número de grupos em comum a que pertencem. Na Figura 44(a), os membros estão coloridos por país, e na Figura 44(b), por idade. Em cada uma, os membros à esquerda são do sexo masculino, e à direita, do sexo feminino, apesar da projeção considerar os outros atributos além do gênero. Pode-se perceber que existem muito mais membros do sexo masculino do que do sexo feminino. Além disso, há muitos membros do Reino Unido, como era de se esperar, já que os grupos são dedicados a times de futebol desse país, mas também há muitos membros do Irã e da Arábia 


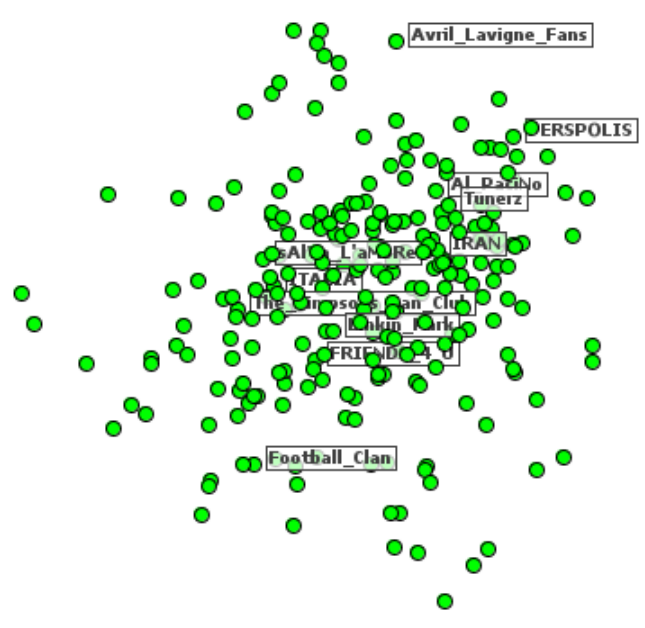

(a)

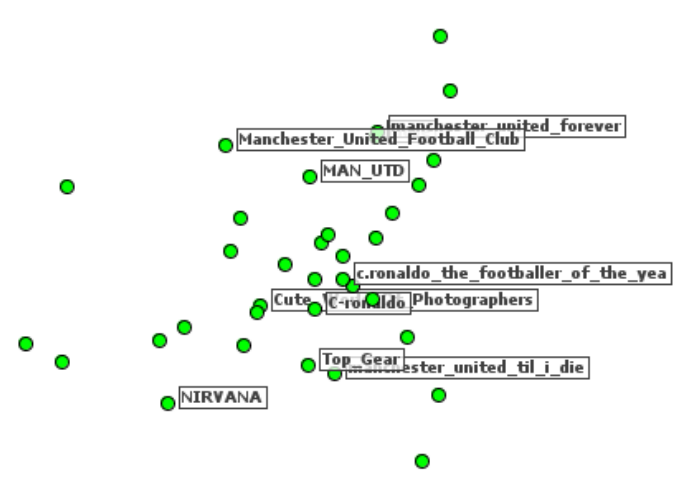

(b)

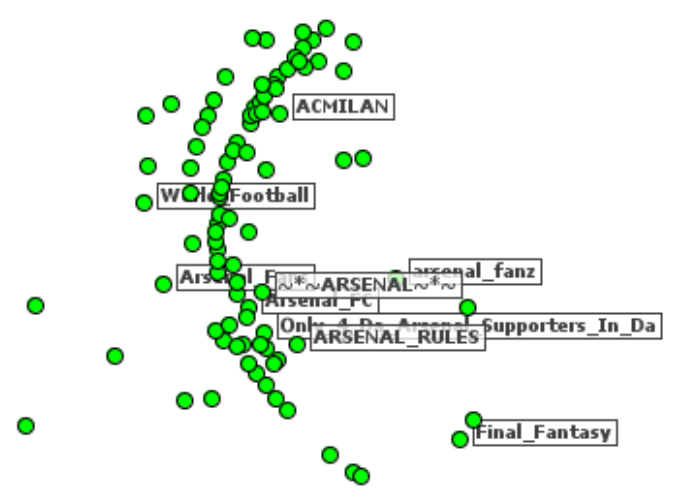

(c)

Figura 43: Subconjuntos da rede heterogênea do Netlog: (a) grupos com membros em comum tanto com o "Arsenal Fanz" quanto com o "Manchester United Til I Die", (b) grupos com membros em comum ao "Manchester United Til I Die", e (c) grupos com membros em comum ao "Arsenal Fanz".

Saudita. Também é possível observar que a maioria dos membros são jovens.

O peso das arestas indica o número de grupos em comum aos quais os membros fazem parte. Com o auxílio do slider de controle de peso implementado na ferramenta, foram mantidas somente as arestas com peso maior ou igual a dez. A Figura 45 exibe o resultado. É fácil perceber que a maioria dos membros que fazem parte de pelo menos dez grupos em comum são do Irã e da Arábia Saudita. Ao analisar conjuntos de membros de outros países mais detalhadamente, incluindo o Reino Unido, é possível ver que seus membros não pertencem a mais do que quatro grupos em comum.

Também é possível projetar os grupos utilizando a matriz de adjacência modificada. As arestas indicam se dois grupos possuem membros em comum. A Figura 46(a) mostra os grupos que têm membros em comum com o "Arsenal Fanz", e a Figura 46(b) mostra 


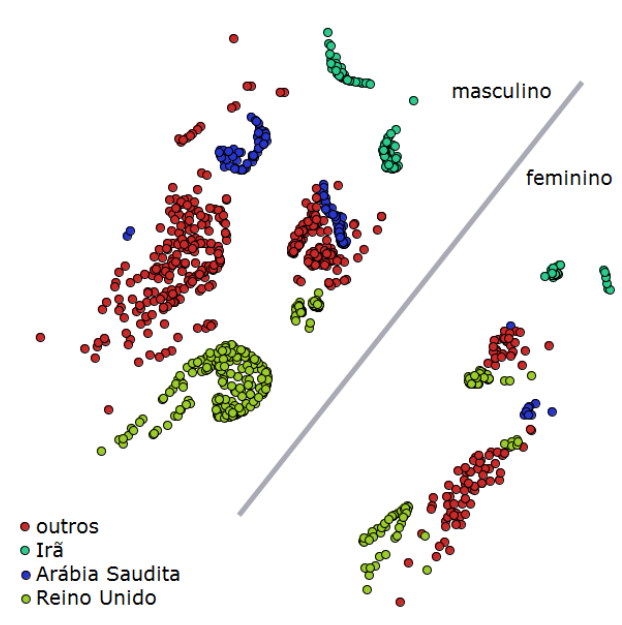

(a)

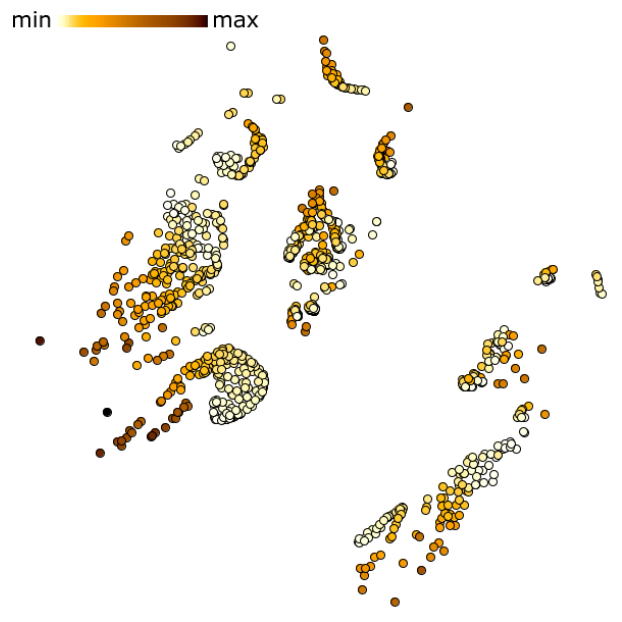

(b)

Figura 44: Projeção multidimensional dos membros do conjunto de dados do Netlog: (a) coloridos por país, e (b) coloridos por idade.

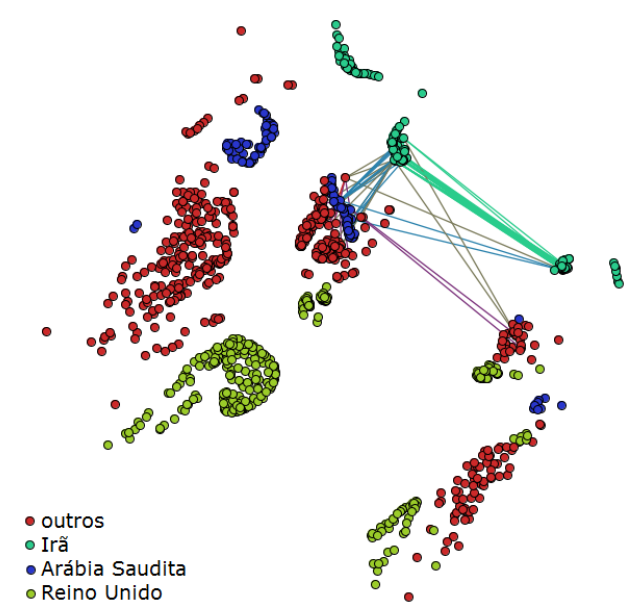

Figura 45: Projeção multidimensional dos membros do conjunto de dados do Netlog exibindo as arestas entre membros que fazem parte de pelo menos dez grupos em comum.

os grupos que têm membros em comum com o "Manchester United Til I Die". É possível observar que tanto o "Arsenal Fanz" quanto o "Manchester United Til I Die" estão conectados ao "Italia", "Real Madrid C.F.", "30 seconds to mars", "Formula 1 fanatics", entre outros.

\subsubsection{Orkut}

Usando o conjunto de dados do Orkut apresentado na Seção 4.2, foi explorado o perfil dos membros de comunidades relacionadas às marcas Peugeot e Volkswagen. A Figura 47 mostra uma rede heterogênea projetada usando a matriz de adjacência modificada. 


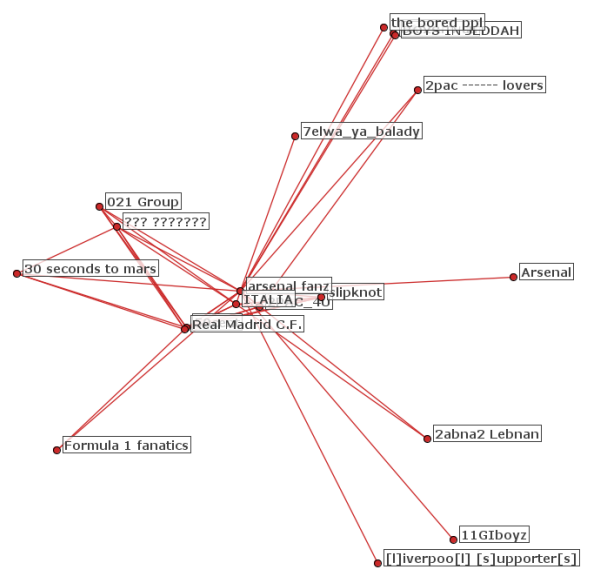

(a)

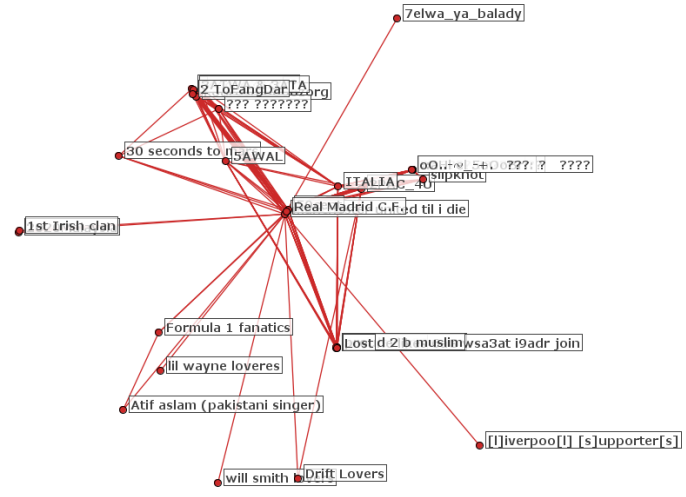

(b)

Figura 46: Projeção multidimensional dos grupos do conjunto de dados do Netlog: (a) grupos com membros em comum com o "Arsenal Fanz", e (b) grupos com membros em comum com o "Manchester United Til I Die".

As arestas conectam membros que pertencem a pelo menos dez comunidades em comum, comunidades que possuem pelo menos dez membros em comum, e os membros às comunidades a que pertencem. As comunidades são representadas como círculos cinzas, os membros do sexo feminino como quadrados vermelhos, e os do sexo masculino como quadrados azuis. É possível observar que a maioria dos membros do sexo feminino está agrupada na parte inferior, juntamente com as comunidades a que pertencem.

A Figura 48(a) mostra as redes egocêntricas das três comunidades relacionadas à Volkswagen, e a Figura 48(b) mostra as redes egocêntricas das duas comunidades relacionadas à Peugeot.

É possível observar que as comunidades relacionadas à Volkswagen possuem apenas membros do sexo masculino, enquanto que as comunidades relacionadas à Peugeot têm tanto membros do sexo masculino quanto do sexo feminino. Além disso, os membros das comunidades relacionadas à Peugeot também pertencem a comunidades mais românticas, como "Carpe Diem", "Nada acontece por acaso", "Eu amo música" e "Lost", enquanto os membros das comunidades relacionadas à Volkswagen também pertencem a comunidades mais materiais, como "Churrasco", "Queremos Coca 20 litros" e "Os Simpsons".

A Figura 49 exibe a projeção multidimensional dos membros do conjunto de dados do Orkut utilizando a matriz somada dos atributos. As quatro imagens representam a mesma projeção, mas cada uma está colorida de acordo com um atributo. Na Figura 49(a), a cor indica o gênero, na Figura 49(b), a cor indica o estado civil, na Figura 


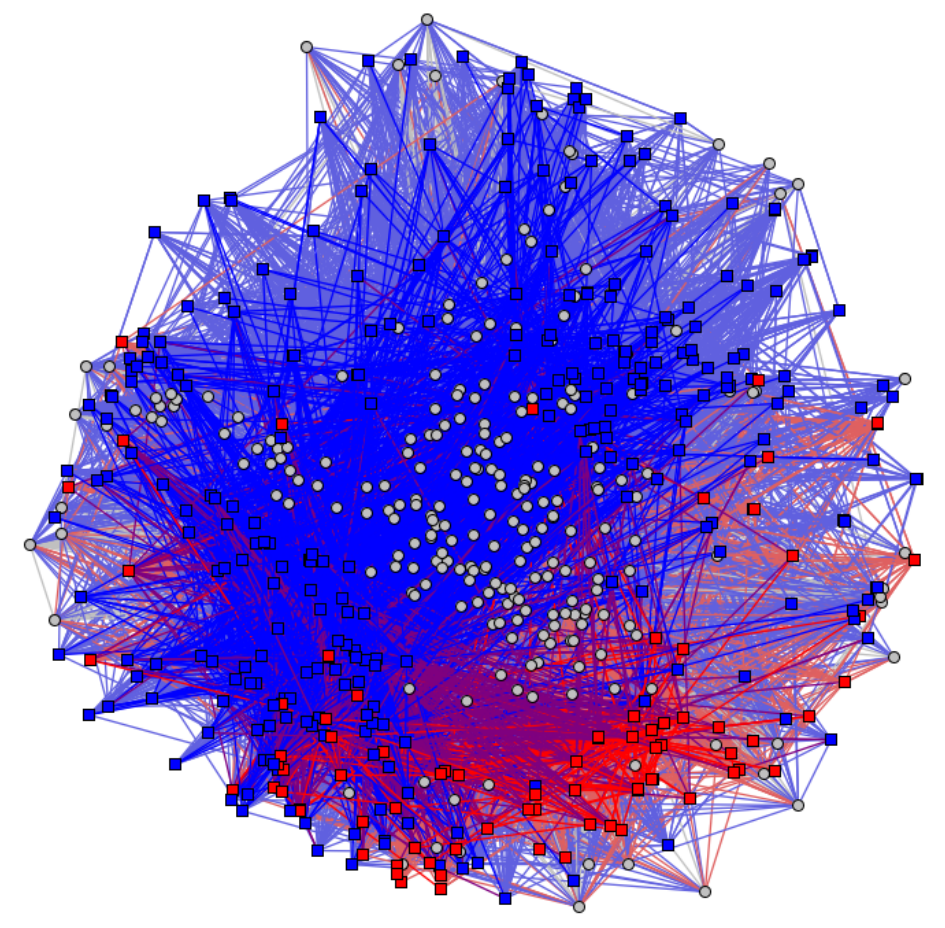

Figura 47: Rede heterogênea do conjunto de dados do Orkut, na qual os círculos cinzas representam as comunidades; os quadrados azuis, os indivíduos do sexo masculino; e os quadrados vermelhos, os indivíduos do sexo feminino.

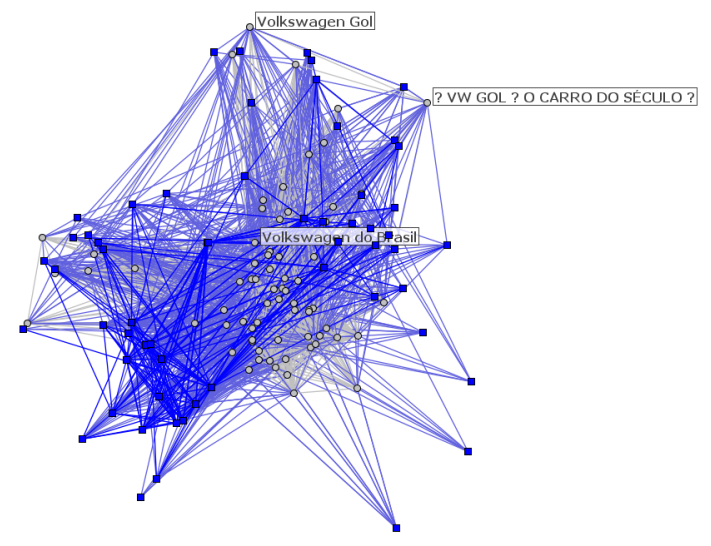

(a)

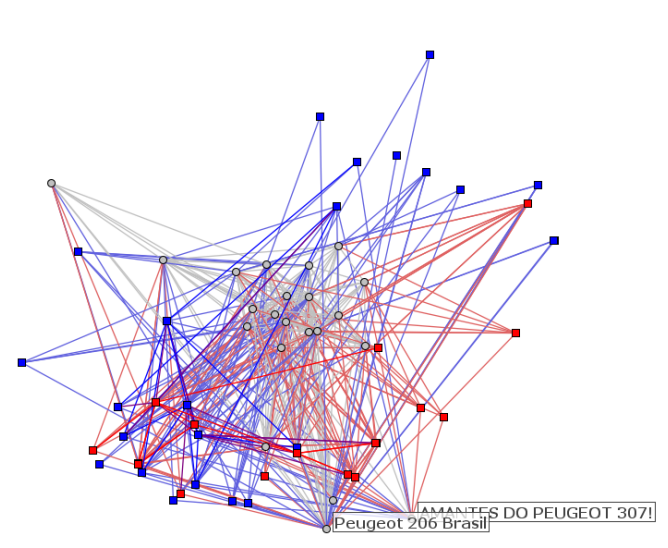

(b)

Figura 48: Redes egocêntricas: (a) das três comunidades relacionadas à Volkswagen, e (b) das duas comunidades relacionadas à Peugeot. Os círculos cinzas representam as comunidades; os quadrados azuis, os indivíduos do sexo masculino; e os quadrados vermelhos, os indivíduos do sexo feminino.

49(c), a cor indica o aniversário contendo dia e mês, de primeiro de janeiro a 31 de dezembro, conforme a escala de cores no canto superior esquerdo, e na Figura 49(d), a cor indica a idade, de 18 a 53 anos, conforme a escala de cores no canto superior esquerdo. Como é possível observar, usuários com perfis muito semelhantes aparecem próximos no plano, sendo fácil identificar os valores de atributos mais comuns. 


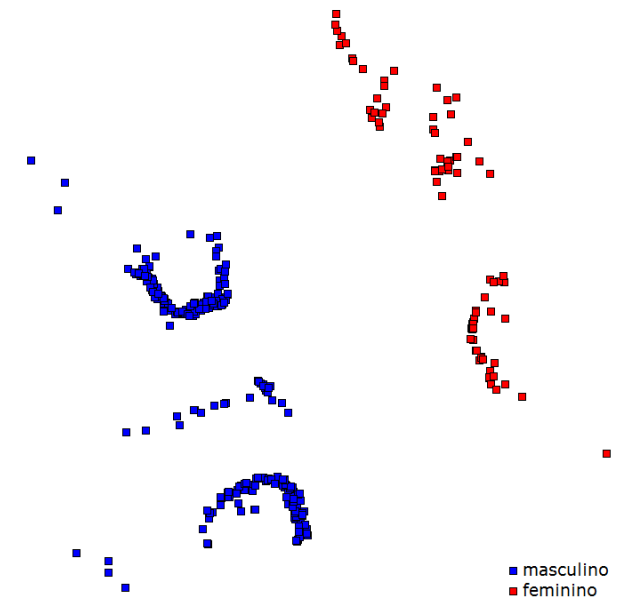

(a)

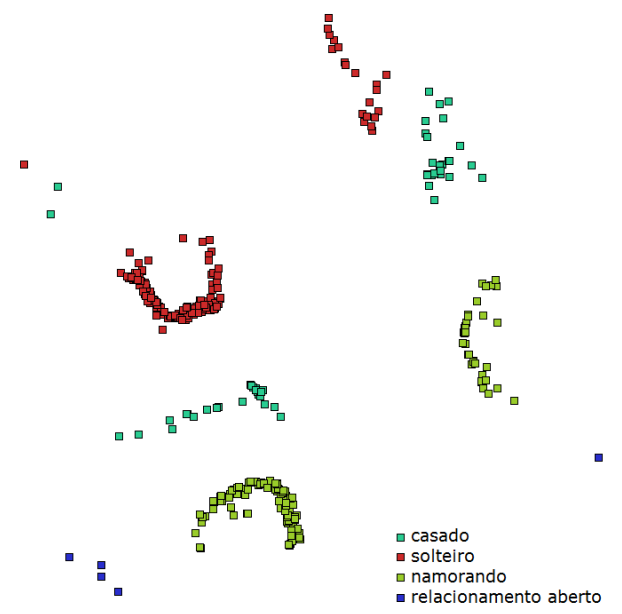

(b)

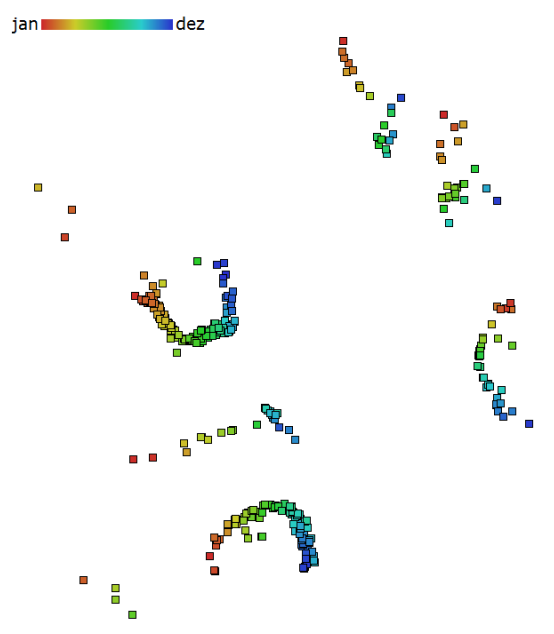

(c)

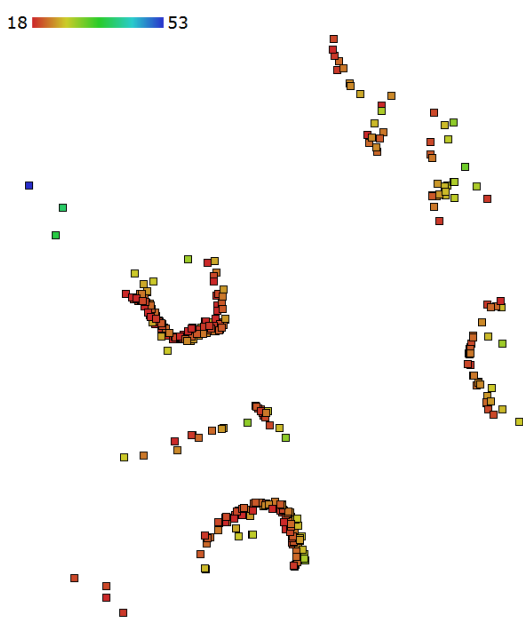

(d)

Figura 49: Projeção multidimensional dos membros do conjunto de dados do Orkut utilizando a matriz somada dos atributos. A cor representa: (a) gênero, (b) estado civil, (c) aniversário, e (d) idade.

Algumas métricas para análise de redes sociais foram implementadas na ferramenta PEx-Graph e aplicadas sobre a projeção multidimensional dos membros do conjunto de dados do Orkut. A Figura 50 exibe a mesma projeção da Figura 49, mas na Figura 50(a) a cor quanto o tamanho refletem o grau de intermediação, e na Figura 50(b) a cor quanto o tamanho refletem o grau de proximidade. A cor varia do branco, que indica o menor grau, ao marrom escuro, o maior grau. Como é possível observar, o grau de intermediação deixa apenas um vértice em marrom escuro, indicando que ele é um vértice bastante central, isto é, muitos vértices passam por ele para chegar aos 
demais. Já o grau de proximidade permite verificar que a grande maioria dos vértices, em marrom, são próximos entre si, isto é, fazem parte de comunidades em comum, e que existem alguns poucos vértices, em branco, que estão "isolados socialmente", isto é, que não fazem parte de comunidades em comum com os demais.

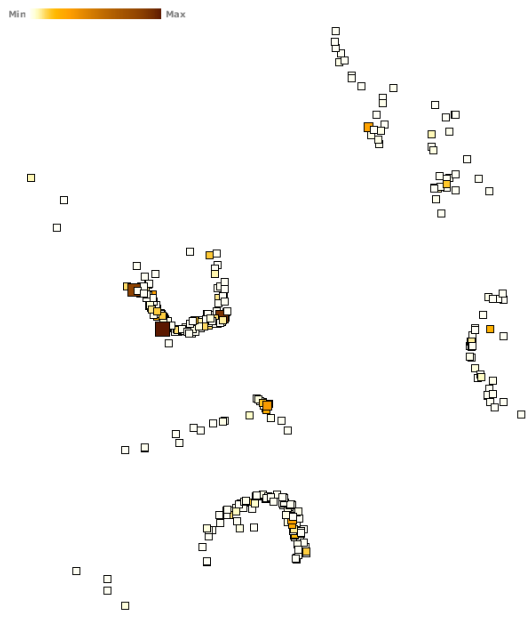

(a)

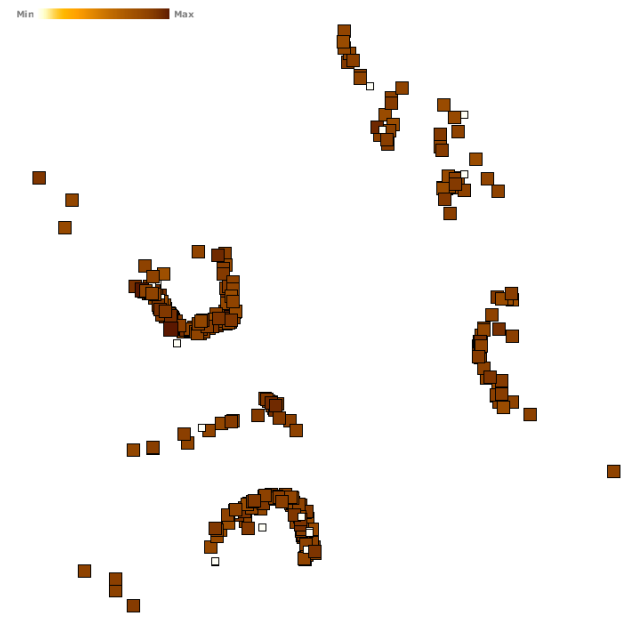

(b)

Figura 50: Projeção multidimensional dos membros do conjunto de dados do Orkut utilizando a matriz somada dos atributos. A cor e o tamanho representam: (a) grau de intermediação, e (b) grau de proximidade.

As Figuras 51 e 52 mostram uma coordenação relacional entre a projeção da Figura 49(b), à esquerda, e a projeção da matriz de adjacência modificada das comunidades, à direita. Assim, ao selecionar um grupo de comunidades na projeção da direita, somente seus membros continuaram visíveis na projeção da esquerda. Na Figura 51, as comunidades relacionadas à Peugeot foram selecionadas, e na Figura 52, as comunidades relacionadas à Volkswagen foram selecionadas. Como era esperado, os membros das comunidades relacionadas à Peugeot aparecem mais espalhados, enquanto os das comunidades relacionadas à Volkswagen aparecem mais próximos. Esse tipo de visualização pode apoiar uma empresa a criar estratégias de mercado voltadas para uma audiência que ela ainda não abrange.

\subsubsection{Revisão sistemática}

A revisão sistemática é uma maneira de avaliar e interpretar toda pesquisa relevante e disponível sobre uma questão de pesquisa específica, tópico ou fenômeno de interesse, fazendo uso de uma metodologia de revisão que seja confiável, rigorosa e que permita auditagem [Kitchenham, 2004]. O processo de revisão sistemática possui várias etapas, 


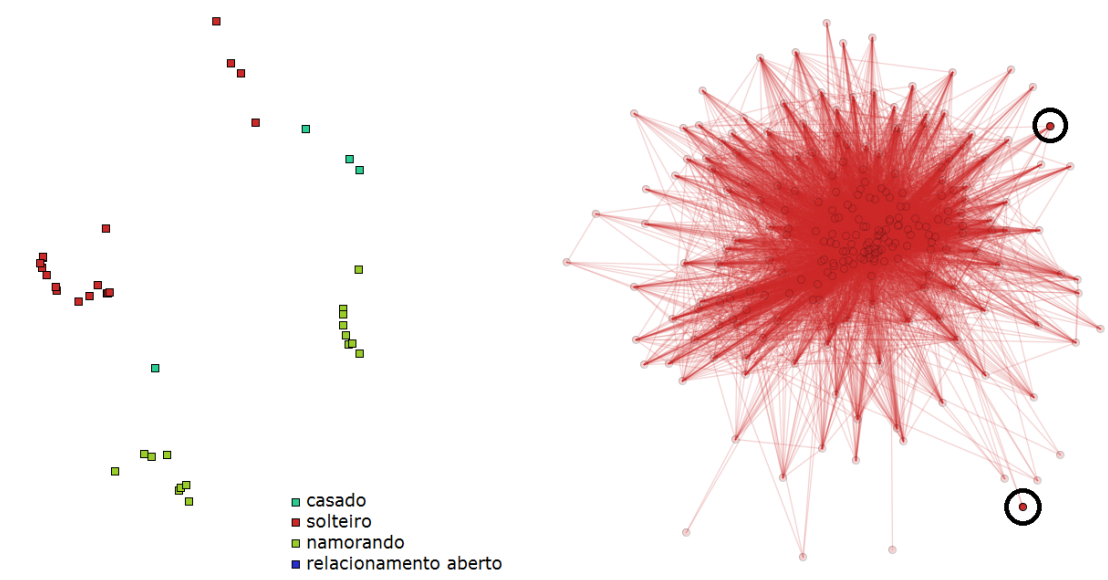

Figura 51: Coordenação relacional entre a projeção dos membros e a projeção das comunidades. As comunidades relacionadas à Peugeot foram selecionadas na projeção da direita e somente seus membros permaneceram visíveis na projeção da esquerda.
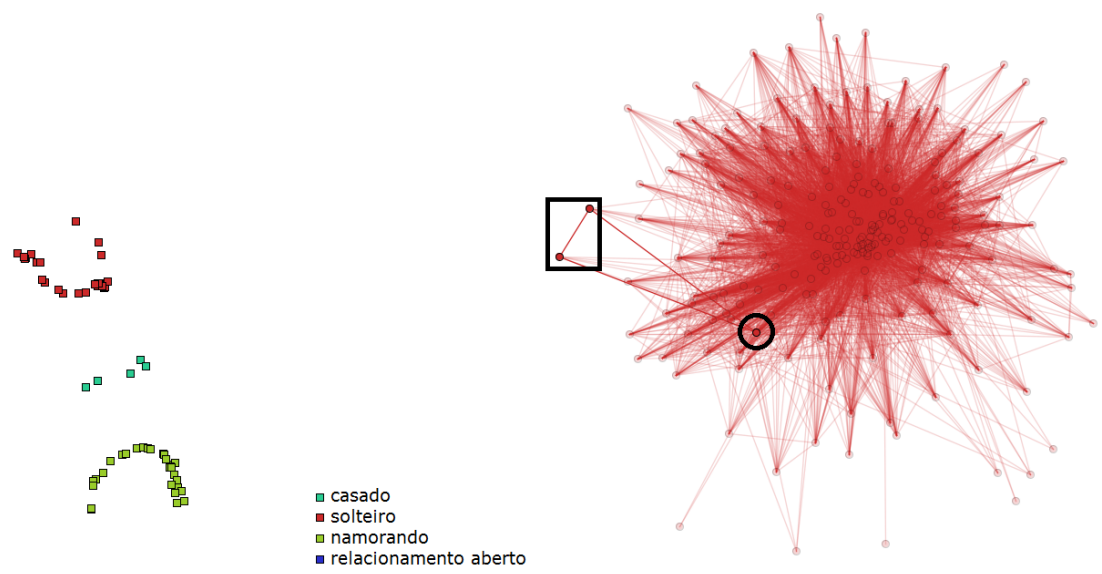

Figura 52: Coordenação relacional entre a projeção dos membros e a projeção das comunidades. As comunidades relacionadas à Volkswagen foram selecionadas na projeção da direita e somente seus membros permaneceram visíveis na projeção da esquerda.

sendo uma delas responsável pela seleção dos artigos e outra pela revisão da seleção. Durante a etapa de seleção, uma lista de artigos relacionados ao tema da pesquisa é levantada e os artigos são avaliados, podendo ser incluídos na revisão ou excluídos. Durante a etapa de revisão da seleção, os artigos devem ser reavaliados para garantir que não foram eliminados artigos relevantes. Visualizar a rede de citação dos artigos pode apoiar essa revisão.

Por meio da rede de citação, é possível identificar, por exemplo, estudos que não estão conectados aos demais, ou seja, que não compartilham referências. Esses estudos, que estão isolados em termos de referências, merecem atenção. Outro caso que merece destaque são as referências de estudos incluídos com muitas conexões, pois as listas de referência dos estudos revisados e classificados como incluídos também devem ser 
levadas em consideração [Kitchenham et al., 2007].

Um dos resultados deste trabalho foi a aplicação das técnicas de visualização de redes sociais para geração de redes de citação. Juntamente com outras técnicas de visualização, as redes de citação foram incorporadas com êxito ao processo de revisão sistemática. A descrição e os resultados da aplicação dessas técnicas estão apresentados em um artigo publicado como outro resultado deste trabalho [Felizardo et al., 2009]. Além disso, uma ferramenta de visualização específica para revisão sistemática, denominada ReVis, foi criada a partir da implementação das técnicas implementadas no PEx-Graph.

As Figuras 53 e 54 representam duas redes de citações de revisões sistemáticas diferentes. Os pontos vermelhos representam artigos excluídos; os azuis representam os incluídos; e os cinzas, artigos referenciados.

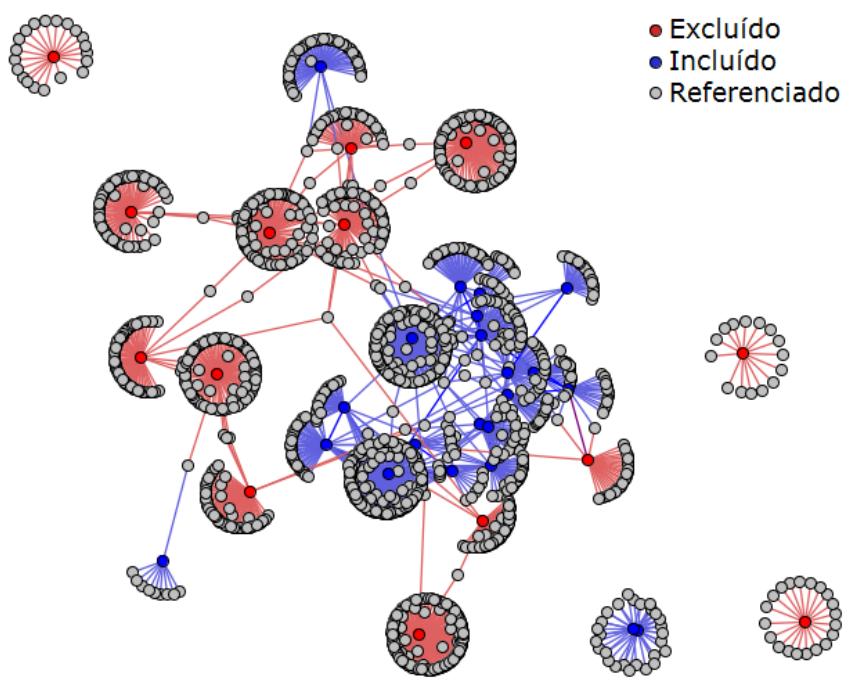

Figura 53: Rede de citação de uma revisão sistemática. Os pontos vermelhos representam artigos excluídos; os azuis representam os incluídos; e os cinzas, artigos referenciados.

Foi possível visualizar na rede de citações da Figura 53 que a maioria dos artigos incluídos, localizados na região central, compartilham as mesmas referências, assim como os excluídos, localizados à esquerda e acima. Os estudos isolados foram todos classificados como excluídos. Vale destacar que o "ponto azul" localizado no canto inferior direito, se observado com detalhe, não é um único ponto isolado, mas dois pontos que compartilham exatamente as mesmas referências, não citadas em nenhum outro estudo.

Situações críticas e que merecem ser reavaliadas foram percebidas na rede de citações correspondente à revisão sistemática da Figura 54. Uma delas é a presença de estudos 


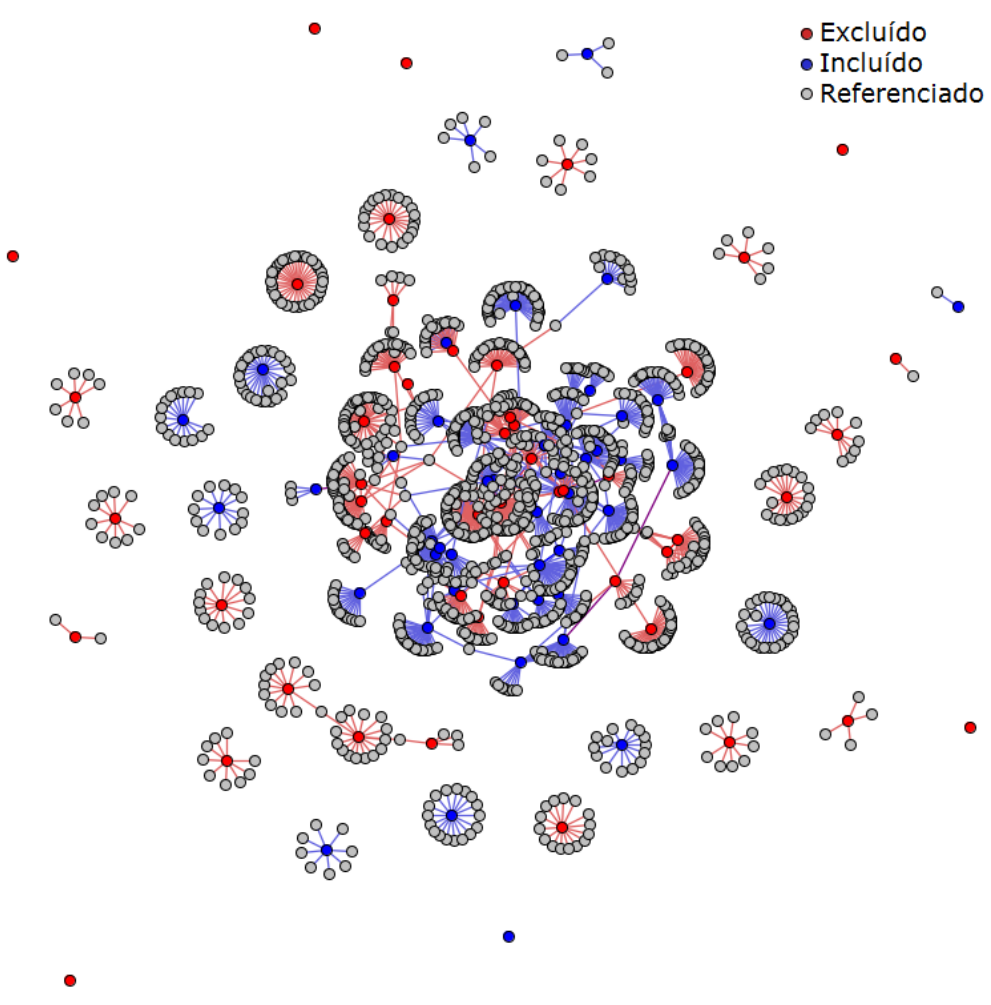

Figura 54: Rede de citação de uma revisão sistemática. Os artigos incluídos que não estão conectados aos demais merecem atenção.

incluídos totalmente isolados do restante, isto é, pontos azuis conectados apenas com suas respectivas referências, que totalizam 10 ocorrências.

Uma grande vantagem em utilizar a rede de citações no processo de revisão sistemática é que ela elimina a escolha aleatória dos artigos a serem reavaliados, sendo essa escolha baseada em informações contidas no próprio conjunto de artigos, porém não reveladas sem o auxílio visual.

\subsection{Avaliação com usuário}

Uma avaliação foi conduzida com trinta usuários para verificar a utilidade de parte da funcionalidade da ferramenta PEx-Graph. Os usuários são alunos do curso de Bacharelado em Ciências de Computação do ICMC-USP. Nenhum dos usuários conhecia a ferramenta com antecedência. Usando o conjunto de dados do Orkut, a avaliação consistiu em descobrir o perfil dos usuários de algumas comunidades, primeiro utilizando a coordenação entre a projeção dos membros e a projeção das comunidades, como visto nas Figuras 51 e 52, e depois utilizando a rede heterogênea de membros e comunidades, como visto na Figura 47.

A avaliação foi executada em três fases. Na primeira fase, os usuários tentaram as- 
sociar comunidades relacionadas a marcas famosas com gênero e estado civil, usando as visões coordenadas. Na segunda fase, foi dado um conjunto de nomes de comunidades, e os usuários tentaram descobrir se as comunidades consistiam predominantemente de homens, de mulheres, ou se tal relação de gênero não existia, usando a visão de rede heterogênea. Na terceira fase, os usuários tentaram descobrir outras relações entre comunidades e membros livremente, usando a visão de rede heterogênea.

Para cada fase, os usuários preencheram um formulário. No início do preenchimento do formulário, era marcado o tempo decorrido entre o início da fase e as respostas dadas. Ao final da avaliação, os usuários responderam a um questionário sobre o sistema, atribuindo notas à facilidade de uso, ao conforto com a interface, e à utilidade do sistema, além de dar sugestões para melhorá-lo. O Apêndice A apresenta os formulários que foram preenchidos.

Na primeira fase, todos os usuários associaram pelo menos uma marca com gênero, e onze usuários associaram pelo menos uma marca com estado civil. As marcas citadas para gênero foram "Volkswagen", "Fiat", "Honda", "Skol", "Nike", "Quiksilver", "Smirnoff", "Ferrari" e "Adidas". As comunidades relacionadas a essas marcas possuem quase exclusivamente membros do sexo masculino, o que reflete o maior número de indivíduos do sexo masculino no conjunto de dados. As marcas citadas para estado civil foram "Fiat" e "Volkswagen", cujas comunidades possuem muitos membros solteiros ou namorando, mas poucos casados.

A Figura 55 mostra um gráfico contendo os resultados da segunda fase da avaliação. As cinco comunidades que os usuários analisaram foram: "Eu amo meu Honda Civic", "Pareço metida(o), mas sou legal", "Eu acredito no amor", "O que é para ser nosso ninguém tira", e "Tuning". Como é possível observar, os usuários identificaram unanimemente que as comunidades 1 e 5 consistem predominantemente de homens, e $90 \%$ dos usuários conseguiram identificar que a comunidade 2 consiste predominantemente de mulheres. Alguns usuários demonstraram surpresa ao descobrirem que a comunidade "Eu acredito no amor" tem tanto homens quanto mulheres, uma vez que eles pensavam que ela seria predominantemente feminina.

Na terceira fase, os usuários detectaram que as comunidades relacionadas a carros têm muitos membros em comum, assim como as comunidades relacionadas a sentimentos. Entretanto, as comunidades relacionadas a carros são predominantemente masculinas, enquanto aquelas relacionadas a sentimentos são predominantemente fe- 


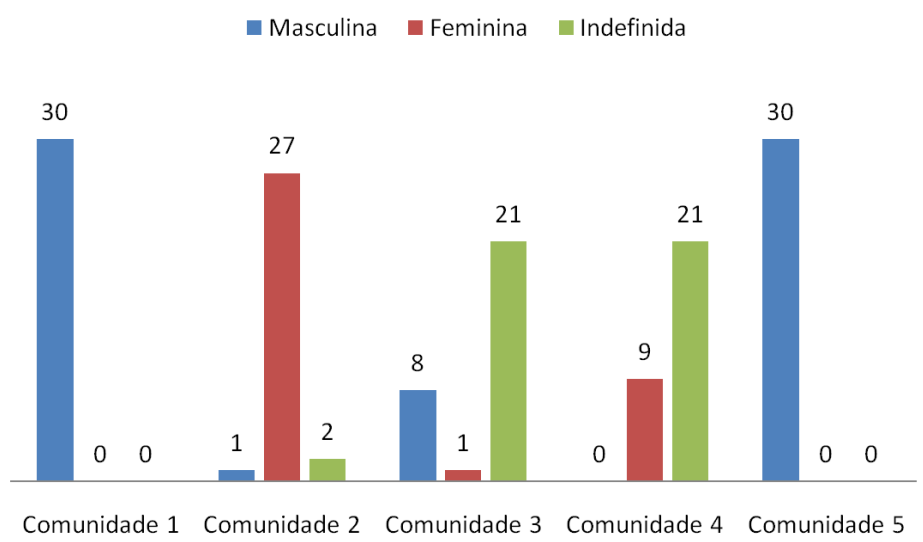

Figura 55: Resultado gráfico da segunda fase da avaliação. As barras indicam o número de usuários que classificaram cada uma das comunidades como sendo predominantemente masculina, predominantemente feminina, ou indefinida. As cinco comunidades referem-se a "Eu amo meu Honda Civic", "Pareço metida(o), mas sou legal", "Eu acredito no amor", "O que é para ser nosso ninguém tira", e "Tuning", respectivamente.

mininas. Além disso, os usuários também descobriram que as comunidades relacionadas a bebidas e jogos são predominantemente masculinas.

O tempo médio para os usuários responderem à primeira fase foi de 11 minutos. Para a segunda fase, os usuários gastaram, em média, 8 minutos analisando a projeção antes de preencherem o formulário. Na terceira fase, o tempo médio para analisar a projeção foi de 7 minutos.

As notas atribuídas pelos usuários à facilidade de uso, ao conforto com a interface, e à utilidade do sistema podem ser vistas na Figura 56. Cada gráfico contém o resultado de um item avaliado. Em cada um, o eixo $x$ representa a nota, que varia de 1 a 5 , e o eixo y representa o número de usuários.
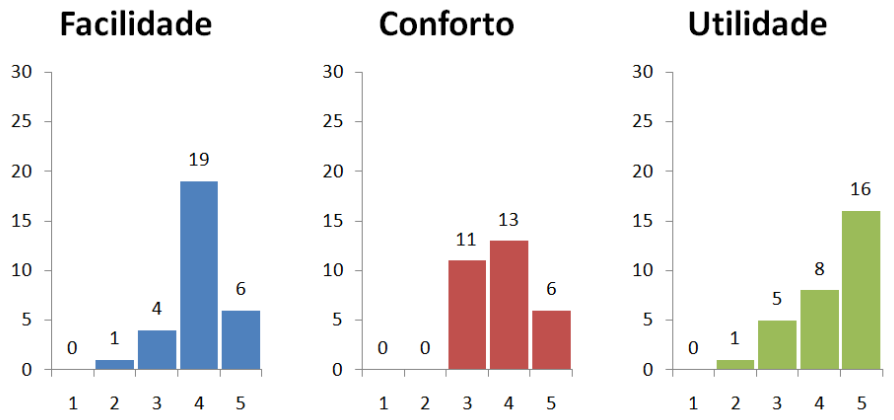

Figura 56: Notas atribuídas pelos usuários à facilidade de uso, ao conforto com a interface, e à utilidade do sistema. As notas variam de 1 a 5 .

Por fim, os usuários classificaram a ferramenta como útil para descobrir associações interessantes entre membros e comunidades, e eles deram sugestões de funcionalidade 
e de como melhorar a interface. Algumas das sugestões incluem: exibir os pesos das arestas, forçar uma separação entre objetos sobrepostos ao passar o mouse sobre eles, criar outras opções de busca, e acrescentar estatísticas para os valores de atributos. 


\section{Conclusões}

A maioria das ferramentas para análise visual de redes sociais utilizam grafos como forma de representação para esse tipo de dado. Em geral, as técnicas empregadas para visualização e interação em grafos preocupam-se em encontrar o melhor posicionamento dos vértices e arestas para facilitar a extração de informações e padrões interessantes. Entretanto, os indivíduos de uma rede social possuem atributos que podem fornecer informações valiosas sobre seu comportamento e suas preferências.

As abordagens apresentadas neste trabalho oferecem novas alternativas para realizar exploração visual de redes sociais, levando em consideração tanto as conexões da rede quanto os atributos dos vértices, além de permitirem visualizar dados relacionais com mais de um tipo de objeto.

\subsection{Contribuições}

A principal contribuição deste trabalho é a integração de técnicas de projeção multidimensional à visualização de redes sociais, tanto em redes homogêneas quanto em redes heterogêneas.

Os resultados obtidos sugerem que as redes heterogêneas podem auxiliar em um processo de investigação direcionado, isto é, quando o usuário sabe o que está procurando, enquanto que as projeções multidimensionais fornecem uma visão geral da rede, dos indivíduos e de seus atributos, permitindo localizar novos padrões. Assim, as projeções multidimensionais podem ser usadas como ponto de partida em um processo de investigação. A coordenação entre essas visões pode ajudar os usuários a descobrir padrões de relacionamento não expressos diretamente por nenhuma das duas abordagens individualmente.

Ao analisar uma rede social, é importante identificar comunidades e atores centrais, além de analisar o papel e as posições dos atores e das conexões [Freitas et al., 2008]. 
Os dados coletados e analisados nos estudos de caso já possuem informações sobre as comunidades, seus membros e as relações entre eles, sendo que a abordagem de rede heterogênea permite destacar imediatamente todos os membros de qualquer comunidade. A abordagem de projeção multidimensional busca agrupar os vértices tanto de acordo com a semelhança entre seus atributos quanto pelos relacionamentos da rede, permitindo analisar os papéis e posições dos atores. Além disso, as medidas de centralidade também auxiliam a identificar objetos importantes.

A avaliação conduzida com usuários também permitiu averiguar a eficácia da ferramenta e das abordagens apresentadas. Todos os usuários conseguiram utilizar a ferramenta e descobrir associações entre usuários e comunidades com facilidade.

\subsection{Trabalhos futuros}

As abordagens apresentadas neste trabalho preocupam-se principalmente em visualizar e explorar os diferentes tipos de vértices e seus atributos, mas também é de interesse investigar redes com múltiplas arestas de diferentes tipos e seus atributos. Além disso, também é interessante analisar a variação sofrida na rede ao longo do tempo. Assim, os próximos passos envolvem:

1. criar mecanismos para inserir atributos nas arestas, permitindo filtragem por valor de atributo;

2. visualizar redes com múltiplas arestas, isto é, arestas de diferentes tipos, tanto na mesma visão quanto em visões paralelas;

3. implementar métricas para comparar a variação sofrida na rede ao alternar entre os diferentes tipos de arestas ou ao longo do tempo;

4. implementar um mapeamento das redes sociais sobre uma esfera. Esse mapeamento permite melhor ocupação do espaço visual.

A ferramenta e os dados deste trabalho podem ser encontrados no site do grupo (http://infoserver.lcad.icmc.usp.br/) no item "Tools". 


\section{Referências}

J. Abello and J. Korn. Mgv: a system for visualizing massive multidigraphs. IEEE Transactions on Visualization and Computer Graphics, 8(1):21-38, Jan/Mar 2002. ISSN 1077-2626. doi: 10.1109/2945.981849.

J. Abello, F. van Ham, and N. Krishnan. Ask-graphview: A large scale graph visualization system. IEEE Transactions on Visualization and Computer Graphics, 12(5): 669-676, October 2006. ISSN 1077-2626. doi: 10.1109/TVCG.2006.120.

E. Adar. Guess: a language and interface for graph exploration. In Proceedings of the SIGCHI conference on Human Factors in computing systems, pages 791-800, New York, NY, USA, 2006. ACM Press. ISBN 1-59593-372-7. doi: 10.1145/1124772. 1124889.

D. Archambault, T. Munzner, and D. Auber. Grouse: Feature-based, steerable graph hierarchy exploration. In K. Museth, T. M"oller, and A. Ynnerman, editors, Proceedings of Eurographics/IEEE-VGTC Symposium on Visualization (Eurovis '07), pages 67-74. Eurographics, Eurographics Association, 2007. URL http: //www.labri.fr/publications/mabiovis/2007/AMA07a.

A. Aris and B. Shneiderman. Network visualization by semantic substrates. IEEE Transactions on Visualization and Computer Graphics, 12(5):733-740, October 2006. ISSN 1077-2626. doi: 10.1109/TVCG.2006.166.

C. Batini, L. Furlani, and E. Nardelli. What is a good diagram? a pragmatic approach. In Proceedings of the Fourth International Conference on Entity-Relationship Approach, pages 312-319, Washington, DC, USA, 1985. IEEE Computer Society. ISBN 0-444-87951-X. 
A. Bezerianos, F. Chevalier, P. Dragicevic, N. Elmqvist, and J. Fekete. Graphdice: A system for exploring multivariate social networks. In Proceedings of Eurographics/IEEE-VGTC Symposium on Visualization (Eurovis '10). Eurographics, Eurographics Association, 2010.

S. Boccaletti, V. Latora, Y. Moreno, M. Chavez, and D. U. Hwang. Complex networks: Structure and dynamics. Physics Reports, 424(4-5):175-308, February 2006. doi: 10.1016/j.physrep.2005.10.009.

C. T. Butts. Social network analysis with sna. Journal of Statistical Software, 24(6): 1-51, 12 2007. ISSN 1548-7660. URL http://www.jstatsoft.org/v24/i06.

A. Cuadros, F. Paulovich, R. Minghim, and G. Telles. Point placement by phylogenetic trees and its application to visual analysis of document collections. IEEE Symposium on Visual Analytics Science and Technology, 200\%, pages 99-106, November 2007. doi: 10.1109/VAST.2007.4389002.

R. C. da Motta. Uso de redes complexas na classificação relacional. Master's thesis, ICMC - Universidade de São Paulo, São Carlos, 2009.

P. A. Eades. A heuristic for graph drawing. In Congressus Numerantium, volume 42, pages 149-160, 1984.

P. A. Eades. Drawing free trees. Bulletin of the Institute for Combinatorics and Its Applications, pages 10-36, 1992.

T. Falkowski, J. Bartelheimer, and M. Spiliopoulou. Mining and visualizing the evolution of subgroups in social networks. IEEE/WIC/ACM International Conference on Web Intelligence, 2006, pages 52-58, December 2006. doi: 10.1109/WI.2006.118.

C. Faloutsos and K.-I. Lin. Fastmap: a fast algorithm for indexing, data-mining and visualization of traditional and multimedia datasets. In M. Carey and D. Schneider, editors, Proceedings of the 1995 ACM SIGMOD International Conference on Management of Data, pages 163-174. ACM Press, 1995. doi: 10.1145/223784.223812.

J.-D. Fekete. The infovis toolkit, November 2005. URL http://ivtk.sourceforge. net/. Last access: January 2008. 
K. L. Felizardo, G. F. Andery, J. C. Maldonado, and R. Minghim. Uma abordagem visual para auxiliar a revisão da seleção de estudos primários na revisão sistemática. In Proceedings of the 6th Experimental Software Engineering Latin American Workshop (ESELAW 2009), pages 83-92, São Carlos, Brasil, 2009.

D. Fisher and P. Dourish. Social and temporal structures in everyday collaboration. In Proceedings of the SIGCHI conference on Human factors in computing systems, pages 551-558, New York, NY, USA, 2004. ACM. ISBN 1-58113-702-8. doi: 10. $1145 / 985692.985762$.

L. Freeman. Visualizing social groups. In Proceedings of the Section on Statistical Graphics, pages 47-54. American Statistical Association, 1999.

L. C. Freeman. Visualizing social networks. Journal of Social Structure, 1(1), 2000.

C. M. D. S. Freitas, L. P. Nedel, R. Galante, L. C. Lamb, A. S. Spritzer, S. Fujii, J. P. M. de Oliveira, R. M. Araújo, and M. M. Moro. Extração de conhecimento e análise visual de redes sociais. In SEMISH - Seminário Integrado de Software e Hardware, pages 106-120, Belém do Pará, Brasil, 2008. SBC.

N. Fujimura, S. Fujiyoshi, T. Hope, and T. Nishimura. Tabletop community: visualization of real world oriented social network. In Proceedings of the 14 th annual ACM international conference on Multimedia, pages 1035-1036, New York, NY, USA, 2006. ACM. ISBN 1-59593-447-2. doi: 10.1145/1180639.1180868.

P. A. Gloor, J. Krauss, S. Nann, K. Fischbach, and D. Schoder. Web science 2.0: Identifying trends through semantic social network analysis. In Proceedings of the 2009 International Conference on Computational Science and Engineering (CSE '09), pages 215-222, Washington, DC, USA, 2009. IEEE Computer Society. ISBN 978-07695-3823-5. doi: http://dx.doi.org/10.1109/CSE.2009.186.

J. Heer and D. Boyd. Vizster: Visualizing online social networks. In Proceedings of the IEEE Symposium on Information Visualization, 2005, page 5, Washington, DC, USA, 2005. IEEE Computer Society. ISBN 0-7803-9464-x. doi: http://dx.doi.org/ 10.1109/INFOVIS.2005.39.

N. Henry and J.-D. Fekete. Matrixexplorer: a dual-representation system to explore 
social networks. IEEE Transactions on Visualization and Computer Graphics, 12 (5):677-684, September 2006. ISSN 1077-2626. doi: 10.1109/TVCG.2006.160.

N. Henry, J.-D. Fekete, and M. McGuffin. Nodetrix: a hybrid visualization of social networks. IEEE Transactions on Visualization and Computer Graphics, 13(6):13021309, November 2007. ISSN 1077-2626. doi: 10.1109/TVCG.2007.70582.

I. Herman, G. Melancon, and M. Marshall. Graph visualization and navigation in information visualization: A survey. IEEE Transactions on Visualization and Computer Graphics, 6(1):24-43, Jan-Mar 2000. ISSN 1077-2626. doi: 10.1109/2945.841119.

W. Huang, S.-H. Hong, and P. Eades. How people read sociograms: a questionnaire study. In Proceedings of the 2006 Asia-Pacific Symposium on Information Visualisation, pages 199-206, Darlinghurst, Australia, 2006. Australian Computer Society, Inc. ISBN 1-920682-41-4.

X. Huang, P. Eades, and W. Lai. A framework of filtering, clustering and dynamic layout graphs for visualization. In Proceedings of the Twenty-eighth Australasian conference on Computer Science, pages 87-96, Darlinghurst, Australia, Australia, 2005. Australian Computer Society, Inc. ISBN 1-920-68220-1.

M. Huisman and M. A. J. Duijn. Models and Methods in Social Network Analysis, chapter Software for Social Network Analysis, pages 270-316. Cambridge University Press, 2005.

I. T. Jolliffe. Principal Component Analysis. Springer, New York, NY, 2nd edition, 2002.

H. Kang, L. Getoor, and L. Singh. Visual analysis of dynamic group membership in temporal social networks. ACM SIGKDD Explorations Newsletter, 9(2):13-21, 2007. ISSN 1931-0145. doi: 10.1145/1345448.1345452.

T. Keahey and E. Robertson. Techniques for non-linear magnification transformations. Information Visualization '96, Proceedings IEEE Symposium on, pages 38-45, Oct 1996. doi: 10.1109/INFVIS.1996.559214.

D. Keim and H. Kriegel. Visualization techniques for mining large databases: a comparison. IEEE Transactions on Knowledge and Data Engineering, 8(6):923-938, December 1996. ISSN 1041-4347. doi: 10.1109/69.553159. 
B. Kitchenham. Procedures for performing systematic reviews. Technical Report TR/SE-0401, Keele University and NICTA, 2004.

B. A. Kitchenham, E. Mendes, and G. H. Travassos. Cross versus within-company cost estimation studies: A systematic review. IEEE Transactions on Software Engineering, 33(5):316-329, May 2007. ISSN 0098-5589. doi: 10.1109/TSE.2007.1001.

Y. Koren. On spectral graph drawing. In T. Warnow and B. Zhu, editors, COCOON, volume 2697 of Lecture Notes in Computer Science, pages 496-508. Springer, 2003. ISBN 3-540-40534-8. URL http://dblp.uni-trier.de/db/conf/cocoon/ cocoon2003.html\#Koren03.

J. Lamping and R. Rao. The hyperbolic browser: a focus + context technique for visualizing large hierarchies. Readings in information visualization: using vision to think, pages 382-408, 1999.

J. Leskovec, J. Kleinberg, and C. Faloutsos. Graphs over time: densification laws, shrinking diameters and possible explanations. In Proceedings of the eleventh ACM SIGKDD international conference on Knowledge discovery in data mining, pages 177-187, New York, NY, USA, 2005. ACM. ISBN 1-59593-135-X. doi: 10.1145/ 1081870.1081893 .

Y. K. Leung and M. D. Apperley. A review and taxonomy of distortion-oriented presentation techniques. ACM Transactions on Computer-Human Interaction, 1(2): 126-160, 1994. ISSN 1073-0516. doi: http://doi.acm.org/10.1145/180171.180173.

C.-T. Li and S.-D. Lin. Egocentric information abstraction for heterogeneous social networks. In Proceedings of the 2009 International Conference on Advances in Social Network Analysis and Mining (ASONAM '09), pages 255-260, Washington, DC, USA, 2009. IEEE Computer Society. ISBN 978-0-7695-3689-7. doi: http://dx.doi. org/10.1109/ASONAM.2009.38.

E. Loubier, W. Bahsoun, and B. Dousset. Visualization and analysis of large graphs. In Proceedings of the ACM first Ph.D. workshop in CIKM, pages 41-48, New York, NY, USA, 2007. ACM. ISBN 978-1-59593-832-9. doi: 10.1145/1316874.1316882.

S. E. Marcus, M. Moy, and T. Coffman. Mining Graph Data, chapter Social Network Analysis, pages 443-468. Wiley, 2007. 
S. Milgram. The small world problem. Psychology Today, 2:60-67, 1967.

R. Minghim, F. V. Paulovich, and A. de Andrade Lopes. Content-based text mapping using multi-dimensional projections for exploration of document collections. volume 6060, page 60600S. SPIE, 2006. doi: 10.1117/12.650880. URL http://link.aip. org/link/?PSI/6060/60600S/1.

C. Mitchell. Situational analysis and network analysis. Connections, 17(1):16-24, 1994. ISSN 0226-1776.

J. L. Moreno. Application of the Group Method to Classification. National Committee on Prisons and Prison Labor, New York, NY, 1932.

J. L. Moreno. Who shall survive? : a new approach to the problem of Human Interrelations, volume 58 of Nervous and mental disease monograph series. Nervous and Mental Disease Publ., Washington, DC, 1934.

J. L. Moreno. Who Shall Survive? Foundations of Sociometry, Group Psychotherapy and Sociodrama. Beacon House, January 1953.

P. Mutton. Inferring and visualizing social networks on internet relay chat. Proceedings of the Eighth International Conference on Information Visualisation, pages 35-43, July 2004. ISSN 1093-9547. doi: 10.1109/IV.2004.1320122.

G. M. Namata, B. Staats, L. Getoor, and B. Shneiderman. A dual-view approach to interactive network visualization. In Proceedings of the sixteenth ACM conference on Conference on information and knowledge management, pages 939-942, New York, NY, USA, 2007. ACM. ISBN 978-1-59593-803-9. doi: 10.1145/1321440.1321580.

G. Navarro. A guided tour to approximate string matching. ACM Computing Surveys, 33(1):31-88, 2001. ISSN 0360-0300. doi: http://doi.acm.org/10.1145/375360.375365.

M. E. J. Newman. The structure and function of complex networks. SIAM Review, 45: 167-256, 2003.

M. L. Northway. A method for depicting social relationships obtained by sociometric testing. Sociometry, 3(2):144-150, 1940. ISSN 00380431. URL http://www.jstor . org/stable/2785439.

M. L. Northway. A Primer of Sociometry. University of Toronto Press, Toronto, 1952. 
F. Paulovich, L. Nonato, and R. Minghim. Visual mapping of text collections through a fast high precision projection technique. Tenth International Conference on Information Visualization, 2006, pages 282-290, July 2006. ISSN 1550-6037. doi: 10.1109/IV.2006.122.

F. V. Paulovich, M. C. F. Oliveira, and R. Minghim. The projection explorer: A flexible tool for projection-based multidimensional visualization. XX Brazilian Symposium on Computer Graphics and Image Processing, 2007, pages 27-36, October 2007. ISSN 1530-1834. doi: 10.1109/SIBGRAPI.2007.21.

A. Perer and B. Shneiderman. Balancing systematic and flexible exploration of social networks. IEEE Transactions on Visualization and Computer Graphics, 12(5):693700, 2006. ISSN 1077-2626. doi: http://dx.doi.org/10.1109/TVCG.2006.122.

T. Pisanski and J. Shawe-Taylor. Characterizing graph drawing with eigenvectors. Journal of Chemical Information and Computer Sciences, 40(3):567-571, 2000. URL http://pubs.acs.org/doi/full/10.1021/ci9900938.

E. M. Reingold and J. S. Tilford. Tidier drawings of trees. IEEE Transactions on Software Engineering, SE-7(2):223-228, March 1981. ISSN 0098-5589.

D. Roos. How social networks work, August 2007. URL http://communication. howstuffworks. com/how-social-networks-work.htm. Last access: January 2008.

M. Sarkar and M. H. Brown. Graphical fisheye views. Communications of the ACM, 37 (12):73-83, 1994. ISSN 0001-0782. doi: http://doi.acm.org/10.1145/198366.198384.

Z. Shen, K.-L. Ma, and T. Eliassi-Rad. Visual analysis of large heterogeneous social networks by semantic and structural abstraction. IEEE Transactions on $\mathrm{Vi}$ sualization and Computer Graphics, 12(6):1427-1439, 2006. ISSN 1077-2626. doi: 10.1109/TVCG.2006.107. Student Member-Zeqian Shen and Senior Member-KwanLiu Ma and Member-Tina Eliassi-Rad.

B. Shneiderman. Tree visualization with tree-maps: 2-d space-filling approach. $A C M$ Transactions on Graphics, 11(1):92-99, 1992. ISSN 0730-0301. doi: 10.1145/102377. 115768.

SmartMoney. Map of the market, January 2008. URL http://www . smartmoney.com/ map-of-the-market/. Last access: January 2008. 
M. Smith, C. Giraud-Carrier, and N. Purser. Implicit affinity networks and social capital. Inf. Technol. and Management, 10(2-3):123-134, 2009. ISSN 1385-951X. doi: http://dx.doi.org/10.1007/s10799-009-0057-2.

A. S. Spritzer and C. M. D. S. Freitas. A physics-based approach for interactive manipulation of graph visualizations. In Proceedings of the working conference on Advanced visual interfaces, pages 271-278, New York, NY, USA, 2008. ACM. ISBN 0-978-60558-141-5. doi: 10.1145/1385569.1385613.

K. Sugiyama, S. Tagawa, and M. Toda. Methods for visual understanding of hierarchical system structures. IEEE Transactions on Systems, Man and Cybernetics, 11 (2):109-125, Feb. 1981. ISSN 0018-9472. doi: 10.1109/TSMC.1981.4308636.

R. Tamassia and I. Tollis. Planar grid embedding in linear time. IEEE Transactions on Circuits and Systems, 36(9):1230-1234, Sep 1989. ISSN 0098-4094. doi: 10.1109/ 31.34669 .

E. Tejada, R. Minghim, and L. G. Nonato. On improved projection techniques to support visual exploration of multidimensional data sets. Information Visualization, 2(4):218-231, 2003. ISSN 1473-8716. doi: 10.1057/palgrave.ivs.9500054.

P. Velardi, R. Navigli, A. Cucchiarelli, and F. D'Antonio. A new content-based model for social network analysis. In Proceedings of the 2008 IEEE International Conference on Semantic Computing (ICSC '08), pages 18-25, Washington, DC, USA, 2008. IEEE Computer Society. ISBN 978-0-7695-3279-0. doi: http://dx.doi.org/10.1109/ ICSC.2008.30.

F. Viegas, D. Boyd, D. Nguyen, J. Potter, and J. Donath. Digital artifacts for remembering and storytelling: posthistory and social network fragments. Proceedings of the 37th Annual Hawaii International Conference on System Sciences, 2004, pages 10 pp.-, January 2004. doi: 10.1109/HICSS.2004.1265287.

J. Q. Walker. A node-positioning algorithm for general trees. Software: Practice and Experience, 20(7):685-705, 1990. ISSN 0038-0644. doi: 10.1002/spe.4380200705.

T. Washio, L. De Raedt, and J. N. Kok. Advances in mining graphs, trees and sequences. Fundamenta Informaticae, 66(1-2):5-8, 2005. ISSN 0169-2968. 
S. Wasserman and K. Faust. Social Network Analysis : Methods and Applications (Structural Analysis in the Social Sciences). Cambridge University Press, 1994.

M. Wattenberg. Visual exploration of multivariate graphs. In Proceedings of the SIGCHI conference on Human Factors in computing systems, pages 811-819, New York, NY, USA, 2006. ACM. ISBN 1-59593-372-7. doi: 10.1145/1124772.1124891.

S. Whittaker, Q. Jones, B. Nardi, M. Creech, L. Terveen, E. Isaacs, and J. Hainsworth. Contactmap: Organizing communication in a social desktop. ACM Trans. Comput.Hum. Interact., 11(4):445-471, 2004. ISSN 1073-0516. doi: 10.1145/1035575. 1035580.

S. Zhao, M. McGuffin, and M. Chignell. Elastic hierarchies: combining treemaps and node-link diagrams. IEEE Symposium on Information Visualization, 2005, pages 57-64, October 2005. doi: 10.1109/INFVIS.2005.1532129.

Y. Zhou. Hyperbolic trees, May 2004. URL http://iv.slis.indiana.edu/sw/ hyptree.html. Last access: January 2008. 


\section{A. Formulários da avaliação com usuário}

Cada uma das fases da avaliação com usuário era precedida por um texto explicativo sobre a visualização e sobre a tarefa a ser realizada. O texto explicativo da primeira fase era:

A primeira fase exibe duas janelas, cada uma contendo um grafo. O grafo da esquerda apresenta os membros de uma rede social, enquanto o grafo da direita apresenta suas comunidades.

Os membros estão posicionados de acordo com a similaridade entre seus atributos (sexo, estado civil, idade, aniversário).

As comunidades estão posicionadas de acordo com suas conexões, que indicam se duas comunidades têm pelo menos 10 membros em comum.

Ao selecionar os membros no grafo da esquerda, as suas comunidades serão destacadas no grafo da direita, e vice-versa.

Nesta primeira fase, tente descobrir se existe alguma relação entre marcas associadas às comunidades (como Peugeot e Volkswagen) e os atributos dos membros (sexo e estado civil).

O formulário da primeira fase continha os seguintes itens:

- É possivel relacionar alguma marca com:

1. Gênero? Em caso afirmativo, quais marcas?

2. Estado civil? Em caso afirmativo, quais marcas?

O texto explicativo da segunda fase era:

A segunda fase exibe uma rede heterogênea, isto é, um grafo cujos vértices representam mais de um tipo de objeto. Neste caso, o grafo apresenta tanto membros quanto comunidades de uma rede social. Membros são apresentados como quadrados e comunidades como círculos cinzas. Membros do sexo masculino aparecem em azul, e do sexo feminino em vermelho. 
Os vértices estão posicionados de acordo com suas conexões. Conexões entre comunidades indicam que duas comunidades têm pelo menos 10 membros em comum, conexões entre membros indicam que dois membros estão em pelo menos 10 comunidades em comum, e conexões entre comunidades e membros indicam quais membros pertencem a que comunidades.

Nesta segunda fase, tente encontrar comunidades predominantemente masculinas, predominantemente femininas e comunidades mistas.

O formulário da segunda fase continha os seguintes itens:

- Indique se cada uma das comunidades abaixo é predominantemente masculina, predominantemente feminina, ou se não é possível estabelecer uma relação de gênero:

1. Eu amo meu Honda Civic;

2. Pareço metida(o), mas sou legal;

3. Eu acredito no amor;

4. O que é para ser nosso ninguém tira;

5. Tuning.

O texto explicativo da terceira fase era:

A última fase é livre. Tente encontrar outras relações na rede heterogênea.

Por exemplo, verifique se existe alguma relação entre diferentes marcas, ou seja, se os membros da comunidade de uma determinada marca também pertencem a comunidades relacionadas a outras marcas.

O formulário da terceira fase continha apenas o seguinte item:

- Você encontrou outras relações entre membros e comunidades? Em caso afirmativo, quais?

Ao final da avaliação, o usuário respondia a um questionário sobre o sistema. O questionário continha os seguintes itens:

- Sobre o sistema, dê uma nota de 1 (péssimo) a 5 (ótimo) para os itens abaixo:

1. Facilidade de uso;

2. Conforto com a interface;

3. Utilidade.

- Se você considerou o sistema útil, foi útil para quê?

- Sugestões? 